Aus dem Herzzentrum Göttingen

(Prof. Dr. med. G. Hasenfuß)

Arbeitsgruppe Kardiovaskuläre Molekulargenetik

der Medizinischen Fakultät der Universität Göttingen

\title{
Functional and Mutational Analysis of Kinase Domain of the Giant Protein Titin
}

\author{
INAUGURAL-DISSERTATION \\ zur Erlangung des Doktorgrades \\ der Medizinischen Fakultät \\ der Georg-August-Universität zu Göttingen
}

vorgelegt von
Aleksandra Kirova
aus
Yaroslavl, Rußland

Göttingen 2011 
Dek a n:

I. Berichterstatter:

II. Berichterstatter/in:

III. Berichterstatter/in:

Tag der mündlichen Prüfung:
Prof. Dr. med. C. Frömmel

Prof. Dr. Knöll

Prof. Dr. Lutz

Prof. Dr. rer. nat. Schu

26. Juni 2012 


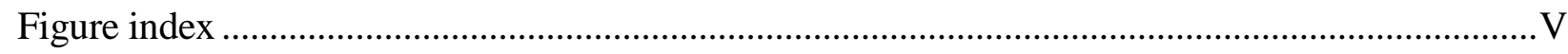

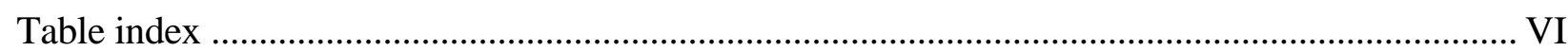

\section{Contents}

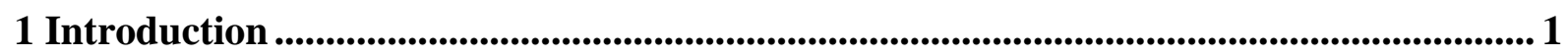

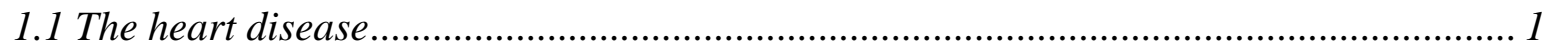

1.2 Contractile unit of the crosstriated muscle ................................................................. 1

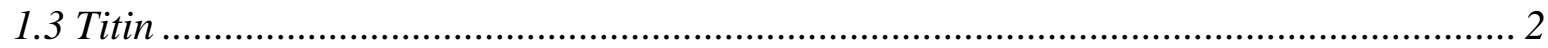

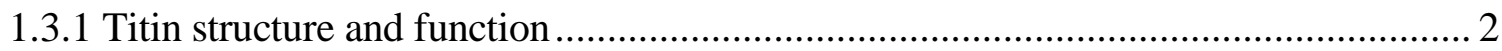

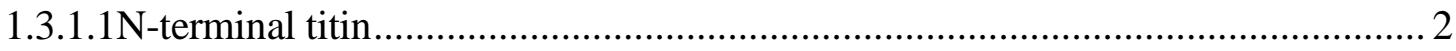

1.3.1.2 I-band titin and myocardial passive stiffness ............................................ 3

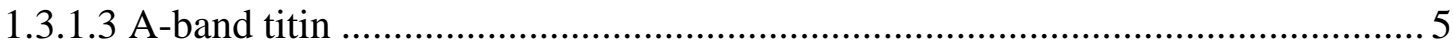

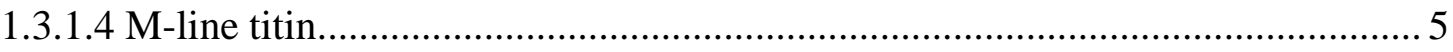

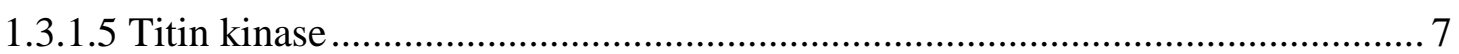

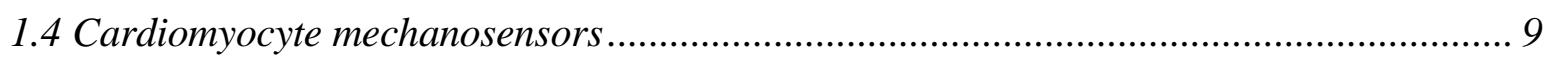

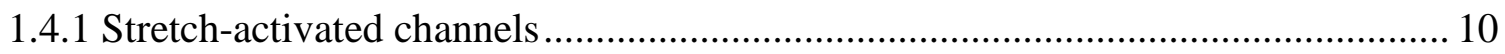

1.4.2 G-protein coupled receptors as stress sensors .............................................. 10

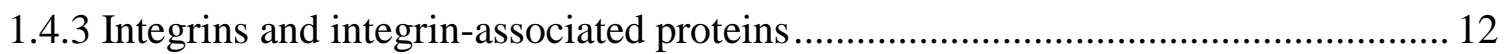

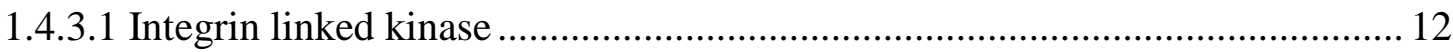

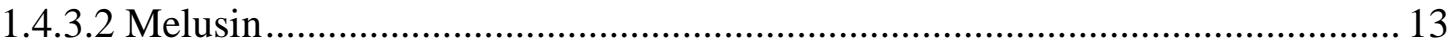

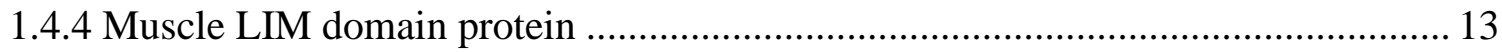

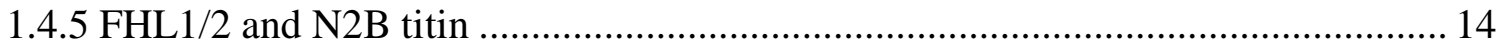

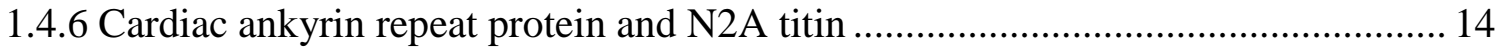

1.5 Cytoskeleton and its role in myofibrillogenesis, maintenance of the sarcomere and

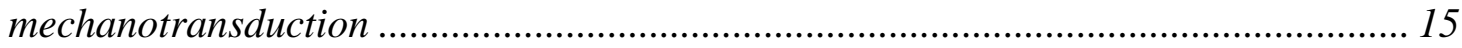

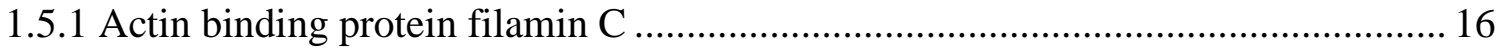




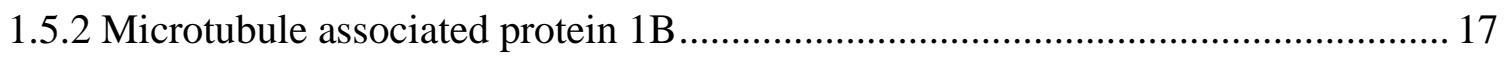

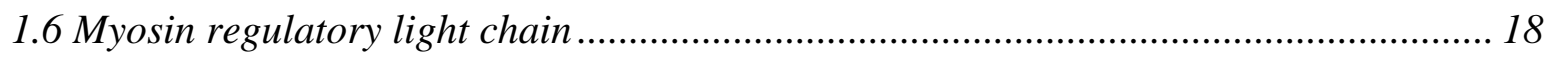

1.7 Cardiomyopathies and clinical relevance of titin .................................................... 19

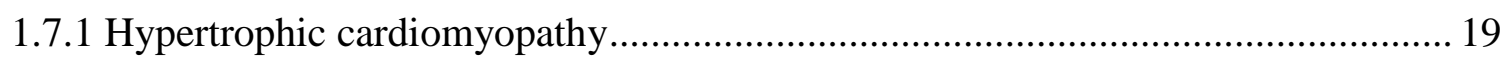

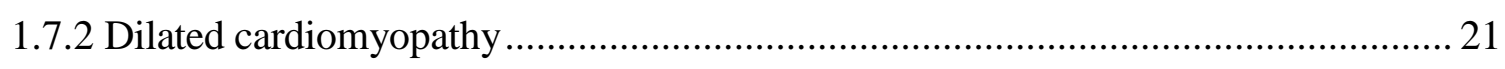

1.8 Newly identified C-terminal titin mutation in a small family ....................................... 25

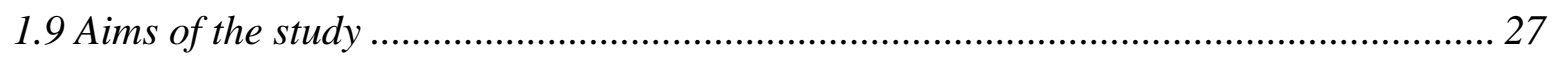

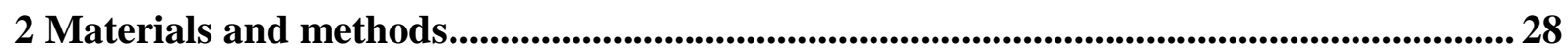

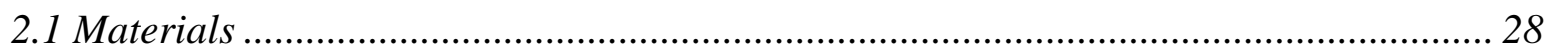

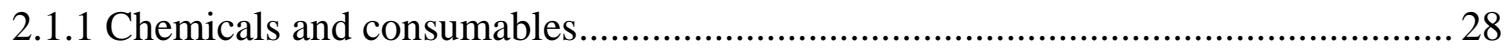

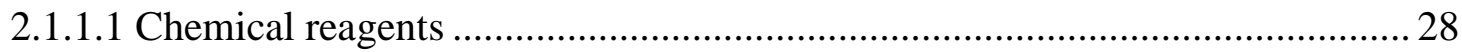

2.1.1.2 Plastic, glassware and other consumables ...............................................29

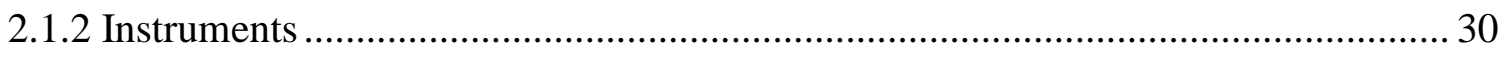

2.1.3 Detection, purification and synthesis systems (kits) ......................................... 31

2.1.4 Proteins, enzymes, protease inhibitors and standards ...................................... 32

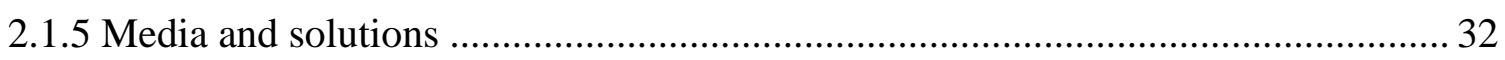

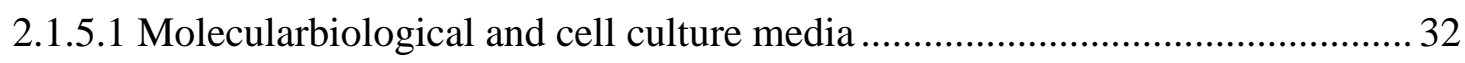

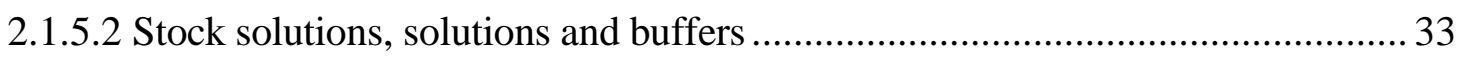

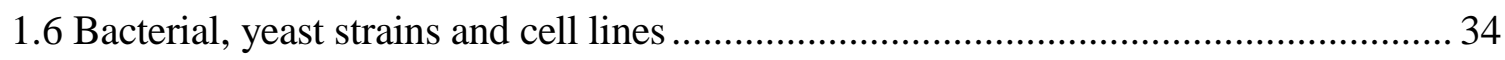

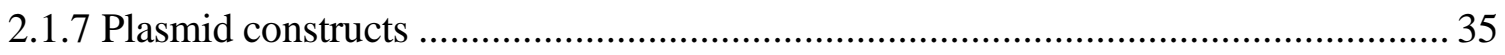

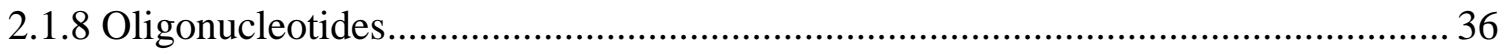

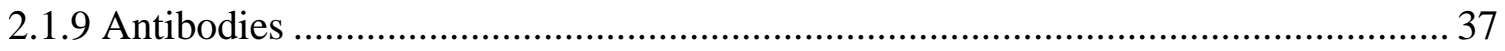

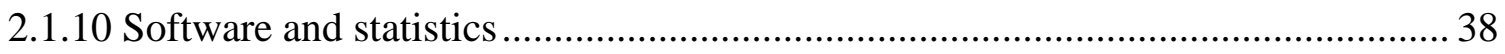

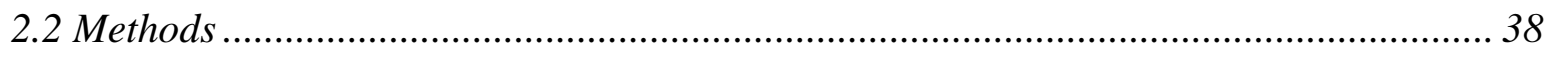

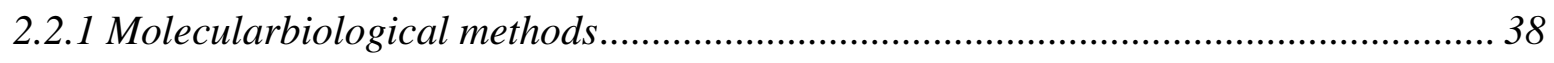

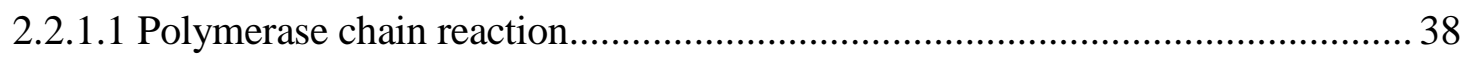

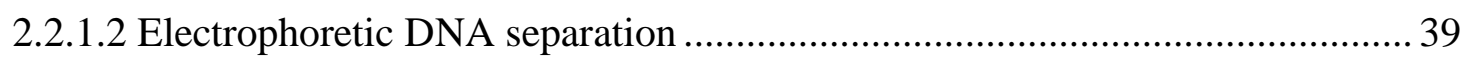




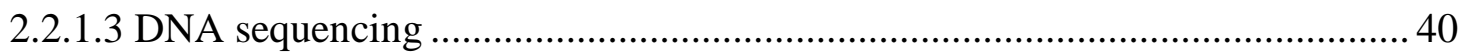

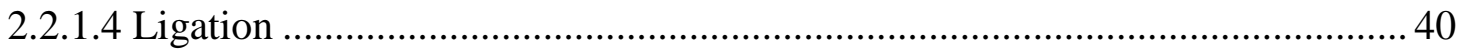

2.2.1.5 Transformation of E. coli by heat shock method .......................................... 40

2.2.1.6 Transformation of E. coli by electroporation ............................................. 41

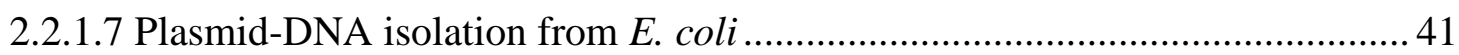

2.2.1.8 DNA extraction from yeast cells ................................................................ 41

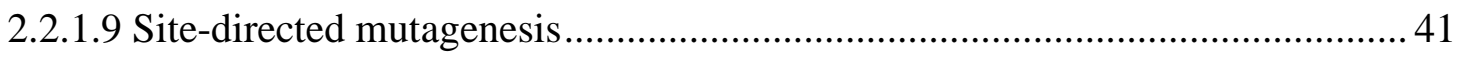

2.2.2 Yeast two hybrid: A system for detection of protein interactions........................... 42

2.2.2.1 Principle of GAL4 based yeast two hybrid system......................................... 42

2.2.2.2 Construction of the "target" or "bait" ................................................................ 43

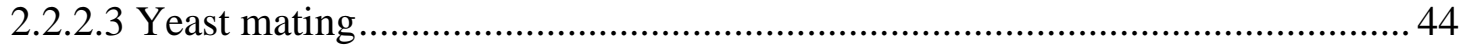

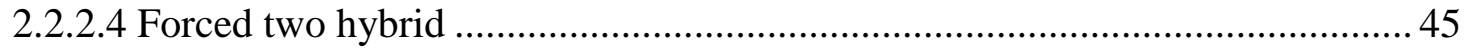

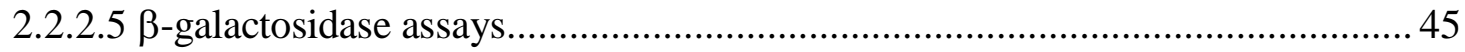

2.2.2.5.1 Liquid phase $\beta$-galactosidase assay with ONPG as a substrate ................ 46

2.2.2.5.2 Colony-lift filter $\beta$-galactosidase assay ................................................ 46

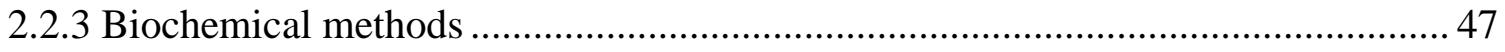

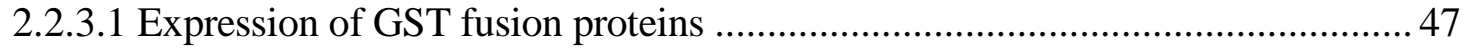

2.2.3.2 Expression of recombinant 6xHis- and T7-tagged proteins ............................ 47

2.2.3.3 Purification of recombinant GST- and His-tagged proteins ............................ 47

2.2.3.4 Protein isolation from mammalian cells.................................................... 48

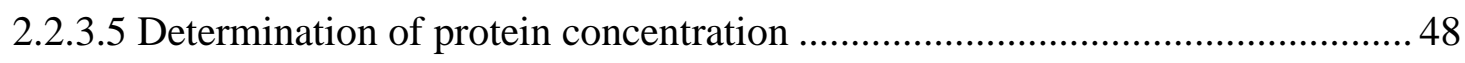

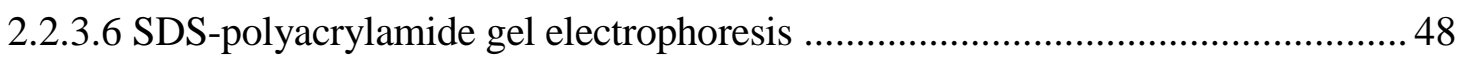

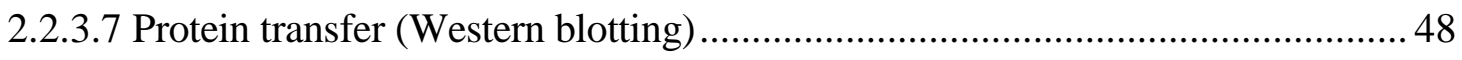

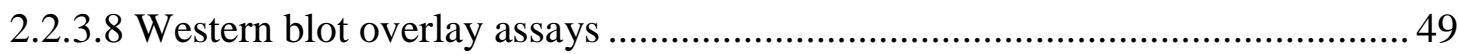

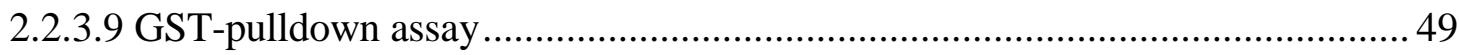

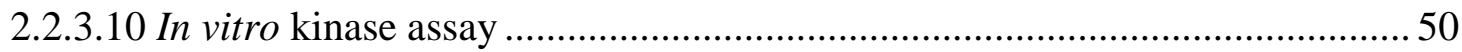

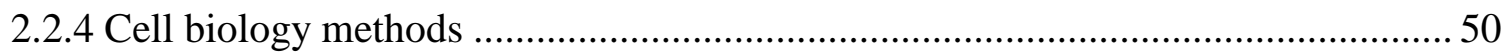




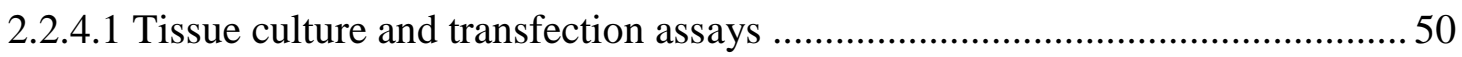

2.2.4.2 Immunochemical staining procedures ................................................... 51

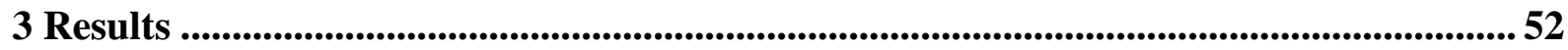

3.1 Identification of titin kinase interacting partners in yeast two hybrid library screen ... 52

3.2 Sequence and structure of three potential interacting partners ................................... 55

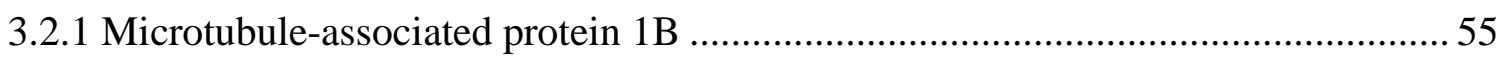

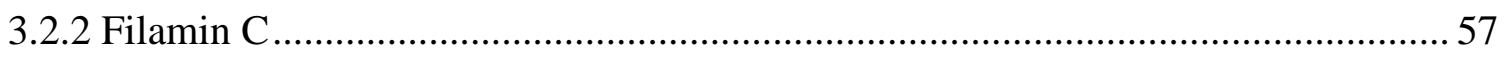

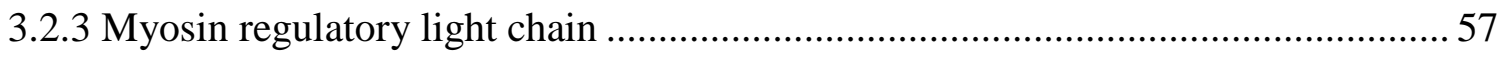

3.3 Forced two hybrid confirm yeast two hybrid library screen interaction results ............... 58

3.4 TKin interacts with FLNC-D24 but not with MAP1B-LC1 or MLC2 in Far Western Blot assay. 60

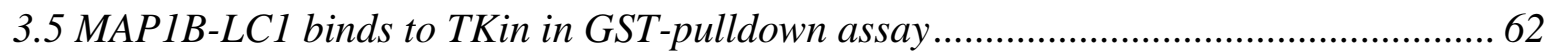

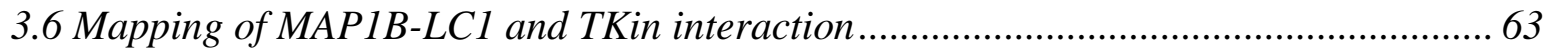

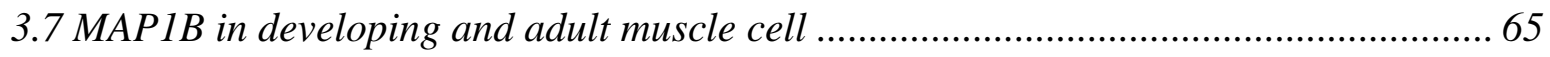

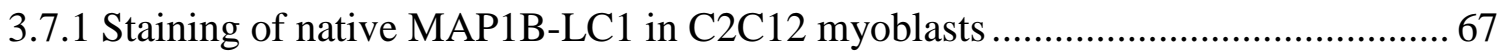

3.7.2 MAP1B-LC1 is downregulated in proliferating C2C12 myoblasts and induced

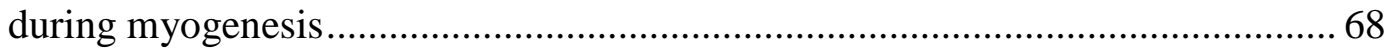

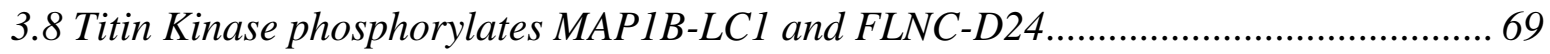

3.9 Asp24.727Val-mutated titin exhibit altered binding to MAP1B-LC1 ......................... 70

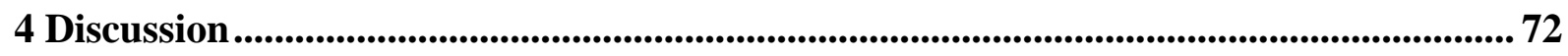

4.1 Challenges with the giant titin and large-scale protein interaction studies ................. 72

4.2 Titin kinase region and its interacting partners ...................................................... 73

4.2.1 Filamin C: interacting partner of titin kinase region......................................... 74

4.2.2 MAP1B-LC1 performs specific function in muscle cell and associates with titin kinase .75

4.2.3 MLC2: a false substrate of titin kinase? .77

4.3 Analysis of phosphorylation of FilC-D24 and MAP1B-LC1 by titin kinase ................... 78

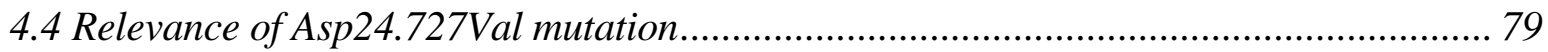




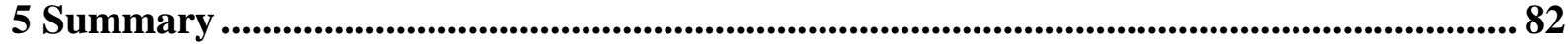

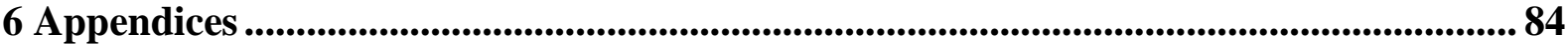

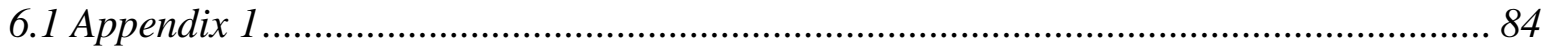

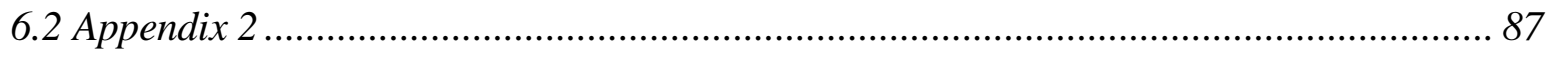

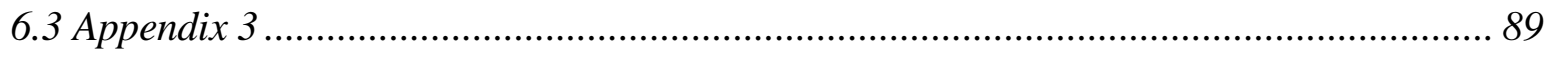

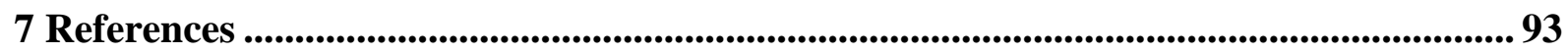

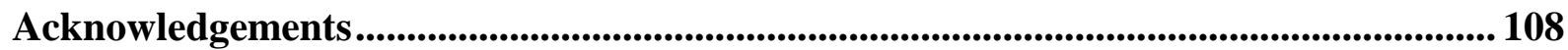

Curriculum Vitae

..Fehler! Textmarke nicht definiert. 


\section{Figure index}

Figure 1: Titin's cardiac and skeletal muscle isoforms ….................................................. 4

Figure 2: Schematic presentation of the titin's M-line interactions ..................................... 6

Figure 3: The ribbon presentation of the autoinhibited form of titin kinase .............................. 8

Figure 4: Principle of GAL4 based yeast two hybrid system .............................................. 43

Figure 5: Titin kinase constructs used for protein-protein interactions studies.......................52

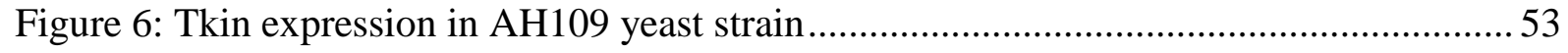

Figure 7: Schematic presentation and protein sequence alignment of MAP1B-LC1 ….........56

Figure 8: Protein sequence alignment of C-terminal portion of Filamin C ............................57

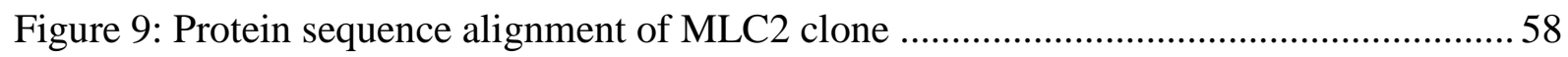

Figure 10: Interaction of TKin and MAP1B-LC1 and TKin and FLNC-D24 in Forced two

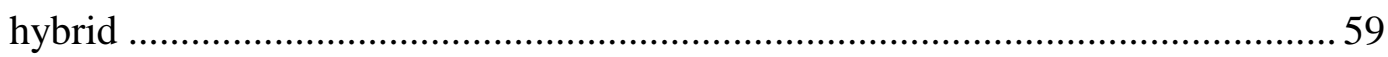

Figure 11: Kin2 expressed in E.coli and purified by Ni-NTA affinity chromatography ......... 60

Figure 12: Western Blot overlay of GST-fused binding partners with Kin2 recombinant

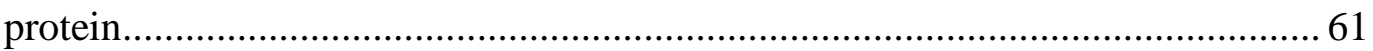

Figure 13: Western Blot overlay of purified FILN-D24 with titin kinase ................................ 62

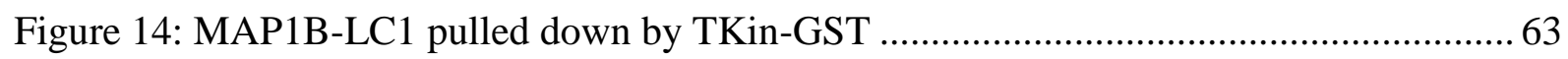

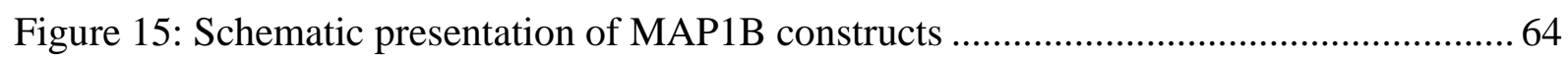

Figure 16: GST-Pulldown of MAP1B-LC1 tubulin and actin binding portions by Tkin ........ 64

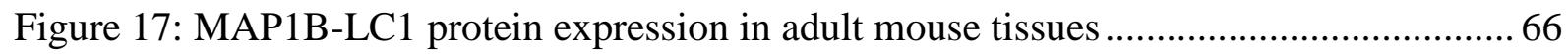

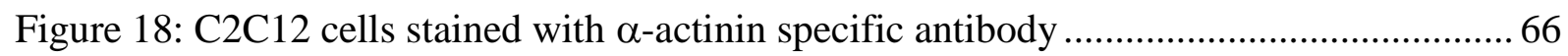

Figure 19: Endogenous distribution of MAP1B-LC1 in C2C12 myoblasts ............................ 67

Figure 20: Expression profile of MAP1B-LC1 in differentiating C2C12 myoblasts ..............68

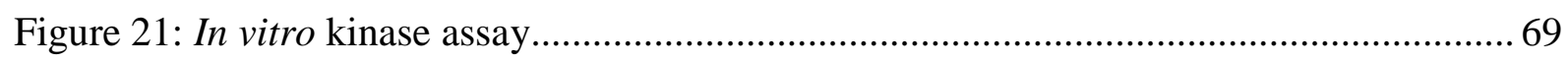

Figure 22: Chromatogramm of wildtype and Asp24.727Val-mutated titin .......................... 70

Figure 23: Graphic presentation of $\beta$-galactosidase activity mesured for MAP1B-LC1 and TKin-WT/-Mut interaction and FLNC-D24 and TKin-WT/-Mut-interaction ..... 71

Figure 24: Vector map of pET23aT7 prokaryotic expression vector ...................................... 88

Figure 25: Vector map of pCMV5-T7 mammalian expression vector .................................... 89 


\section{Table index}

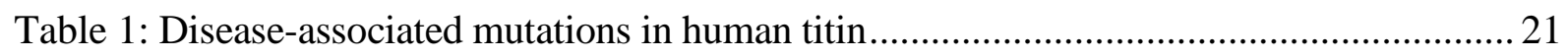

Table 2: Mutations in candidate genes associated with hereditary DCM ............................... 23

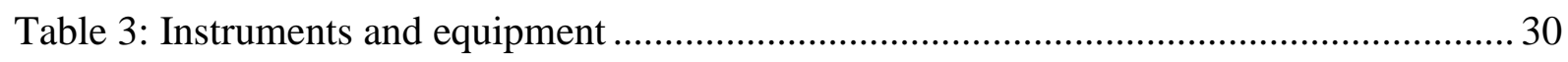

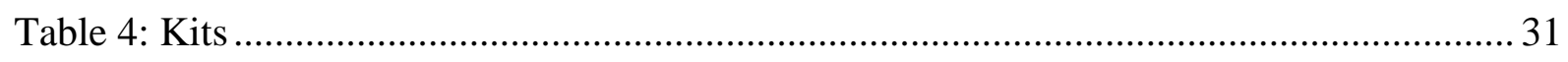

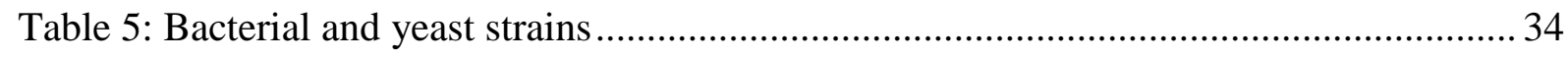

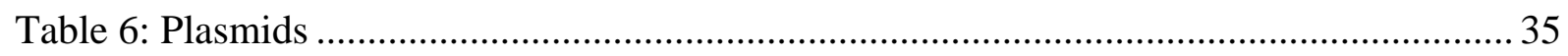

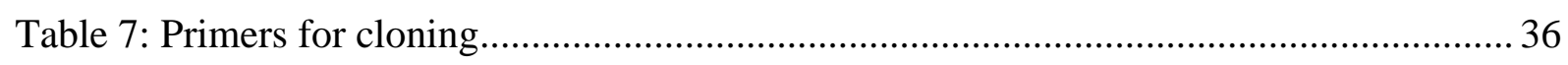

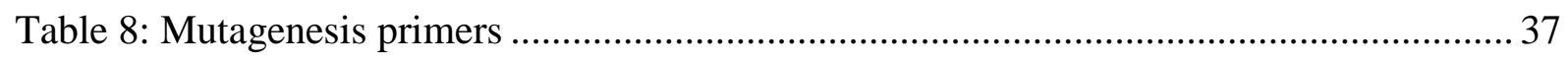

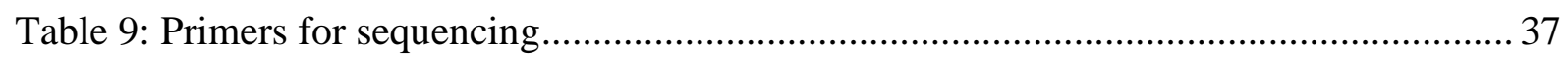

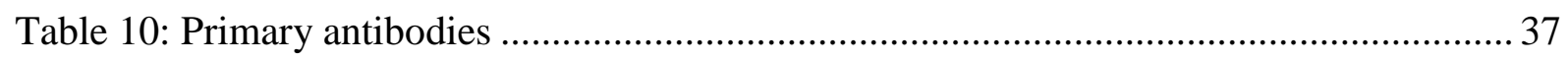

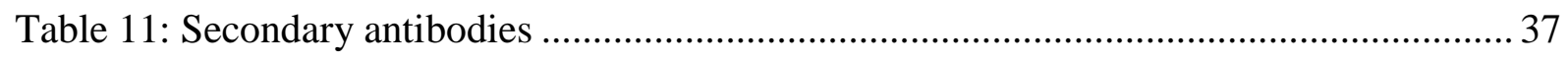

Table 12: Components of the PCR using Pfu DNA polymerase ............................................ 39

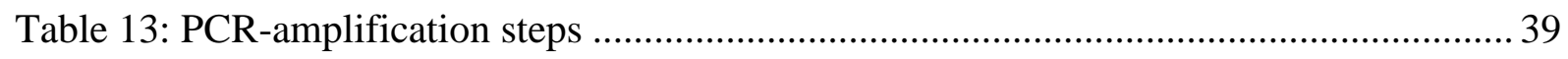

Table 14: Overview of the titin kinase potential binding partners ......................................... 54

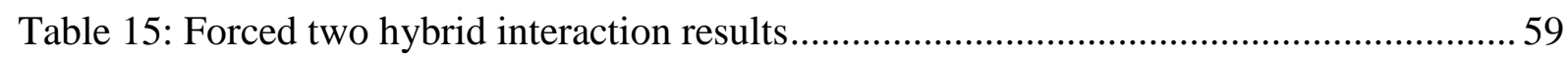

Table 16: Interaction result of different portions of MAP1B-LC1 with TKin......................... 65 


\section{Introduction}

\subsection{The heart disease}

Heart disease is the leading non-infectious cause of death in children and adults. During the previous twenty years, there has been immense progress in resolving the molecular genetic background of the pathophysiological mechanisms of heart disease. Pathogenetic mechanisms and details of the muscle cell structure and function have been studied both at the molecular and cellular levels. However, many questions remain to be answered. One of the most intriguing is the molecular background of the mechanosensation in muscle cell as a basis of the heart development and of the maintenance of the heart function under physiological and pathological conditions.

\subsection{Contractile unit of the crosstriated muscle}

Contractile elements of the muscle cell are cylindrical organelles known as myofibrils, which are made up of repeated units known as sarcomere. The muscle cell is nearly filled with myofibrils running parallel to each other on the long axis of the cell. The sarcomeric subunits of one myofibril are in nearly perfect alignment with those of the myofibrils next to it. This alignment gives rise to certain optical properties, which cause the cell to appear striped or striated. The light band is termed the I-band because it is isotropic in polarized light; the dark band is known as the A-band because it is anisotropic.

The principle components of striated muscle sarcomeres include parallel arrays of actincontaining thin filaments that span the I-band and overlap with myosin-containing thick filaments in the A-band. The third filament system is made up of single molecules of titin (the largest vertebrate protein identified to date), which spans half of the sarcomere. Z-discs, the borders of sarcomeres, function as anchorage sites for titin and the thin filaments. The mammalian sarcomere is $\sim 2 \mathrm{~mm}$ in length and can shorten up to $\sim 70 \%$ of its original length during contraction (Tskhovrebova and Trinick 2003).

Each myofibril is bundled to form cable-like structures which are anchored into the cell membrane laterally at the structures called costameres and along the longitudinal axis at the intercalated discs. Costameres are the rib-like bands that run perpendicular to myofibrilar axis located peripheral to the Z-discs. These are physically coupled to the force-generating sarcomeres and to the sarcolemma as well to the extracellular matrix in striated muscle cells. 
The cell-cell contacts at the longitudinal axis are formed by the intercalated discs which are classified accordingly to the protein composition and signaling mechanisms in which they are involved: the adherens junctions, the desmosomes and the gap junctions. These three macromolecular complexes in addition to the integrin-based focal adhesions, the dystroglycan complex and spectrin-ankyrin membrane cytoskeleton, are connected to the myofibrils through various linkage systems and serve as the lateral force sensing structures (Samarel 2005).

\subsection{Titin}

Titin is a giant elastic filamentous modular protein that is approximately 4.2 mega Daltons in size and is the third most abundant protein in vertebrate striated muscle. In humans, titin is encoded by a single gene on chromosome 2, region 2q31 (Labeit et al. 1990), containing 363 exons coding together for 38,138 residues (Bang et al. 2001).

In the skeletal and cardiac muscles, each titin molecule spans half a sarcomere from the Mline to the Z-disc, associates with myosin thick filaments along most of its length, and connects the thin filaments to the Z-disc via an extensible I band segment. The sequence of human titin was first published in 1995 (Labeit and Kolmerer 1995) and was completed by additional PEVK exons and three unique I-band exons (termed novex-1 to -3) (Bang et al. 2001).The complete sequence of human cardiac titin was shown to contain approximately 166 copies of immunoglobulin (Ig) and 132 copies of FnIII-like domains, a single protein kinase domain, and a PEVK region.

Titin is positioned within the sarcomere such that its $\mathrm{N}$-terminal segments are anchored in the $\mathrm{Z}$ disc, and its C-terminal segments are bound to the thick filament in the M-line region. The $\mathrm{N}$-terminal segment penetrating the Z-disc is capped by telethonin. The M-line region of titin bound to the thick filament is nonextensible.

\subsubsection{Titin structure and function}

\subsubsection{N-terminal titin}

The N-terminal part of titin is integrated into the Z-disc and link the actin filament through $\alpha$ actinin. The Z-repeats of titin interacts with C-terminal part of $\alpha$-actinin (Gregorio et al. 1998; Gregorio et al. 1999). The number of these Z-repeats depends on the type of cross striated 
muscle and determines the tightness of the $\alpha$-actinin cross links in the Z-disc. The extreme $\mathrm{N}$ terminal part of titin (Z1Z2 domains) interacts with protein called telethonin. Z1Z2-telethonin complex seems to be important for attachment of $\mathrm{N}$-terminal titin to the Z-disc. The interaction of titin to telethonin further extends the protein interactions to other Z-disc proteins such as Ankrd2, calsarcin-2, and Z-disc protein MLP. These proteins in turn bind to $\alpha$-actinin, filamentous actin, and other Z-disc-associated proteins, which make the Z-disc highly stable and essential for contractile function and stress sensing.

\subsubsection{I-band titin and myocardial passive stiffness}

The relaxation of the myocardium in the diastole is regulated by passive and active mechanisms. Active mechanisms refer to $\mathrm{Ca}^{2+} /$ ion channel dependent actin-myosin deattachment. In the regulation of myocardial passive stiffness, the I-band titin is thought to be involved, along with the extracellular matrix, microtubules (tubulin) and cell-cell contacts (desmosomes).

The I-band of titin is an elastic part of the molecule, which participates in the generation of passive forces in response to sarcomere stretch. The elastic components are PEVK segments, N2-unique sequences as well as tandem immunoglobulin segments. The shorter and stiffer cardiac isoformes of titin contain a lower number of proximal tandem Ig-repeats as a result of differential splicing and a shorter PEVK segment. During elongation of the sarcomere, the extensible elements develop elastic tension with sequential extension of the molecule, beginning with Ig segments and followed by PEVK and N2B/N2BA unique segments.

The alternative splicing of $\mathrm{N} 2$ unique segments results in N2A, N2B, and combined N2BA isoforms. The N2A isoform usually occurs in skeletal muscle, whereas the N2B and N2BA isoforms are found exclusively in cardiac muscle (Labeit and Kolmerer 1995; Freiburg et al. 2000). A truncated titin isoform, novex-3, is expressed at low levels in both skeletal and cardiac muscles, where it integrates into the Z-disk in complex with another modular protein obscurin, forming Z-disc-I-band elastic linking system (Bang at al. 2001) (Figure 1). 


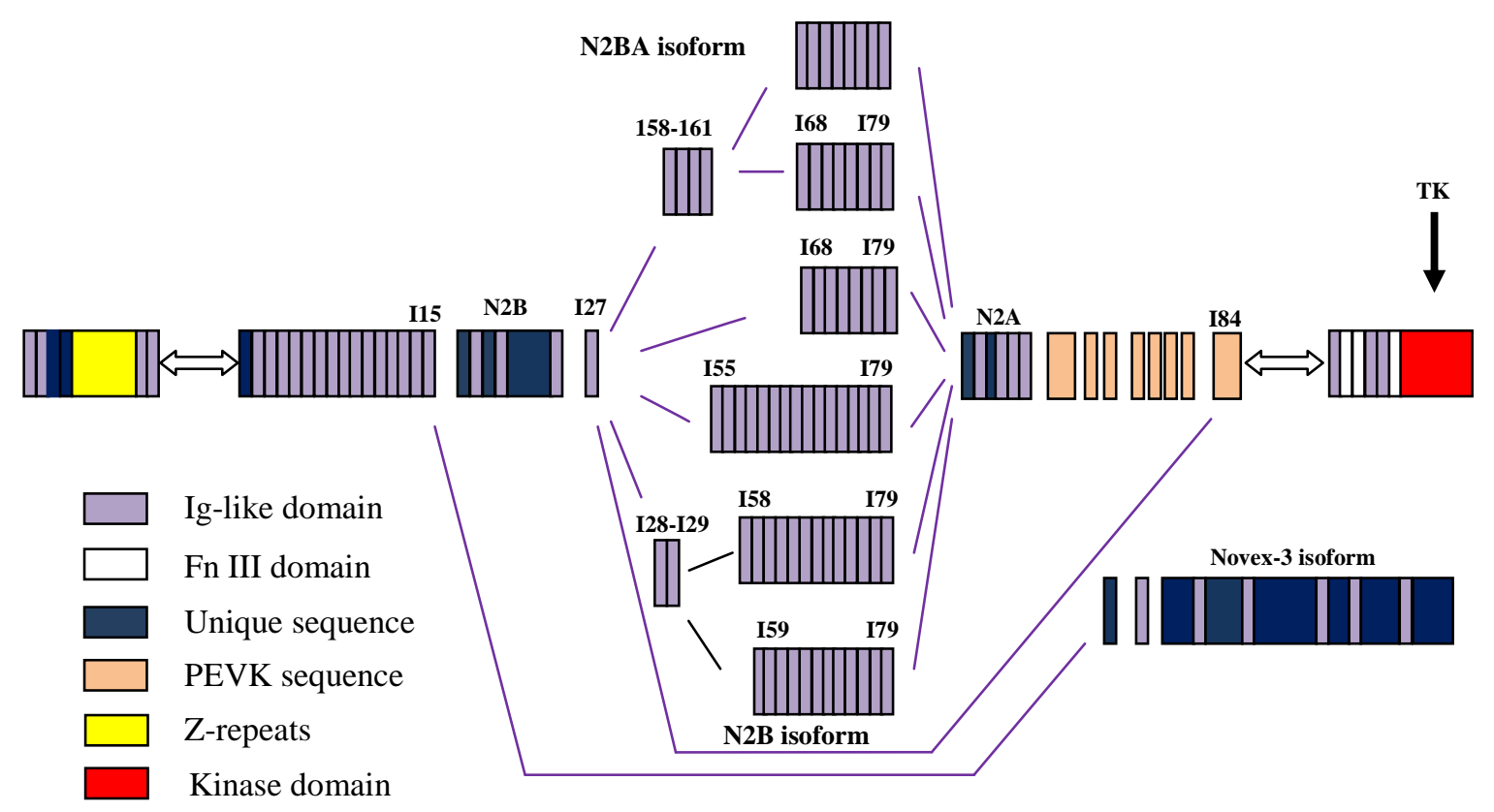

Figure 1: Titin's cardiac and skeletal muscle isoforms (Granzier and Labeit 2007, p. 746, modified)

The small cardiac isoform contains only an N2B element, in contrast to another more elastic cardiac isoform containing both N2B and N2A elements. Fetal and neonatal myocardium expresses more compliant fetal cardiac titin. Novex-3 lacks the N2B region and all downstream domains are expressed in both cardiac and skeletal muscle. Cardiac muscle expresses N2BA titin varying in size, based on a different number of I-band Ig-like domains.

In mammals, the cardiac isoforms $\mathrm{N} 2 \mathrm{BA}$ and $\mathrm{N} 2 \mathrm{~B}$ are co-expressed in the ventricle with a gradient in isoform ratio from the endocardium to the epicardium: the more extensible larger isoform N2BA is present in larger amounts in the subendocardium, and N2B is prevalent in the subepicardium. In the tachypacing heart failure model, this gradient is significantly exaggerated resulting in a reduction in the ability to generate ventricular restoring forces accompanied by increased titin-based passive stiffness (Bell et al. 2000). In hypertensive rats, the increase in diastolic muscle stiffness is accompanied by an increased N2B expression. Thereby, the isoform-switch can modify cardiac function causing disease phenotype. The N2B sequence of titin is a substrate for protein kinase A. Phosphorylation results in reduced passive tension at short sarcomere lengths (Yamasaki at al. 2002).

Mutations in I-band titin associated with familial DCM and muscular dystrophy (Table 1). 


\subsubsection{A-band titin}

A-band titin is a modular part of the molecule composed of the Ig and FnIII domains arranged in super-repeats. This part of titin was divided into three zones, D, C and P, in respect to myosin. The D-zone contains seven super-repeats of five FnIII and two Ig domains. The Czone is made up of 11 super-repeats containing seven FnIII and four Ig domains. The interaction of titin with MyBP-C, which is mapped for the first Ig-domain of each superrepeat of the C-zone, is important for the precise arrangement of the actin-myosin filaments in the sarcomere (Maruyama et al. 1985; Fürst et al. 1992; Koretz et al. 1993). The P-zone comprises a unique patch of Ig-IgFnIII-FnIII-Ig-Ig-FnIII and a kinase domain. The A-band titin is functionally nonextensible since it is bound via FnIII domains to the tail region of myosin. The C-termini of titin filamens from the opposite side overlap in the middle of the Aband (M-line), six titin molecules are bound to each thick filament through their interaction with myosin, myomesin and M-protein (Obermann et al. 1997). Titin was proposed to act as a molecular scaffold for the thick filament assembly during myofibrillogenesis. This hypotesis was supported by studies in rat cardiomyocytes treated with antisense oligonucleotides to abolish the titin expression. In this cell culture model, the myosin incorporation into forming myofibrils was disturbed (Person et al. 2000). The homozygous knockout of titin in myofibroblasts resulted in a lack of thick filament formation and impaired myofibril assembly (van der Ven et al. 2000a).

\subsubsection{M-line titin}

The carboxyterminal part of titin (exons 355-363) is located at the A/M junction and the Mband of the sarcomere. This segment of titin is also composed of alternated Ig and FnIII and several unique sequences, including the serine-threonine kinase domain. Titin molecules from the opposite half sarcomeres overlap in the M-band. Henceforth, titin was proposed to have an anchoring function for the components of the thick filament at the M-band. The appearance of the M-band indicates the completing of myofibrillogenesis, and the ultrastructure of the Mband may be dictated by expression of differently spliced titin isoforms (Kolmerer et al.1996). 


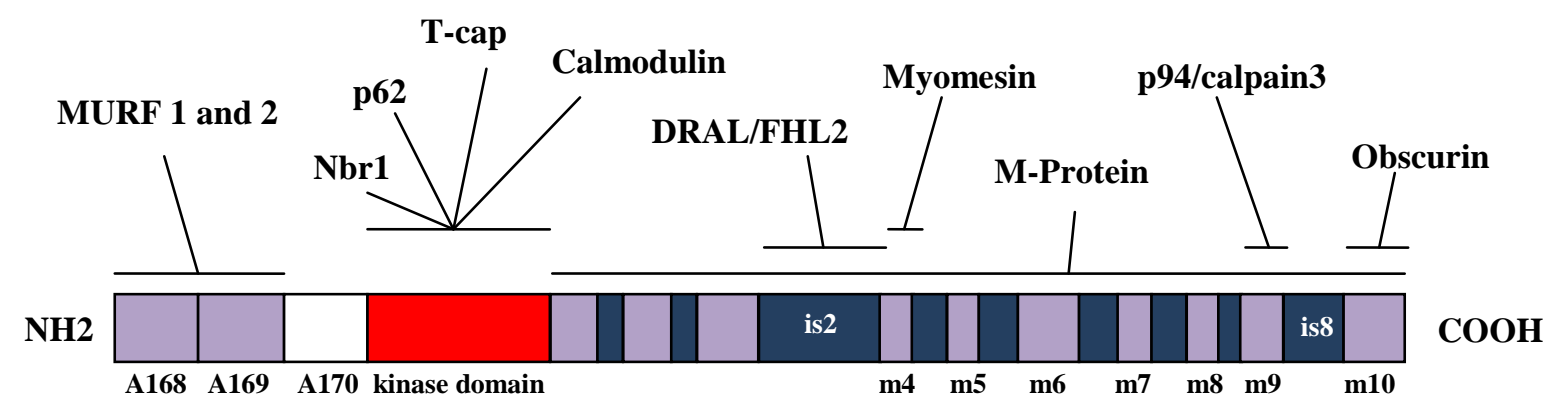

Figure 2: Schematic presentation of the titin's M-line interactions

The titin M-line region is composed of Ig domains (violet) and M-insertions (blue). Adjacent to titin kinase (red) FnIII domain is shown in white. Binding partners and interacting sites have been mapped to this region of titin like indicated (explanations in text).

The A169-170 domains of M-band titin interact with MURF1 directly N-terminal from serine-threonine kinase domain (Centner et al. 2001). MURF1 is an E3 ubiquitin ligase that binds various other muscle proteins, including troponins, myosin light chain, myotilin, telethonin, N-RAP, and nebulin presumably to control their proteasome-dependent degradation (Gautel et al. 1995). Two other homologues have been identified in the muscle cell: MURF2 (Person et al. 2000; McElhinny et al. 2002) and MURF3 (Spencer et al. 2000). They have been proposed to link components between myofibrils, microtubules, intermediate filaments, and nuclear factors. MURF2 is proposed to be a part of the titin kinase signaling pathway (1.4.1.5). Apart from the M-line, the proteins were also found in the Z-disc, in the nucleus, and in association with microtubules and myosin (Pizon et al. 2002).

The structural protein myomesin binds to the titin $\mathrm{m} 4$ domain at the M-band, crosslinks two overlapping titin molecules, and connects titin filament and thick filament through interaction with myosin (Obermann et al. 1996; Nave et al. 1989; Bähler et al. 1985). The myomesintitin-myosin complex is most likely to be the critical structure that maintains the stability of the M-band (Linke 2008). The FHL2 binds apart from the titin N2B region also to the Mis-2 unique sequence of the M-line titin (Lange et al. 2002).

The interaction of the titin M7-M10 domains with components of the nuclear membrane lamins supports the hypothesis of the presence of titin-isoforms in the nucleus of the nonmuscle cell and their participation in the nuclear organization during the interphase. The titin unique sequence Mis-7 at its very C-terminus, which harbours a nuclear localization signal, 
has also a second binding side for calpain 3/p94 (Kinbara et al. 1997), a cysteine protease with autolytic activity whose loss of function was shown to result in limb girdle muscular dystrophy type 2A (Richard et al. 1995).

The function of titin's M-line portion was extensively studied in vivo. M-line titin knock out including titin kinase domain in the myoblast-culture shows impaired myofibrillogenesis in the cells with one truncated allele (Miller G et al. 2003). Conditional knockout in adult mice leads to reduction of the contractile responce to $\beta$-adrenergic agonists and extracellular calcium with reduced levels of calmodulin, phospholamban, and SERCA2 expression. Those mice develop cardiac hypertrophy and heart failure with involvement of PKC signaling pathway (Peng et al. 2007).

\subsubsection{Titin kinase}

Titin kinase is a kinase domain that is located in the transition between the A-band and the Mline and encoded within exon 358 of titin (Labeit et al. 1992). Protein kinases are significant for the control of the cell proliferation and differentiation, and they require specific mechanisms of regulation and substrate recognition. Titin kinase is a serine/threonine kinase from the MLCK family, which catalyses the transfer of the gamma-phosphate of ATP to the hydroxyl group of a serine, threonine, or tyrosine within the substrate protein. The kinase domain of titin is philogenetically conserved in titin homologues from different species like: I-connectin from crayfish (Fukuzawa et al. 2001), D-titin (Machado and Andrew 2000; Zhang et al. 2000), twitchin (Benian et al. 1989) and projectin (Ayme-Southgate et al. 1991) from Drosophila melanogaster; kettin (Lakey et al. 1993; Hakeda et al. 2000; Kolmerer et al. 2000) and stretchin from Caenorhabditis elegans (Champagne et al. 2000).

All kinases share a conserved region of about 250 amino acids, which are required for their activity. This region is carrying the kinase catalytic core: a bi-lobed structure comprising a small ATP binding domain made primarily of $\beta$-strands, and a larger substrate binding domain made primarily of $\alpha$-helices, connected by a small linker region. This linker region acts as a hinge that allows the two globular domains of the catalytic region to open and close through the different stages of the catalytic cycle. The substrate binds to the activation loop or activation segment. In the titin kinase, the activation segment has to be activated by phosphorylation to allow substrate binding. The titin kinase is a so-called non-RD kinase, which gets activated by phosphorylation, in which the catalytic aspartate is preceded by a phenylalanine but not by an arginine like RD-kinases (Mayans et al. 1998). In the autoinhibited titin kinase, the catalytic residue aspartate 127 (D127) is embedded in a 
hydrogen-network with the residues R129 (in the catalytic loop), Q150 (in the activation segment), and Y170 (in the $\mathrm{P}+1$ loop) blocking the active site from access of its protein substrate and thus inhibiting catalysis. The central part of the $\mathrm{C}$-terminal regulatory tail, $\alpha \mathrm{R} 1$ and $\beta \mathrm{R} 1$ termini, blocks the ATP-binding side of the catalytic domain additionally. The $\alpha \mathrm{R} 1$ covering segment of titin kinase carries the calmodulin-binding site (Gautel et al. 1995).

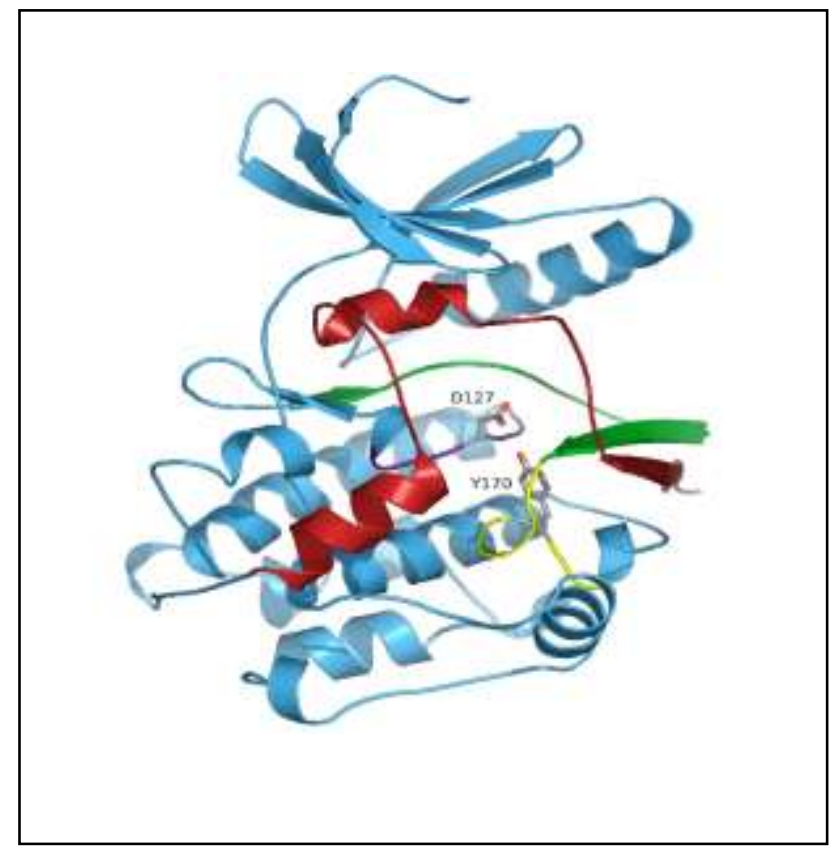

Figure 3: The ribbon presentation of the autoinhibited form of titin kinase (Mayans et al. 1998, p. 865)

The catalytic centre of the kinase and catalytic residue D127 (violet) is blocked by the Y170 residue from the $\mathrm{P}+1$ loop (yellow) of the activation segment (green) and by the regulatory tail (red).

The first activation step of the titin kinase, the phosphorylation of a tyrosine 170 in the $\mathrm{P}+1$ loop, was demonstrated by a Y170E mutation, designed to mimic tyrosine phosphorylation, which allowed substrate binding to occur. The second step is achieved by the removal of a regulatory tail from the ATP binding site by the interaction of the $\mathrm{Ca} 2+/$ calmodulin complex. In absence of calmodulin, the substrate binding site is blocked by an intrinsic autoinhibition mechanism (Kobe et al. 1996). These two inhibitory mechanisms result in the tight control of the catalytic activity of titin kinase.

Titin kinase is proposed to phosphorylate the Z-line protein telethonin, an event hypothesized to be involved in myofibrillogenesis (Mayans et al. 1998). Another study identified the zinc finger protein Nbr1 as a putative interacting partner of titin kinase. The minimal binding site was narrowed down to $\alpha-\mathrm{R} 1$ helix in the titin kinase and PB1 domain in Nbr1 in yeast two 
hybrid studies (Lange et al. 2005). The stretch-dependent activation of titin kinase (Gräter et al. 2005) is a starting point in the newly proposed titin kinase signaling pathway. The semiopen nonphosphorylated titin kinase in turn interacts with Nbr1-dimer when the sarcomere is stretched. Nbr1 is phosphorylated at S115 or S116 by titin kinase and targets the ubiquitously expressed zinc finger protein p62 to the sarcomere by interaction via the PB1 domains. The p62 itself is a poor in vitro substrate of titin kinase (Lange et al. 2005). The p62 is characterized as a scaffold protein in several signaling pathways via aPKC and NF-kB as a transcriptional cofactor. Its UBA domain binds to ubiquitin chains (participation in binding and storage of ubiquitinated proteins). Apart from the association of titin A168-A169 with MURF-1 and possibly also MURF-2 (Centner et al. 2001; Pizon et al. 2002), an interaction of the RING B-box domain of MURF-2 with the C-terminal ubiquitin association (UBA) domain of p62 was proposed (Lange et al. 2005; Mayans et al. 1998). MURF-2 shuttles between cytosole and nucleus and was found in increasing amounts in the nucleus under atrophic conditions (Pizon et al. 2002). In the signaling pathway proposed by Lange et al., MURF-2 interacts (inhibitory effects) with SRF, the major transcription factor involved in the transcriptional regulation of immediate-early genes.

The titin kinase mutation mapped in the $\alpha \mathrm{R} 1$ helix (R279W) is associated with the hereditary myopathy with early respiratory failure. The presence of the mutation leads to the abrogation of Nbr1 binding resulting in its abnormal localization, which subsequently leads to the disruption of the signaling pathway described above.

\subsection{Cardiomyocyte mechanosensors}

The process of sensing and relaying the physical entities, a finely tuned conversion of forces into biochemical components, is defined as "mechanotransduction" and the molecules that sense the stimuli are called "mechanosensors". Evidently, the human heart continuously experiences the filling pressure and volume of blood as well as the neurohumoral signals. In response to the alterations in these signals the cardiac system reacts to maintain required cardiac output by remodeling the myofibrillar apparatus. There are different extra- and intracellular components proposed to have stretch-dependent activation mechanism in the heart. The presumptive mechanosensors include stretch-sensitive ion channels at the cell membrane, integrins and integrin-associated proteins (such as melusin or integrin linked kinase (ILK)), sarcomeric proteins such as titin or small LIM-domain protein MLP, and cell 
surface receptors (such as G-protein-coupled receptors) that can be activated by stretching even in the absence of ligands. These mechanosensors activate complex and overlapping cellular signaling pathways through such mediators like Ras/Rho and mitogen activated protein kinase, phospholipase $\mathrm{C}$, calcium/calcineurin and nuclear factor of activated $\mathrm{T}$ cells, insulin-like growth factor-I-phosphatidylinositol 3-kinase-AKT/protein kinase B and others. These pathways trigger the expression of hypertrophic genes and cause an increase in myocyte length and/or width. There are multiple levels of crosstalk between these pathways. Here I present a short description of the presumptive cardiomyocyte mechanosensors.

\subsubsection{Stretch-activated channels}

Membrane channels sensitive to mechanical stimulation are present in most cell types, and play an essential role in how cells and higher organisms interact with their immediate environment (reviewed in Blount 2003).

A subgroup of mechanosensitive channels: stretch activated channels (SACs) open in response to stretch and contribute to stretch-dependent increase in cardiac performance (Craelius et al. 1988; Kim 1992; Ruknudin et al. 1993; Hu H and Sachs 1996; Zeng et al. 2000). It has been suggested that SAC's directly interact with the cytoskeleton and thus can intrinsically sense the cell stretch (Sokabe and Sachs 1990). SAC's are permeable to monovalent cations and to $\mathrm{Ca}^{2+}$, and can therefore act as a source of intracellular $\mathrm{Ca}^{2+}$ either directly, or indirectly, via the $\mathrm{Na}^{+} / \mathrm{Ca}^{2+}$-exchanger in response to an increase in intracellular sodium ion. Mechano-sensitive L-type $\mathrm{Ca}^{2+}$ channel found in atrial and ventricular myocytes contribute to the stretch-dependent increase in contractility of ventricular tissue by enhancing the $\mathrm{Ca}^{2+}$ current (Matsuda et al. 1996). The calcium ion influences directly cardiac function through the thin and thick filaments overlap in response to calcium bonding to troponin $\mathrm{C}$ during diastole and indirectly through induction of protein synthesis.

Other possible channels-mechanosensors are TREK-1 family of channels, ATP-sensitive potassium channels, and Cl-selective anion channels (Terrenoire et al. 2001; Sigurdson et al. 1992; Sorota et al. 1991).

\subsubsection{G-protein coupled receptors as stress sensors}

GPCRs are a class of transmembrane receptors coupled with heterotrimeric guaninenucleotide regulatory proteins (G-proteins) which mediate immediate contractile response and remodeling through hormonal stimulation or direct stretch activation. The GPCR-mediated 
$\mathrm{G}_{\mathrm{q}}$-pathway is involved in the development of pathological cardiac hypertrophy (Salazar et al. 2007). Overexpression of $G_{q}$ leads to development of cardiac hypertrophy and heart failure in mice (Heineke and Molkentin 2006). $\mathrm{G}_{\alpha \mathrm{q}} / \mathrm{G}_{\alpha 11}$-coupled receptors, such as endothelin, angiotensin, and $\alpha$-adrenergic receptors play a vital role in cardiac physiology, and have been widely studied with respect to the cardiac system.

Angiotensin II is a by-product of the chemical reaction involving angiotensin I by the action of ACE bound to vascular endothelial cells. Angiotensin II is known to be released upon stretch from secretory granules in cardiomyocytes (Sadoshima et al. 1993). There are two types of angiotensin receptors, the angiotensin II receptor type 1 and angiotensin II receptor type 2. Distribution of angiotensin II type 1 receptor $\left(\mathrm{AT} 22_{1}\right)$ is commonly observed in the central nervous system, adrenals, heart, vasculature and kidney. To maintain electrolyte balance the type 1 receptor infuses sodium into the cell in exchange for releasing $\mathrm{H}^{+}$out of the cell upon activation by angiotensin II using the $\mathrm{Na}^{+} / \mathrm{H}^{+}$-exchanger. In addition, it stimulates several signaling pathways through activation of phospholipase $C \beta$ which in turn leads to activation of $\mathrm{PKC}$ and mobilization of internal $\mathrm{Ca}^{2+}$ resulting in the modulation of hypertrophic signaling through calcineurin-NFAT activation or calmodulin-dependent kinase-HDAC inactivation (Wilkins et al. 2004; Wu et al. 2006). The activation of $\mathrm{G}_{\alpha \mathrm{\alpha q}}$ also induces MAPK-dependent hypertrophic pathway of the heart (Clerk and Sugden 1999).

The angiotensin-independent activation mechanism upon mechanical stress was proposed for AT2 1 receptor. AT2 $2_{1}$ receptor directly associates with Janus kinase-2 and induces the translocation of $\mathrm{G}$ proteins into the cytosol upon stretch. It leads to activation of the extracellular signal-regulated kinase and the induction of hypertrophy (Zou et al. 2004). Activated by mechanical stretch $\mathrm{AT} 2{ }_{1}$ receptor can activate hypertrophic growth pathways independent of $\beta_{1}$ integrin in contrast to adrenergic stimulation (Pham et al. 2000). However, AT2 $2_{1}$ activation can modulate $\beta_{1}$ integrin signaling (Lal et al. 2007) and $\beta_{1}$ integrin expression (Jia et al. 2003). Furthermore, AT2 receptor activation induces apoptosis, differentiation, antiproliferation, modulation of extracellular matrix, and vasodilation (Unger 2002).

Endothelin 1 involved in activation of proximal effectors of cardiac hypertrophic pathways: kinases Raf1 and MAPK (Yamazaki et al. 1996). Studies using inhibitors of the primary $\mathrm{G}_{\mathrm{q}} / \mathrm{G}_{11}$ coupled endothelin or AT1 receptors showed a dose-dependent decrease in hypertrophic response (Ito et al. 1994; Griendling et al. 1996). These studies indicate involvement of certain GPCRs in the biomechanical aspects of cardiac function and disease. 


\subsubsection{Integrins and integrin-associated proteins}

Integrins are the transmembrane proteins/receptors involved in maintenance of tissue structure, mechanosensation and mechanotransductory processes, cell migration, and pathophysiology. In cardiomyocytes integrins modulate the hypertrophic response. Overexpression of $\beta_{1}$ integrin showed an increase in ANP protein. Integrins associate with FAK and c-Src to the actin cytoskeleton in hypertrophied feline hearts (Kuppuswamy et al. 1997). Consequently, integrin-FAK-cytoskeleton forms a complex, which can transduce signals from the outside to the inside of the cell. A modulation of the protein complex or the activity of the kinase due to the cytoskeleton changes the amount of integrin receptor complex that adhere to the extracellular matrix which constitutes an "inside-out" signaling activity. In the force transmission via integrins Rho small GTPases are involved. Cdc42 was suggested to play an important signaling role in stretch-induced hypertrophy of myocytes (Pan et al. 2005). Several studies have also implicated the RhoA/Rho kinase (ROCK) pathway in cardiac hypertrophy and in the transition from hypertrophy to overt heart failure ( $\mathrm{Hu}$ and Lee 2003; Ren and Fang 2005). Activation of RhoA in cardiomyocytes leads to upregulation of hypertrophy-related genes. This response is dependent upon interactions between $\beta_{1}$ integrins and actin cytoskeleton (Kawamura et al. 2003; Wei et al. 2001).

\subsubsection{Integrin linked kinase}

Integrin interacting proteins such as ILK have been identified to participate in the hypertrophic signaling. ILK binds to parvin and PINCH to form a complex called an "IPPcomplex" and subsequently forms a link between integrin and the actin cytoskeleton. The complex acts as a scaffolding structure to several actin associated and signaling molecules. ILK expression was found to be increased in patients diagnosed with hypertrophy of the heart, and further, its overexpression induces cardiac hypertrophy ( $\mathrm{Lu} \mathrm{H}$ et al. 2006). Studies on mutant ILK with loss of kinase activity and interaction to $\alpha$-parvin showed significant downregulation of stretch responsive genes like VEGF and ANP indicating a loss of mechanosensation (Bendig et al. 2006). In a similar model system, a total abrogation of ILK protein expression caused severe defects in cardiomyocytes and endothelial cell function with enlarged hearts (Postel el al. 2008). Therefore, the integrin-integrin linked kinasecytoskeleton axis is an important "outside-in" and "inside-out" signaling pathway with several downstream effectors responsible for cardiac mechanosensation/-transduction. 


\subsubsection{Melusin}

The human integrin $\beta_{1}$ binding protein 2 (melusin) is a muscle specific protein localized at costameres and binds to the cytoplasmic tail of $\beta_{1}$ integrin (Brancaccio et al. 1999). The function of melusin in cardiomyocytes was elaborated by the melusin null and transgenic mice. Knockdown of melusin manifested in the alteration of left ventricular response to TAC induced pressure overload and stimulated cardiac dilation. On the contrary, overexpression of melusin remarkably preserved cardiac structure and function to high pressure overload pressed on it by aortic banding (Brancaccio et al. 2003). Further, the transgenic mice showed higher efficiency of kinase activity as determined by the substrate phosphorylation of AKT and GSK3 $\beta$ downstream to integrin-ILK-melusin macromolecule.

\subsubsection{Muscle LIM domain protein}

MLP is highly expressed in the myocardium and located predominantly at the level of Zdiscs, costameres and in the nucleus and interacts with such proteins as actin, actinin, telethonin, MyoD, MRF4, myogenin, calcineurin, NFAT, ILK, histone deacetylases (HDAC4) and acetylases (PCAF) (reviewed in Buyandelger et al. 2011). The earliest evidence of MLP's involvement in cardiac disease was shown in MLP-null mice, which developed DCM very early into adulthood (Arber et al. 1997; Ehler et al. 2001). MLP null mice expressed high amounts of ANF, MARP and actin. The downstream effectors of MLPcalcineurin and NFAT (Heineke et al. 2005) are part of the main hypertrophic response pathway in heart (Heineke and Molkentin 2006). Cardiomyocytes isolated from MLP deficient mice showed decreased BNP (important stretch marker of ventricular cardiomyocytes) induction upon mechanical stimulation in comparison to wild type (Knöll et al. 2002). A similar defect in BNP gene expression was observed in W4R-MLP (mutation found in cardiomyopathy patients) knock-in mouse model (Knöll et al. 2010). MLP can translocate from the Z-disc, cytosol, or intercalated disc to the nucleus, where it associates with the muscle transcriptional regulators: MyoD, MRF4, and myogenin (Kong et al. 1997). Based on these findings, it has been suggested that MLP is part of a stretch-responsive signaling pathway of the heart. This hypothesis is supported by mutations that cause DCM or HCM (Bos et al. 2006, Geier et al. 2003; Hershberger et al. 2008; Knöll et al. 2002; Knöll et al.2010; Mohapatra et al. 2003) and by an MLP KO mouse that shows cardiac hypertrophy, myofibrillar disarray, and reduced myocardial stiffness (Knöll et al. 2002). MLP is linked through its interaction to telethonin to the giant titin. A loss of telethonin in the Z-disc was 
observed in MLP deficient cardiomyocytes and in myocardial biopsies from patients carrying the W4R-MLP mutation (Knöll et al. 2002; Knöll et al. 2010). The MLP-telethonin-titin ternary complex at the level of Z-disc was proposed to be directly modulated by mechanical forces and with the help of other ligands, for example calcineurin-NFAT or PKC pathways, or directly via activation of muscle transcriptional regulators, to trigger hypertrophy pathways of the heart (Linke 2008). Another possible force transmitting complex locates at the costameres and involves MLP, ILK, zyxin, $\beta 1$ spectrin and $\alpha$ actinin.

\subsubsection{FHL1/2 and N2B titin}

FHL1 is present in skeletal and cardiac muscle cells. FHL1 mRNA expression is upregulated in response to hypertrophy inducing agents and an increased FHL1 is found in human patients suffering from DCM and HCM (Gaussin et al. 2003). FHL1 interaction with the N2B region of titin and further association with Raf1, MEK1/2, and ERK2 hypertrophy signaling molecules has been identified (Sheikh et al. 2008). Through its association with proteins of the $\mathrm{G}_{\alpha \mathrm{q}}-\mathrm{MAPK}$ pathway, it may sense biomechanical stress responses in the sarcomere which leads to pathological hypertrophy. Mice lacking FHL2 show an increased hypertrophic response on $\beta$-adrenergic stimulation, indicating an involvement of FHL2 in the remodeling mechanisms employed by cardiomyocytes in response to stress (Kong et al. 2001). FHL1 deficient mice subjected to pressure overload by aortic banding showed a blunted response in comparison to the wild type mice, characterized by lower ANP gene expression levels. These studies indicate that FHL1/2 is a part of the cardiac hypertrophic gene transcription network.

\subsubsection{Cardiac ankyrin repeat protein and $\mathrm{N} 2 \mathrm{~A}$ titin}

CARP is a member of the muscle ankyrin repeat proteins family of muscular proteins, which also includes Ankrd2/Arpp and DARP involved in muscular stress response (Miller MK et al. 2003). CARP has been identified as a gene that is highly expressed in the left ventricular myocardium in animal models and classified cardiac patients presenting dilation of the myocardium (Zolk et al. 2002; Nagueh et al. 2004). It consists of nuclear localization signal, PEST sequence and ankyrin repeat domains with which it interacts to the giant molecule titin. CARP localize to the sarcomeric I band and could act in association to N2A elastic region of giant titin, myopalladin, and the calpain protease p94 as a part of stress sensing complex (Miller MK et al. 2003). CARP has been reported to be a nuclear protein which negatively regulates expression of cardiac genes including troponin $\mathrm{C}$, myosin light chain 2 , and ANP 
(Jeyaseelan et al. 1997; Zou et al. 1997).The Ankrdl gene is strongly upregulated during cardiomyogenesis and is downstream to cardiogenic homeobox gene $N k x 2.5$ (Zou et al. 1997). Interestingly, conditional knock-out of C-terminal titin including titin kinase domain from the titin filament causes upregulation of CARP (Gotthardt et al. 2003). Further, Ankrd1 protein interacts with desmin, Casq2, MURF1/MURF2 involved in maintenance of myofibrillar and sarcomeric integrity, EC coupling, protein quality, and stress sensing, all of which indicate that MARPs are pivotal in stress sensation and response.

\subsection{Cytoskeleton and its role in myofibrillogenesis, maintenance of the sarcomere and mechanotransduction}

The cytoskeleton is essential for the organization and maintenance of cellular function and shape. The myocyte cytoskeleton is represented by the so-called sarcomeric cytoskeleton, which includes specific sarcomeric proteins: titin, $\alpha$-actinin, C-protein, myomesin, and Mprotein. The true 'cytoskeletal' proteins: tubulin, desmin, and actin are ubiquitous in all types of cells and have an extensive network of associated regulatory proteins.

One of the cytoskeletal components are the microtubules - cellular organelles composed of polymerized $\alpha$ - and $\beta$-tubulin. Microtubules transmit mechanical and chemical stimuli within and between cells, and they contribute substantially to cell stability by anchoring subcellular structures, including myofibrils. A plethora of microtubule associated proteins (MAPs) regulating polymerization, stabilization and depolymerization of tubulins is responsible for the formation and reorganization of the MT network and its interaction with other cytoskeletal proteins. For example, the microtubule associated proteins 1, 2, and 4 contain both tubulin and non-sarcomeric actin bindig sequences.

The titin M-line interacting muscle specific ring finger proteins (MURFs) belong to MAPs. MURF-2 was shown to transiently associate with microtubules, myosin, and titin during the sarcomere assembly (Pizon et al. 2002). Microtubules could be involved in the elongation of the titin molecule through their adaptor-proteins such as MURF-2 (possibly also MURF-1 and 3 ), incorporation of myosin and titin into nascent sarcomere and forming of longitudinally aligned sarcomers.

Electronmicroscopic studies demonstrated that microtubules participate in myofibrillogenesis, during which an elongated network of microtubules closely associated with sarcomeres is formed. In adult cardiomyocyte, microtubules are accociated with myofibrils in a helical 
arrangement and form a network that runs transversely at the level of I-band and axially between the myofibrils (Goldstein and Entman 1979). The induction of cardiac hypertrophy, and thereby the formation of new sarcomeres, is associated with the rapid increase in the number of microtubules and their reorganization parallel to the myofibrillar axis (Rappaport et al. 1985; Saitoh et al. 1988; Samuel et al. 1984). Adult re-differentiating cardiomyocytes with destroyed by specific drugs microtubules reveal defective myofibrillogenesis with disturbed lateral alignment of the sarcomeres (Toyama et al. 1982). Neonatal rat cardiomyocytes were able to maintain sarcomeric structures even after the microtubules were destroyed, presumably because their myofibrils are preformed (Rothen-Rutishauser et al. 1998).

The actin-based cytoskeleton of the muscle cell with several actin-binding proteins is very important in establishing a link via the integrins between extracellular matrix and intracellular components, participating thereby in mechanotransduction with involvement of such actin binding proteins as vinculin, $\alpha$-actinin, talin, filamin, paxillin and many others. MLP is presumable scaffold for the assembly of the titin/telethonin-based mechanosensory complex of Z-disc proteins along the actin-based cytoskeleton (see 1.4.4).

\subsubsection{Actin binding protein filamin $\mathrm{C}$}

Filamins are cytoplasmic proteins, which play an important role in cross-linking cortical actin filaments into a dynamic three-dimensional structure. Filamin $\mathrm{C}$ isoform was identified as a Z-disc protein in mammalian striated muscles by immunocytochemistry and immunoelectron microscopy. In addition, filamin was identified as a component of intercalated discs in mammalian cardiac muscle and of myotendinous junctions in skeletal muscle.

This latter function is exemplified further by the documentation of interactions between filamins and several transmembrane proteins: $\beta_{1}$-integrin (Pfaff et al. 1998; Loo et al. 1998), $\beta_{2}$-integrin (Sharma et al. 1995), caveolin-1 (Stahlhut and van Deurs 2000), and $\gamma$ - and $\delta$ sarcoglycan (Thompson et al. 2000) were all identified as ligands for filamins.

The filamin $\mathrm{C}$ isoform harboring a unique insertion of 78 amino acids was shown to be expressed specifically in muscular tissues (Maestrini et al. 1993; Xie et al. 1998; van der Ven et al. 2000b). Its upregulation during the initial stages of myocyte differentiation and its localization predominantly at the periphery of Z-discs implied an important role of this filamin variant during myofibrillogenesis (van der Ven et al. 2000b). 
Filamins are likely participating in transduction of mechanical stimuli through its direct binding to both integrin $\beta$ tails and F-actin. Filamin $\mathrm{C}$ also binds to $\mathrm{N}$-terminal titin (Zis-1) (Labeit et al. 2006) linking thereby the giant molecule to actin cytoskeleton. The N-terminal titin is coupled thereby to integrin and sarcoglycan at the costameres (Samarel 2005; Brancaccio et al. 2006), $\alpha$-actinin, actin, myotilin, ZASP (cypher/oracle) and calsarcin at the Z-disks (Ervasti 2003), and N-RAP at the intercalated disks (Lu S et al. 2003). The interaction of titin and filamin $\mathrm{C}$ allows titin to participate in external force transmitting system with involvement of proteins like vinculin, melusin, talin, focal-adhesion kinase, integrin linked kinase, Src-tyrosine kinase, zyxin, paxillin, protein-kinase-Ce, and members of the Rhofamily GTPases (Samarel 2005; Brancaccio et al. 2006; Mitra et al. 2005).

\subsubsection{Microtubule associated protein 1B}

Proteins co-purified with microtubules have been termed microtubule-associated proteins or MAPs. MAP1B is a high-molecular weight MAP which is predominantly expressed in the nervous system during embryonic development and is down regulated in adult. MAP1B has been shown to play an important role in neuronal morphogenesis and axon guidance (Riederer 2007). MAP1A and MAP1B both are synthesized as polyprotein precursors, which are posttranslationally cleaved into heavy chains (HC) and light chains (LC). The LC1, 2 or separately encoded LC3 can non-covalently interact with MAP1A and MAP1B heavy chains to form HC-LC complex. The LC1, is associated non-covalently with the $\mathrm{N}$-terminal region of the heavy chain, has a tubulin binding site near its $\mathrm{N}$-terminal part and an actin-binding site in its C-terminal extremity (Noiges at al. 2002, Tögel et al. 1998). It appears as a long filamentous molecule which forms cross-bridges between microtubules with mainly phosphorylated forms in axons and unphosphorylated forms (or differentially phosphorylated forms) in soma and dendrites (Sato-Yoshitake et al. 1989).

The main role of MAP1B is to promote tubulin assembly and to stabilize microtubules (Takemura et al. 1992). In addition, MAP1B from calf brain could bind actin, but only when the purified protein was previously treated with alkaline phosphatase, thus suggesting that phosphorylation of MAP1B-LC1 may influence directly actin-binding (Pedrotti et al. 1996) by influencing the MAP1B-actin binding site located in the C-terminal domain (Noiges at al. 2002; Tögel et al. 1998). 
The LC3 is an important autophagosome marker which links titin kinase through the reported interactions with an ubiquitin-binding protein p62 (Pankiv et al. 2007) and Nbr1 (Waters et al. 2009) to protein turnover via autophagy and proteasomal degradation.

The MAP1B interacts with other proteins and participants in downstream signaling pathways, including MAP kinase and glycogen synthase kinase-3 $\beta$ pathways. It has also been postulated that MAPs may function as a link between the microtubule and microfilament cytoskeleton (Dehmelt and Halpain 2004). Data about MAP1B-LC1 performing specific function in cardiac muscle is lacking.

\subsection{Myosin regulatory light chain}

Cardiac myosin II isoforms comprise the motor of myocardial contraction and like all members of this family composed of six subunits: two heavy chains (ca. $200 \mathrm{kDa}$ ), two socalled essential light chains (or light chain 1) and two regulatory light chains (or light chain 2). The light chains stabilize the long alpha helical neck of the myosin head (Rayment 1996). Myosin II light chains are similar in structure to calmodulin, but in many organisms have lost the ability to bind $\mathrm{Ca}^{2+}$. However, the calmodulin-like light chains of some myosins do bind $\mathrm{Ca}^{2+}$. MLC2 is a small polypeptide wrapping around long the alpha-helical neck region of myosin heavy chain. Its molecular weight is ca. $19 \mathrm{kDa}$. There are two types of cardiac RLCs, a ventricular myosin light chain, MLC2v, and an atrial-specific form, MLC2a (Collins 2006).

The contraction in heart and skeletal muscle begins with $\mathrm{Ca}^{2+}$ binding to troponin in the actin thin filament, thereby allowing myosin heads to attach to actin for sarcomeric force development and shortening (Kobayashi and Solaro 2005). An additional mechanism that regulates contraction in skeletal muscle is the phosphorylation of RLC in fast-twitch muscle fibers by a skeletal muscle-specific MLCK, which leads to increase in contractile response by potentiating frequency-dependent force development (Sweeney et al 1993; Zhi et al. 2005; Ryder et al. 2007).

In the heart RLC phosphorylated by cardiac isoform MLCK - a serine-theonine kinase, structural homolog of titin kinase, which is activated by Calmodulin/ $/ \mathrm{Ca}^{2+}$ binding. Lack of RLC phosphorylation due to ablation cMLCK expression leads to blunted stress responce in mice (Ding et al. 2010). There is a report about an ability of twitchin kinase (titin kinase homolog in mollusc) to phosphorylate RLC in vitro (Heierhorst et al. 1995), but there is no evidence for vertebrate titin performing the same function. 
MLC2 has been shown to be essential for myocardial assembly. The studies in zebrafish lacking atrial isoform of RLC shows disruption of myofibrillar organization in the atria similar to the picture in zebrafish lacking titin (Rottbauer et al. 2006). Thus, MLC2 was shown to play an essential role in the assembly of cardiac thick filament and the sarcomere, but whether this is because of a structural or contractile effect of RLC is presently unknown. Over ten mutations in MYL2 gene have been reported to be associated with mid-left ventricular chamber type HCM.

\subsection{Cardiomyopathies and clinical relevance of titin}

The experts of American Heart Association proposed following definition of cardiomyopathies: "Cardiomyopathies are a heterogeneous group of diseases of the myocardium associated with mechanical and/or electrical dysfunction that usually (but not invariably) exhibit inappropriate ventricular hypertrophy or dilatation and are due to a variety of causes that frequently are genetic. Cardiomyopathies either are confined to the heart or are part of generalized systemic disorders, often leading to cardiovascular death or progressive heart failure-related disability" (Maron et al. 2006, p. 1809).

Among the variety of cardiomyopathy causes, genetic is of the greatest interest for the discovery of the pathogenetic aspects of heart disease and new therapy options. In particular, the familial forms of cardiomyopathy are very important for cardiovascular research, since they are often caused by a single mutation in genes encoding cardiac proteins. The functional change of a single protein allows the discovery of unknown signaling pathways and new possible therapeutic targets.

Since mutations in my protein of interest (titin) are known to be a cause for at least two forms of cardiac muscle disorder - DCM and HCM (Table 2), I shall restrict the short introduction to these two major forms.

\subsubsection{Hypertrophic cardiomyopathy}

HCM is a clinically heterogeneous genetic heart disease characterized by left ventricular wall thickening without dilation, interstitial fibrosis, and myocyte disarray. These disease is 
diagnosed relatively often (phenotype recognized by echocardiogaphy, 1:500 of the general population) and are the most common cause of sudden cardiac death in the young age.

$\mathrm{HCM}$ produces a thickening of the ventricular wall prominent in the interventricular septum with decrease in ventricular chamber volumes. The systolic function is increased or not affected, while the diastolic dysfunction is thought to be responsible for the development of the heart failure symptoms. The disease symptoms are usually developed during adolescence, however, in severe cases it can occur in an infant or even during foetal life. Among the variety of symptoms HCM patients can exhibit, most frequently found are dyspnoea, angina pectoris, palpitations, fatigue, presyncope, and syncope. Last two symptoms often occur due to dynamic left ventricular outflow or midventricular obstruction.

Clinical diagnosis is usually made based on echocardiography by detection of unexplained LV wall hypertrophy and additional signs like asymmetry of LV wall thickening, presence of systolic anterior motion of mitral valve, smaller LV cavity, systolic pressure gradient in LVOT. Cardiac magnetic resonance imaging, heart catheterisation, endomyocardial biopsy, ECG and genetic analysis are used for differential diagnosis and clinical risk assessment.

HCM is caused by a variety of mutations in genes encoding contractile proteins of the cardiac sarcomere. The largest number of HCM-causing mutations described in genes coding following sarcomeric proteins: $\beta$-myosin heavy chain (MYH7), regulatory myosin light chain (MYL2) and essential myosin light chain (MYL3), myosin binding protein C (MYBPC3), cardiac troponin T (TNNT2), $\alpha$-tropomyosin (TPM1), cardiac troponin I (TNNI3), a-actin (ACTC) and $\alpha$-myosin heavy chain (MYHO). The prevalence of mutations in these most common myofilament associated genes, currently comprising the commercially available HCM genetic test (www.hpcgg.org), in different international cohorts ranges from 30 to $61 \%$, leaving still a large number of patients with genetically unexplained disease. The genotypephenotype studies of the large cohorts of unrelated patients opens up the prognostic relevance of particular mutations. For example, mutations in cardiac Troponin $\mathrm{T}$ gene are more often associated with sudden cardiac death (also in family members without manifest LVhypertrophy) (Watkins et al. 1995).

Recent research has been focused on proteins involved in the cytoarchitecture and cardiac stretch sensor mechanism of the cardiomyocyte localized to the sarcomeric Z-disc. Mutations in such proteins localized to the sarcomeric Z-disc like CSRP3-encoded MLP, TCAP-encoded telethonin and $V C L$-encoded vinculin, including its cardiac specific insert of exon 19 that yields metavinculin, have previously been established as both HCM- and DCM-susceptibility genes (Geier et al. 2003; Knöll et al. 2002; Mohapatra et al. 2003; Hayashi et al. 2004; Bos et 
al. 2006; Vasile et al. 2006; Knöll et al. 2010). Targeted screening of giant sarcomeric TTNencoded titin revealed two mutations possibly responsible for HCM (Table 1).

\subsubsection{Dilated cardiomyopathy}

Dilated forms of cardiomyopathy are characterized by ventricular chamber enlargement and systolic dysfunction with normal LV wall thickness. It can be primary (genetic, mixed or predominantly familial non-genetic, or acquired) or secondary (infiltrative or automimmune). DCM phenotype can also occur secondary to ischaemic heart disease, valvular heart disease, hypertension and congenital heart disease (reviewed in Luk et al. 2009). DCM leads to progressive heart failure and a decline in LV contractile function, ventricular and supraventricular arrhythmias, conduction system abnormalities, thromboembolism, and sudden or heart failure-related death. DCM is the most common cause of heart failure after ischemic heart disease and arterial hypertension and the primary cause of heart failure in young age (Osterziel et al. 2005).

The clinical symptoms are various and evoked through heart failure and cardiac arrhythmias. In the most severe cases, affected individuals show signs and symptoms like diaphoresis, breathlessness at rest or with exertion, orthopnoea, exercise intolerance, early onset fatigue, abdominal pain, and pallor. Cachexia and peripheral oedema typically arise late in the course of the disease. The clinical investigation methods are not different from used for HCM.

Table 1: Disease-associated mutations in human titin

\begin{tabular}{|l|l|l|l|}
\hline $\begin{array}{l}\text { Phenoty } \\
\text { pe }\end{array}$ & Location on titin & Mutation & Remarks/Reference \\
\hline DCM & Z1 (exon 2) & Val54Met point mutation & $\begin{array}{l}\text { Decreased binding to telethonin (Itoh- } \\
\text { Satoh et al. 2002) }\end{array}$ \\
DCM & Z-repeat 7 (exon 14) & Ala743Val point mutation & $\begin{array}{l}\text { Decreased binding to } \alpha \text {-actinin (Itoh- } \\
\text { Satoh et al. 2002) }\end{array}$ \\
DCM & Z4 (exon 18) & Trp930Arg missense mutation & $\begin{array}{l}\text { Predicted to disrupt IgZ4-fold (Gerull } \\
\text { et al. 2002) }\end{array}$ \\
DCM & N2B-Us (exon 49) & Gln4053ter nonsense mutation & $\begin{array}{l}\text { Predicted to generate truncated titin } \\
\text { (Itoh-Satoh et al. 2002) }\end{array}$ \\
DCM & N2B-Us (exon 49) & Ser4465Asn missense mutation & $\begin{array}{l}\text { Mutation in FHL2-binding site (Itoh- } \\
\text { Satoh et al. 2002) }\end{array}$ \\
DCM & A67 (exon 326) & $\begin{array}{l}\text { 2-basepair insertion, frameshift } \\
\text { mutation }\end{array}$ & $\begin{array}{l}\text { Predicted to generate truncated A-band } \\
\text { titin (Gerull et al. 2002) }\end{array}$ \\
DCM & Mis-2 (exon 358) & Arg25618Gln point mutation & Mutation in FHL2-binding \\
\hline
\end{tabular}




\begin{tabular}{|c|c|c|c|}
\hline & & & (Matsumoto et al. 2005) \\
\hline $\mathrm{HCM}$ & Z-repeat 7 (exon 14) & Ala740Leu point mutation & $\begin{array}{l}\text { Increased binding to a-actinin (Satoh et } \\
\text { al. 1999) }\end{array}$ \\
\hline $\mathrm{HCM}$ & N2B-Us (exon 49) & Ser3799Tyr point mutation & $\begin{array}{l}\text { Increased binding to FHL2 (Itoh-Satoh } \\
\text { et al. 2002; Matsumoto et al. 2005) }\end{array}$ \\
\hline HMERF & $\begin{array}{l}\text { Titin-kinase (exon } \\
358)\end{array}$ & $\begin{array}{l}\text { Arg279Trp in exon } 358 \text {, point } \\
\text { mutation }\end{array}$ & $\begin{array}{l}\text { Mutation in Nbr1-binding site (Lange } \\
\text { et al. 2005) }\end{array}$ \\
\hline $\begin{array}{l}\text { TMD/L } \\
\text { GMD2J }\end{array}$ & M10 (exon 363) & complex 11-bp deletion-insertion & $\begin{array}{l}\text { Mutation near calpain-3-binding site; } \\
\text { found in Finnish population (Hackman } \\
\text { et al. 2002; Udd et al. 2005) }\end{array}$ \\
\hline $\begin{array}{l}\text { TMD/L } \\
\text { GMD2J }\end{array}$ & M10 (exon 363) & Iso293329Asp point mutation & $\begin{array}{l}\text { Found in Belgian family (van den } \\
\text { Berghet al. 2003) }\end{array}$ \\
\hline $\begin{array}{l}\text { TMD/L } \\
\text { GMD2J }\end{array}$ & M10 (exon 363) & Leu293357Pro point mutation & $\begin{array}{l}\text { Found in French family (Hackman et } \\
\text { al. 2002) }\end{array}$ \\
\hline DCM & $\begin{array}{l}\text { A131-A136 } \\
\text { (exon335) }\end{array}$ & $\begin{array}{l}\text { 62890delG1 1-basepair deletion; } \\
\text { frameshift mutation }\end{array}$ & $\begin{array}{l}\text { Predicted to generate truncated A-band } \\
\text { titin (Gerull et al. 2006) }\end{array}$ \\
\hline $\begin{array}{l}\text { DCM } \\
\text { /myopat. }\end{array}$ & M5 (exon358) & g.289385289392delACCAAGTG & $\begin{array}{l}\text { secondary calpain-3 depletion } \\
\text { Homozygous(congenital)mutation } \\
\text { (Carmignac et al. 2007) }\end{array}$ \\
\hline $\begin{array}{l}\text { DCM } \\
\text { /myopat. }\end{array}$ & $\begin{array}{l}\text { Mis-6 } \\
(\text { Mex3=exon360) }\end{array}$ & g.291297delA & $\begin{array}{l}\text { Homozygous (congenital) mutation; } \\
\text { secondary calpain- } 3 \text { depletion } \\
\text { (Carmignac et al. 2007) }\end{array}$ \\
\hline TMD & $\begin{array}{l}\text { Mis-7 } \\
(\text { Mex5=exon362) }\end{array}$ & g.292998delT frameshift mutation & $\begin{array}{l}\text { more severe phenotype than exon363 } \\
\text { (Mex6) mutations; found in Spanish } \\
\text { and French families (Hackman et al. } \\
\text { 2008) }\end{array}$ \\
\hline TMD & $\begin{array}{l}\text { M10 } \\
(\text { Mex6=exon363) }\end{array}$ & $\begin{array}{l}\text { g. } 293376 \text { delA frameshift } \\
\text { mutation }\end{array}$ & $\begin{array}{l}\text { Found in Spanish and French families } \\
\text { (Hackman et al. 2008) }\end{array}$ \\
\hline TMD & $\begin{array}{l}\text { M10 } \\
(\text { Mex6=exon363) }\end{array}$ & $\begin{array}{l}\text { g.293379CNT } \\
\text { nonsense mutation }\end{array} \quad$ (p.Q33396X) & $\begin{array}{l}\text { Found in Spanish and French families } \\
\text { (Hackman et al. 2008) }\end{array}$ \\
\hline
\end{tabular}

Primary DCM is not a very rare cardiac muscle disorder. The prevalence of the disease is about 35 in 100,000, excluding other causes of heart chamber dilation like hypertensive cardiomyopathy, cardiac valve disease, or ischemic heart disease. A case of primary (idiopathic) DCM is present if these exogenous factors are impossible to investigate or they are completely excluded. In 20 to $30 \%$ (Seidman and Seidman 2001) of all primary (idiopathic) DCM cases, a genetic defect is the cause of the disease (Hughes and McKenna 2005). In spite of the well defined clinical diagnostic criteria of DCM, there could still be some difficulties, especially in elderly people, since the only clinical manifestation in some 
cases could be sudden death, ventricular arrhythmia, or conduction defects (Muntoni et al. 1999). Another cause of diagnostic difficulties might be a small pedigree size.

Familial DCM could have autosomal-dominant, autosomal-recessive, X-linked or mitochondrial type of inheritance. The most common type is the autosomal-dominant (approx. $70 \%$ of the investigated cases). Each type has its particular clinical features according to the pathways and mechanisms that areinvolved. For example, autosomal-recessive DCM (18.6\%) manifests usually before age 10 , progresses very quickly and leads to a lethal outcome or a heart transplantation. There is an autosomal-dominant group of DCM with skeletal muscle involvement (7.7\% of familial DCM) (Mesroni et al. 1999), which is often characterized by a restrictive pattern of left ventricular haemodynamics and an elevation of the skeletal muscle isoform of creatine kinase. Autosomal-dominant DCM with AV defects (2.6\%) is characterized by the high risk of sudden death due to ventricular arrhythmias, SA, and AVblocks.

X-linked DCM contributes to approximately $10 \%$ of familial DCM and is mostly associated with dystrophin or taffazin mutations (Valianpour et al. 2002) and also very often combined with myopathy and elevated CK-MM levels.

The mitochondrial type of inheritance is generally considered to be uncommon, since many mutations described as causing a disease were also identified in the healthy population. Described mutations are also responsible for the development of DCM with severe muscle fatigue (Suomalainen et al. 1992).

There are at least 21 main candidate genes, which have to be considered during the investigation of familial DCM cases. The DCM causing mutation is most commonly found in structural sarcomeric proteins as well as in proteins of the sarcomeric cytoskeleton, in intermediate filaments, channel and channel-associated and also in mitochondrial proteins (Table 2).

Table 2: Mutations in candidate genes associated with hereditary DCM

\begin{tabular}{|l|l|l|l|}
\hline Protein & Gene & Mutation & Reference \\
\hline Alpha B-crystallin & CRYAB & R157H & Inagaki et al. 2006 \\
$\begin{array}{l}\text { ATP-sensitive potassium } \\
\text { channel }\end{array}$ & SUR2A/ABCC9 & FsL1524A1513T & Bienengraeber et al. 2004 \\
Cardiac $\alpha$-actin & ACTC & R312H E361G; Q9R & Olson et al. 1998; Mohapatra \\
\hline
\end{tabular}




\begin{tabular}{|c|c|c|c|}
\hline & & & et al. 2003 \\
\hline Cardiac sodium channel & $S C N 5 A$ & $\begin{array}{l}\text { D1275N T220I R814W } \\
\text { D1595H } 2550-2551 \text { insTG; } \\
\text { delQKP } 1507-1509\end{array}$ & $\begin{array}{l}\text { Olson et al. 2005; Shi et al. } \\
2008\end{array}$ \\
\hline Cypher/ZASP & $L D B 3$ & $\begin{array}{lll}\text { I352M } & \text { K136M } & \text { D117N } \\
\text { T213I } & & \end{array}$ & Vatta et al. 2003 \\
\hline Desmin & $D E S$ & I451M; $\quad$ A337PA360P & Li D et al. 1999; Goldfarb et \\
\hline & & $\begin{array}{lll}\text { N393I; } & \text { E180K } & \text { A213V } \\
\text { R213V } & & \end{array}$ & al.1998; Taylor et al. 2007 \\
\hline Dystrophin & $D M D$ & IVS5+1 K18N F3228L & Feng et al. 2002 \\
\hline Integrin linked kinase & $I L K$ & $\mathrm{~A} 262 \mathrm{~V}$ & Knöll et al. 2007 \\
\hline Lamin A/C & $L M N A$ & $\begin{array}{l}\text { R60G L85R N195K } \\
\text { E203G R571S; }\end{array}$ & Fatkin et al.1999; \\
\hline Laminin alpha 4 & LAMA4 & P943L R1073X & Knöll et al. 2007 \\
\hline Metavinculin & $V C L$ & R975W deltaL954 & $\begin{array}{l}\text { Olson et al. 2002, Vasile et al. } \\
2006\end{array}$ \\
\hline Muscle LIM protein & CRP3 & W4R; K69R & $\begin{array}{l}\text { Knöll et al. 2002; Mohapatra } \\
\text { et al. } 2003\end{array}$ \\
\hline Myosin-binding protein C & МYВРСЗ & N948T & Daehmlow et al. 2002 \\
\hline Phospholamban & $P L N$ & $\mathrm{R} 9 \mathrm{C}$ & Schmitt et al. 2003 \\
\hline Tafazzin & $T A Z$ & T43P; R94S; 535delC & $\begin{array}{l}\text { Bachou et al. 2009; Sakamoto } \\
\text { al al. 2002; Vesel et al. } 2003\end{array}$ \\
\hline Titin & $T T N$ & $\begin{array}{l}\text { 43628AT W930R; V154M } \\
\text { A743V Q4053terS4465N }\end{array}$ & $\begin{array}{l}\text { Gerull et al. } 2002 \text { Daehmlow } \\
\text { et al. 2002; Itoh-Satoh et al. } \\
2002\end{array}$ \\
\hline Titin-cap/telethonin & $T E L$ & E132Q & Hayashi et al. 2004 \\
\hline Troponin C & $T N N C l$ & G159D & Mogensen et al. 2004 \\
\hline Troponin I & TNNI3 & $\mathrm{A} 2 \mathrm{~V}$ & Murphy et al. 2004 \\
\hline
\end{tabular}




\begin{tabular}{|c|c|c|c|}
\hline Troponin $\mathrm{T}$ & TNNT2 & R141W; delK210; R131W & Li D et al. 2001; Kamisago et \\
\hline$\alpha$-Myosin heavy chain & МYH6 & $\begin{array}{l}\text { P830L A1004S E1457K; } \\
\text { S532P F764L }\end{array}$ & $\begin{array}{l}\text { Carniel et al. 2005; Schmitt et } \\
\text { al. } 2006\end{array}$ \\
\hline$\beta$-Myosin heavy chain & MYH7 & $\begin{array}{lrr}\text { G377S; } & \text { I201T } & \text { T412N } \\
\text { A550V } & \text { T1019N } & \text { R1193S } \\
\text { E1426K } & \text { R1634S; } & \text { S532P } \\
\text { F764L; R1053Q R1500W; } \\
\text { A223T S642L }\end{array}$ & $\begin{array}{l}\text { Rai et al. 2009; Villard et al. } \\
\text { 2005; Kamisago et al. 2000; } \\
\text { Kärkkäinen et al. 2004; } \\
\text { Daehmlow et al. } 2002\end{array}$ \\
\hline$\alpha$-Tropomyosin & TPM1 & E40K E54K & $\begin{array}{l}\text { Daehmlow et al. 2002, Rajan } \\
\text { et al. } 2007\end{array}$ \\
\hline$\delta$-Sarcoglycan & $S G C D$ & $\begin{array}{l}\text { S151A deltaK238 R97Q; } \\
\text { R71T }\end{array}$ & $\begin{array}{l}\text { Tsubata et al. 2000; } \\
\text { Kärkkäinen et al. } 2003\end{array}$ \\
\hline
\end{tabular}

Several transgenic mouse models carrying mutations in sarcomeric proteins have been created to understand the molecular mechanisms of DCM. For example, the most recent titin c.43628insAT knock-in mice mimic typical features of human DCM under stress conditions. The homozygous mutants were lethal due to defects in sarcomere formation, whereas heterozygous mutants could be used for future investigation of titin participation in cardiac mechanics and remodeling (Gramlich et al. 2009). For the finding of new pathogenetic key points and subsequently new therapy options, the current phase of collecting the data of affected genes and proteins in in vivo DCM models is very important.

\subsection{Newly identified C-terminal titin mutation in a small family}

The initial attempt to investigate possible pathogenetic importance of newly identified mutation is represented in following dissertation. The titin mutation was identified in a 60 years old patient suffering from severe DCM. Echocardiograpic picture showed biventricular and biatrial dilation with decreased left ventricular ejection fraction. Moreover, the patient was suffering on atrial fibrillation and non-sustain ventricular tachycardia. Since the diagnosis, a progressive course of disease was observed. There was no secondary cause of DCM identified. The only daughter of the index patient, who didn't exhibit any clinical or echocardiographic signs of cardiomyopathy, was examined for C-terminal titin mutations. The father and daughter were carrying the same titin mutation 20 amino acids upstream titin kinase domain of giant titin. The mutation introduces exchange of acidic aspartic amino acid 
to neutral valine in the interdomain region between titin kinase domain and FnIII domain in the C-terminal titin. 


\subsection{Aims of the study}

Titin is the third most abundant protein in the crosstriated muscle, which spans half of the sarcomere and forms the so-called third filament system. The giant molecule is anchored at the Z-dics and the M-band. Ithas elastic elements in its I-band and interacts with a variety of structural and signaling proteins, which makes it a perfect candidate to participate in sarcomeric mechanotransdution and regulation of the sarcomere length during relaxation. Titin was proposed to act as a "molecular ruler" responsible for the orientation and incorporation of other stuctural proteins during the sarcomere assembly. The role of this giant molecule is being intensively investigated. The C-terminal serine-threonine kinase domain within titin was proposed to be activated by mechanical stretch and to transfer mechanical stimuli into trophic pathways. There are very few in vitro substrates of titin kinase found. Zdisc titin interacting protein telethonin was reported to be in vitro phosphorylated by titin kinase during myofibrillogenesis. The protein expression data of M-line titin deficient mice in different steps of embryogenesis show that the telethonin expression starts after titin's incorporation into the M-band (Weinert et al. 2006). There are titin mutations responsible for the development of congenital heart and skeletal muscle diseases. We identified a mutation in the FnIII/titin kinase interdomain region as possibly causing familial DCM. To date, there are no titin kinase mutations known to lead to heart disease.

The main aim of this work was to identify new ligands of this region of titin in adult cardiac muscle using yeast two hybrid and biochemical approaches and to investigate possible implications of the newly identified mutation for the development of DCM. 


\section{Materials and methods}

\subsection{Materials}

\subsubsection{Chemicals and consumables}

\subsubsection{Chemical reagents}

2-Mercaptoethanol

$\mathrm{X}-\mathrm{Gal}$

DAPI

Acetic acid 100\%

Acetone

Adenosine monophosphate

Agarose

APS

Bromophenolblue

Carbenicillin

Chloramphenicol

Coomassie $®$ Brilliant Blue G-250

DMSO

DTT

Ethanol absolute

Ethidium bromide

EDTA

Formaldehyde solution $37 \%$

Glycerol 99.9\%

Glycine

Isopropanol

IPTG

Kanamycin

L-Glutamine

Low fat milk powder
Roth/Karlsruhe

Roche/Mannheim

Sigma/Deisenhofen

Merck/Darmstadt

Roth/Karlsruhe

Sigma/Deisenhofen

Biozym/Oldendorf

Sigma/Deisenhofen

Pierce/Bonn

AppliChem/Darmstadt

AppliChem/Darmstadt

BioRad/Munich

Sigma/Deisenhofen

AppliChem/Darmstadt

Merck/Darmstadt

Sigma/Deisenhofen

Merck/Darmstadt

Roth/ Karlsruhe

Sigma/Deisenhofen

Merck/Darmstadt

Sigma/Deisenhofen

AppliChem/Darmstadt

AppliChem/Darmstadt

Invitrogen/Karlsruhe

Roth/Karlsruhe 
Methanol

Mowiol

$\mathrm{Na}_{3} \mathrm{VO}_{4}$

$\mathrm{NaF}$

PBS

Penicillin-streptomycin solution

Phenol/chloroform

PMSF

Ponceau S (ready to use solution)

Rotiphorese Gel 30 (30\% acrylamide stock solution with

$0.8 \%$ bisacrylamide inproportion $37.5: 1$ )

SDS

Sodium hydroxide

TEMED

Tris-Base

Triton X-100

Tween 20

Ultra pure water
Roth/Karlsruhe

Calbiochem/Bad Soden

AppliChem/Darmstadt

AppliChem/Darmstadt

Invitrogen/Karlsruhe

Sigma/Deisenhofen

Roth/Karlsruhe

AppliChem/Darmstadt

Sigma/Deisenhofen

Roth/Karlsruhe

BioRad/Munich

Merck/Darmstadt

Promega/Mannheim

Sigma/Deisenhofen

Sigma/Deisenhofen

BioRad/Munich

Invitrogen/Karlsruhe

\subsubsection{Plastic, glassware and other consumables}

3MM Filterpapier Whatman

96 well plates

Cell culture dishes

Cell scrapers

Cover slips

Falcontubes 15 and $50 \mathrm{ml}$

Glas beads

Glass slides

GSTrap $^{\text {TM }}$ FF prepacked with $1 \mathrm{ml}$ glutathione-sepharose HiTrap ${ }^{\text {TM }}$ columns

Nitrocellulose transfer membrane, $0.45 \mu \mathrm{m}$
Schleicher \&

Schuell/Dassel

BioRad/Munich

Sarstedt/Nuembrecht

Sarstedt/Nuembrecht

Menzel/ Braunschweig

Sarstedt/Nuembrecht

Sigma/Deisenhofen

Menzel/Braunschweig

Amersham/Frieburg

Schleicher \&

Schuell/Dassel 
Petridishes for bacteria and yeast

Pipette tips

Safe-Lock tubes $(0.2,0.5,1.5$ and $2 \mathrm{ml})$

Screw lid polycarbonate centrifuge tubes $(16 \times 76 \mathrm{~mm}$ and $38 \times 102 \mathrm{~mm}$ )

Serological pipettes $(2,5,10,25 \mathrm{ml})$

Sorvall@ polycarbonate centrifuge bottles $(50 \mathrm{ml})$, Sorvall ${ }^{\circledR}$

Centrifuge bottles $(250 \mathrm{ml})$

Sterile filter pipette tips

UV-Cuvettes

X-ray films
Sarstedt/Nuembrecht

Brand/Wertheim

Eppendorf/Hamburg

Kontron/Mailand

Sarstedt/Nuembrecht

Kendro Laboratory

Products/Hanau

Biozym/Oldendorf

Eppendorf/Hamburg

Fuji/Duesseldorf

\subsubsection{Instruments}

Table 3: Instruments and equipment

\begin{tabular}{|c|c|c|}
\hline Instrument & Name & Source \\
\hline Autoclave & Tuttnauer 5075 EKV & Tuttnauer/Jerusalem, Israel \\
\hline Benches & $\begin{array}{l}\text { Biowizard (cell culture) } \\
\text { Technoflow Integra 2F 120-II GS (bacteria } \\
\text { and yeast culture) }\end{array}$ & $\begin{array}{l}\text { Kojair Tech Oy/Vilppula, } \\
\text { Finnland } \\
\text { Integra Biosciences/Zizers, } \\
\text { Switzerland }\end{array}$ \\
\hline Centrifuges & $\begin{array}{l}\text { Sorvall } \AA \text { high speed centrifuge } \\
\text { Rotors: Sorvall@ SS34, } g_{\max }=50228 \text { and } \\
\text { Sorvall } \AA \text { SLA1500, } g_{\max }=35793 \\
\text { Eppendorf Centrifuge } 5415 R\end{array}$ & Eppendorf/Hamburg \\
\hline Digital color camera & DVC-1310C & DVC/Austin, USA \\
\hline DNA electrophoresis system & Easy-Cast Electrophoresis systemB1 & Peqlab/Erlangen \\
\hline Electroporator & EasyjecT & $\begin{array}{l}\text { EquiBio/Needham Heights, } \\
\text { USA }\end{array}$ \\
\hline Fluorescence microscopes & $\begin{array}{l}\text { Olympus BX51 } \\
\text { Axiovert } 200\end{array}$ & $\begin{array}{l}\text { Olympus/Tokyo, Japan } \\
\text { Zeiss/Oberkochen }\end{array}$ \\
\hline Incubators & $\begin{array}{l}\text { Multilmage Light Cabinet with built-in } \\
\text { ultraviolet emitter and video camera } \\
\text { SI-600R - } 83 \text { Litre Refrigerating Shaking } \\
\text { Incubator }\end{array}$ & $\begin{array}{l}\text { Alpha Innotech/Cannock, } \\
\text { Staffordshire, UK } \\
\text { Medline scientific limited/ } \\
\text { Oxon, UK }\end{array}$ \\
\hline
\end{tabular}




\begin{tabular}{|l|l|l|}
\hline & Sanyo Cooled Incubator MIR-153 & Sanyo, Japan \\
Light microscope & Sanyo $\mathrm{CO}_{2}$ IncubatorMCO 20AIC & Sanyo, Japan \\
Magnetic mixer with warming & Motic AE 20/21 Inverted microscope & Motic Instruments/Wetzlar \\
Micropipettes & Ikamag RET & IKA-Werke GmbH/Staufen \\
Microwave oven & Pipetman & Gilson/Middleton, USA \\
pH-Meter & Microwave oven & Siemens/Germany \\
Photometer & Calimatic 761 & Knick/Berlin \\
Plate reader & Eppendorf BioPhotometer & Eppendorf/Hamburg \\
& Plate reader KC4 & BIO-TEK® Instruments, \\
Semi-dry Electroblotter & Semi-dry Electroblotter & inc./USA \\
SDS-PAGE electrophoresis & Biorad Mini PROTEAN 3 & Schleicher \& Schuell/Dassel \\
Thermocycler & Mastercycler Epgradient S & BioRad/Munich \\
Thermomixer & Thermomixer comfort & Eppendorf/Hamburg \\
US-Homogenizer & Sonopuls Ultrasonic Homogenizer UW 2070 & Eppendorf/Hamburg \\
Vortex & Vortex Genie 2 & Bandelin/Berlin \\
Water purification & & Bender and Hobein/Zurich, \\
Waterbath & Milli-Q Ultrapure Water Purification & Switzerland \\
X-ray film cassettes & Grand JB Series & Millipore/Schwalbach \\
X-ray film developing device & X-ray film cassettes 10×18 & Konica Minolta SRX-101A \\
& & Grand/Cambridgeshire, UK \\
& & Siemens/Munich \\
\hline
\end{tabular}

\subsubsection{Detection, purification and synthesis systems (kits)}

\section{Table 4: Kits}

\begin{tabular}{|l|l|}
\hline Name & Source \\
\hline BCA Protein Assay Kit & Pierce Perbio Science GmbH/Bonn \\
Lithium acetate yeast transformation kit & BD Bioscience/Heidelberg \\
Plasmid Midi Kit & Qiagen/Hilden \\
Plasmid Mini Kit & Qiagen/Hilden \\
QiaQuick® Gel Extraction Kit & Qiagen/Hilden \\
QuikChange Site-Directed Mutagenesis Kit & Stratagene/Amsterdam Zoidoost, Netherlands \\
SuperSignal@ West Pico Chemiluminescent & Pierce Perbio Science GmbH/Bonn \\
Substrate & \\
T4 DNA Ligation Kit & Invitrogen/Karlsruhe \\
\hline
\end{tabular}




\subsubsection{Proteins, enzymes, protease inhibitors and standards}

Pfu DNA polymerase, 10xPfu puffer with $\mathrm{MgSO}_{4}$, dNTP and $1 \mathrm{~kb}$ DNA ladder were purchased from Fermentas (St. Leon-Roth). We obtained restriction enzymes, buffers, and BSA from Promega (Mannheim). We used Glutathione S-transferase, trypsin, lysozyme and laminin from Sigma (Deisenhofen). The Glutathione Sepharose 4B and Protein A-sepharose FF were purchased from Amersham (Freiburg). For cutting GST from the protein of interest, the Precision protease ${ }^{\mathrm{TM}}$ and appropriate puffer from GE Healthcare (Freiburg) was used. The dephosphorylated MBP (Cell Signaling Technology, Boston/USA) was used as a positive control for in vitro phosphorylation assays.

The protein standards (Precision Plus Protein ${ }^{\mathrm{TM}}$ Standards, Dual Color) was obtained by BioRad (Munich) and the Complete Protease Inhibitors Coctail tablets from Roche (Mannheim).

\subsubsection{Media and solutions}

\subsubsection{Molecularbiological and cell culture media}

For bacteria we used Luria-Bertani broth and agar with antibiotic supplements (carbenicillin $100 \mu \mathrm{g} / \mathrm{ml}$, chloramphenicol $34 \mu \mathrm{g} / \mathrm{ml}$ or kanamycin $50 \mu \mathrm{g} / \mathrm{ml}$ (Roth, Karlsruhe) and SOCmedium (Invitrogen, Karlsruhe).

Media and supplements for yeast culture, namely: Minimal SD Base agar and liquid medium, YPD-Medium, -Leu, -Trp, -His/-Leu/-Trp, and -Ade/-His/-Leu/-Trp dropout supplements were purchased from BD Bioscience and prepared to use according to the recommendation of the supplier.

Mammalian cells were cultured in Dulbecco's Modified Eagle's Medium (DMEM) (Invitrogen). Dulbecco's Phosphate Buffer Solution without $\mathrm{Ca}^{2+}$ and $\mathrm{Mg}^{2+}$ (DPBS-cm) (Invitrogen) with supplements $0.25 \%$ trypsin with $0.03 \%$ EDTA (Sigma) was used for the cell passage. The fetal calf serum was purchased by Sigma.

- $\mathrm{C} 2 \mathrm{C} 12$ proliferation medium: 15\% FCS, 4 mM L-glutamine, $100 \mathrm{U} / \mathrm{ml}$ penicillin, $1 \mu \mathrm{g} / \mathrm{ml}$ streptomycin, $1 \%$ NEAA in DMEM

- $\mathrm{C} 2 \mathrm{C} 12$ differentiation medium: 0.2\% Ultroser G, $4 \mathrm{mM}$ L-glutamine, $100 \mathrm{U} / \mathrm{ml}$ penicillin, $1 \mu \mathrm{g} / \mathrm{ml}$ streptomycin, $1 \%$ NEAA in DMEM

- COS-7 culture medium: 10\% FCS, 4 mM L-glutamine, $100 \mathrm{U} / \mathrm{ml}$ penicillin, $1 \mu \mathrm{g} / \mathrm{ml}$ streptomycin in DMEM 


\subsubsection{Stock solutions, solutions and buffers}

We used deionized water supplied by a Millipore apparatus and autoclaved solutions ifnecessary $\left(121^{\circ} \mathrm{C} / 20 \mathrm{~min} / 1 \mathrm{bar}\right)$. Thermolabile components were filter-sterilized $(0.22 \mu \mathrm{m})$ and added after autoclaving. The $\mathrm{pH}$ was adjusted using $\mathrm{HCl}$ or $\mathrm{NaOH}$, if not stated differently.

\section{$10 \times$ PBS pH 7.4}

$1.37 \mathrm{M}$ sodium chloride

$0.027 \mathrm{M}$ potassium chloride

$0.043 \mathrm{M} \mathrm{Na}_{2} \mathrm{HPO}_{4}$

$0.014 \mathrm{M} \mathrm{NaH}_{2} \mathrm{PO}_{4}$

$\mathrm{pH} 7.4$

\section{6 x Loading dye for DNA}

$0.25 \%$ (w/v) bromphenol blue

$0.25 \%(\mathrm{w} / \mathrm{v})$ xylene cyanol

$30 \%$ glycerol

\section{Ampicillin stock solution}

$50 \mathrm{mg} / \mathrm{ml}$ sterile filtered

stored at $-20^{\circ} \mathrm{C}$

IPTG 1M stock solution

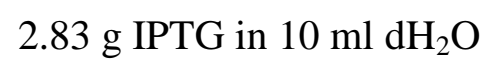

sterile filtered and stored at $-20^{\circ} \mathrm{C}$

\section{EDTA 100 mM}

For $100 \mathrm{ml}$ final concentration EDTA (disodium salt) $3.723 \mathrm{~g} 100 \mathrm{mM}$ $\mathrm{pH}$ was adjusted with $\mathrm{NaOH}$ to 8.0. The solution was sterile filtered and stored at $4{ }^{\circ} \mathrm{C}$.

\section{Chloramphenicol stock solution}

$34 \mathrm{mg} / \mathrm{ml}$ in ethanol

sterile filtered stored at $-20^{\circ}$

\section{Kanamycin stock solution}

$25 \mathrm{mg} / \mathrm{ml}$ in $\mathrm{ddH}_{2} \mathrm{O}$

sterile filtered and stored at $-20{ }^{\circ} \mathrm{C}$

Lysozyme (25 mg/ml) stock solution

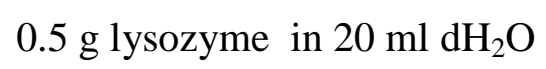

aliquoted and stored at $-20{ }^{\circ} \mathrm{C}$

\section{Solutions and buffers}

Acrylamide solution: $30 \%$ Acrylamide/Bis-Acrylamide (37.5:1)

Coomassie staining solution: $0.1 \%$ Coomassie Brilliant Blue G250, 50 \% (v/v) methanol $20 \%(\mathrm{v} / \mathrm{v})$ acetic acid

Destaining solution: $10 \%(\mathrm{v} / \mathrm{v})$ methanol, $7 \%(\mathrm{v} / \mathrm{v})$ acetic acid E. coli lysis buffer: $50 \mathrm{mM} \mathrm{NaH} \mathrm{PO}_{4}, 300 \mathrm{mM} \mathrm{NaCl}, 10 \mathrm{mM}$ imidazole, $1 \mathrm{mg} / \mathrm{ml}$ lysozyme, 
1 mM DTT, 1 mM PMSF, 1x Roche Complete ${ }^{\circledR}$ Protease Inhibitor, pH 8.0

Elution buffer: $50 \mathrm{mM} \mathrm{NaH} \mathrm{PO}_{4}, 300 \mathrm{mM} \mathrm{NaCl}, 250 \mathrm{mM}$ imidazole, 1x protease inhibitor coctail, $\mathrm{pH} 8.0$

GST-elution buffer: $5 \mathrm{mM}$ GSH, $50 \mathrm{mM}$ Tris- $\mathrm{HCl}, 1$ x protease inhibitor coctail, $\mathrm{pH} 8.0$

Kinase buffer: $20 \mathrm{mM}$ Tris/HCl pH7.5, $50 \mathrm{mM} \mathrm{NaCl}, 25 \mathrm{mM} \beta$-glycerophosphate, $100 \mu \mathrm{M}$ sodium orthovanadate, $1 \mathrm{mM}$ DTT, $1 \mathrm{mM} \mathrm{NaF}, 10 \mathrm{mM} \mathrm{MgCl}_{2}, 50 \mu \mathrm{M}$ cold ATP, $3 \mu \mathrm{Ci}$ ATP (1/10 of total sample volume) and $1 \mathrm{x}$ protease inhibitor coctail

Lysis buffer (kinase assay): $20 \mathrm{mM}$ Tris/HCl pH7.5, $150 \mathrm{mM} \mathrm{NaCl}, 25 \mathrm{mM} \beta$ -

glycerophosphate, $2 \mathrm{mM}$ EDTA, $2 \mathrm{mM}$ pyrophosphate, $1 \mathrm{mM}$ sodium orthovanadate, $1 \%$

Triton X-100, $1 \mathrm{mM}$ DTT, $1 \mathrm{mM} \mathrm{NaF}$ and 1x protease inhibitor cocktail

RIPA-buffer: $20 \mathrm{mM}$ Tris/HCl pH 7.5, $150 \mathrm{mM} \mathrm{NaCl}, 1 \%$ Triton X-100, 0.1\% SDS, $1 \%$ sodium deoxycholate, $1 \mathrm{mM}$ DTT

Running buffer: $25 \mathrm{mM}$ Tris, $250 \mathrm{mM}$ glycine, $0.1 \%$ SDS, pH 8.8

Sample buffer: $125 \mathrm{mM}$ Tris-HCl, $0.2 \%$ SDS, pH 6.8

SDS sample buffer 5x: 5 mM EDTA, $30 \%$ glycerol, $60 \mathrm{mM}$ Tris/HCl, $15 \%$ SDS, $0.1 \%$ bromophenol blue, $\mathrm{pH}$ 6.8, 7.5 \% beta-mercaptoethanol

Separating gel buffer: $375 \mathrm{mM}$ Tris/ $\mathrm{HCl}, 0.2 \%$ SDS, $\mathrm{pH} 8.8$

Stacking gel buffer: $125 \mathrm{mM}$ Tris/HCl, $0.2 \%$ SDS, pH 6.8

TAE puffer: $40 \mathrm{mM}$ Tris-base, 1mM EDTA-Na $\mathrm{m}_{2}$-salt, $20 \mathrm{mM}$ acetic acid, pH 8.0

TE buffer: Tris-HCl (pH 7.5) 10 mM, EDTA 1 mM

Transfer buffer: $20 \% \mathrm{v} / \mathrm{v}$ methanol in running buffer

Wash buffer: $50 \mathrm{mM} \mathrm{NaH}{ }_{2} \mathrm{PO}_{4}, 300 \mathrm{mM} \mathrm{NaCl}, 20 \mathrm{mM}$ imidazole, pH 8.0

X-Gal developing solution: $5 \mathrm{ml}$ Z-buffer, $15 \mu \mathrm{l}$ mercaptoethanol, $85 \mu \mathrm{l} \mathrm{X-Gal}(50 \mathrm{mg} / \mathrm{ml})$

Yeast lysis buffer: $0.2 \%$ (w/v) Triton X-100, 1\% SDS, $100 \mathrm{mM} \mathrm{NaCl}, 20 \mathrm{mM}$ Tris-HCl, $1 \mathrm{mM}$ EDTA, pH 8.0

Z-buffer: $60 \mathrm{mM} \mathrm{Na}_{2} \mathrm{HPO}_{4}, 40 \mathrm{mM} \mathrm{NaH} \mathrm{PO}_{4}, 10 \mathrm{mM} \mathrm{KCl}, 1 \mathrm{mM} \mathrm{MgSO}_{4}$, pH 7.0

\subsection{Bacterial, yeast strains and cell lines}

Table 5: Bacterial and yeast strains

\begin{tabular}{|l|l|l|}
\hline Strain & Reference/Company & Genotype \\
\hline E. coli XL-1 Blue & Bullock et al. 1987/Stratagene & $\begin{array}{l}\text { RecA1, endA1, gyr } \Delta 96, \text { thi-1, hsdR17, supE44, relA1, } \\
\text { lac[F' proAB lacl }{ }^{\mathrm{q}} \mathrm{Z} \Delta \mathrm{M} 15 \text { Tn10 (Tet')] }\end{array}$ \\
\hline
\end{tabular}




\begin{tabular}{|c|c|c|}
\hline $\begin{array}{l}\text { E.coli } \\
\text { BL21(DE3)Codon } \\
\text { Plus }\end{array}$ & Studier et al. 1990/Stratagene & $\begin{array}{l}\text { B F- }^{-} \text {ompT hsdS }\left(\mathrm{r}^{-}{ }_{\text {в }} \mathrm{m}^{-}{ }_{\text {в }}\right) \text { dem Tetr } \\
\text { gal „(DE3) endA Hte [argU proL Camr] }\end{array}$ \\
\hline $\begin{array}{l}\text { S. cerevisiae } \\
\text { AH109 }\end{array}$ & Harper et al. 1993/Clontech & 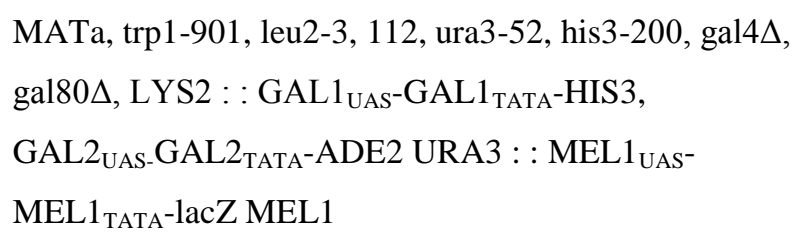 \\
\hline S. cerevisiae Y187 & $\begin{array}{l}\text { Boyer und Roulland-Dussoix } \\
\text { 1969/Clontech }\end{array}$ & $\begin{array}{l}\text { MAT } \alpha \text {, ura3-52, his3-200, ade2-101, trp1-901, leu2-3, } \\
\text { 112, gal4D, met-, gal80D, URA3 : : GAL1 }{ }_{\mathrm{UAS}^{-}} \\
\text {GAL1 }_{\text {TATA }}-\text { lacZ }\end{array}$ \\
\hline
\end{tabular}

\section{Cell lines}

The cells used were mouse C2C12 myoblasts (Yaffe and Saxel 1977) and COS-7 cells (African green monkey kidney fibroblast-like cells transformed with the SV40T antigen (Gluzman 1981)).

\subsubsection{Plasmid constructs}

Table 6: Plasmids

\begin{tabular}{|c|c|c|c|}
\hline Vector & Description & Resistance & Reference \\
\hline pGBKT7 & $\begin{array}{l}\text { promoter: ADH1, T7, host: } E \text {. } \\
\text { coli, yeast }\end{array}$ & Kanamycin & BD Bioscience \\
\hline pGADT7 & $\begin{array}{l}\text { promoter: ADH1, T7, host: } E \text {. } \\
\text { coli, yeast }\end{array}$ & Ampicillin & BD Bioscience \\
\hline pGEX-6P-1 & $\begin{array}{l}\text { production of GST fusion } \\
\text { proteins, tac promoter, } \operatorname{lacI}^{\mathrm{q}} \\
\text { repressor }\end{array}$ & Ampicillin & GE Healthcare \\
\hline $\begin{array}{l}\text { pET23a-T7 } \\
\text { (His6- and T7-Tag) }\end{array}$ & $\begin{array}{l}\text { Promoter: T7, host: E. coli } \\
\text { Prokaryotic Expression }\end{array}$ & Ampicillin & $\begin{array}{l}\text { pET23a (Novagen) modified } \\
\text { (Obermann et al. 1996) }\end{array}$ \\
\hline pCMV5-T7 & $\begin{array}{l}\text { Promoter: CMV } \\
\text { Mammalian Expression }\end{array}$ & Ampicillin & $\begin{array}{l}\text { pCMV5 (Invitrogen) modified } \\
\text { (Obermann et al. 1998) }\end{array}$ \\
\hline
\end{tabular}




\subsubsection{Oligonucleotides}

The oligonucleotides were synthesized by SIGMA-ALDRICH Chemie GmbH.

Sequences of primers are provided in $5^{\prime} \rightarrow 3^{\prime}$ orientation

(Underlined: restriction site; bold: first or last matching codon)

Table 7: Primers for cloning

\begin{tabular}{|c|c|c|c|}
\hline Primer name & bp & Primer sequence & Restriction site \\
\hline TKin & 887 & $\begin{array}{l}\text { GCGCGAATTCTCCGGGTAATAGCTGAAAATAAAT } \\
\text { GCGCGGATCCTTTCACTAACAACCGGTCAACAAA }\end{array}$ & $\begin{array}{l}\text { EcoRI } \\
\text { BamHI }\end{array}$ \\
\hline TKin & 986 & $\begin{array}{l}\text { GCGCGAATTCTCCGGGTAATAGCTGAAAATAAAT } \\
\text { GCGCGTCGACTAATGTTCTGATAAC }\end{array}$ & $\begin{array}{l}\text { EcoRI } \\
\text { SalI }\end{array}$ \\
\hline FLNC-D24 & 411 & 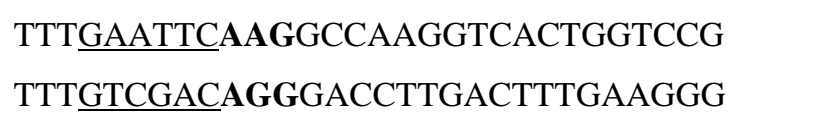 & $\begin{array}{l}\text { EcoRI } \\
\text { SalI }\end{array}$ \\
\hline MAP1B & 756 & $\begin{array}{l}\text { GCGCGAATTCGTGTCCATGGTGGACCCAGAG } \\
\text { GCGCGTCGACCAGTTCAATCTTGCATGCAGG }\end{array}$ & $\begin{array}{l}\text { EcoRI } \\
\text { SalI }\end{array}$ \\
\hline MAP_LC1_TBD & 396 & $\begin{array}{l}\text { GCGCGAATTCGTGTCCATGGTGGACCCAGAG } \\
\text { GCGCGTCGACAGCAGATGACTTGGT }\end{array}$ & $\begin{array}{l}\text { EcoRI } \\
\text { SalI }\end{array}$ \\
\hline MAP_LC1_ABD & 366 & $\begin{array}{l}\text { GCGCGAATTCTCATCTGCTGTGCCCCCA } \\
\text { GCGC } \underline{\text { GTCGACCAGTTCAATCTTGCATGCAGG }}\end{array}$ & $\begin{array}{l}\text { EcoRI } \\
\text { SalI }\end{array}$ \\
\hline MLC2 & 500 & $\begin{array}{l}\text { GCGCGAATTCATGGCACCTAAGAAAGCAAAG } \\
\text { GCGCGTCGACCTAGTCCTTCTCTTCTCCGTG }\end{array}$ & $\begin{array}{l}\text { EcoRI } \\
\text { SalI }\end{array}$ \\
\hline
\end{tabular}


Table 8: Mutagenesis primers

\begin{tabular}{|l|l|l|}
\hline Primer name & Primer sequence & Mutation site \\
\hline DtoVFw & CCAGAGCTATGAACTATGTTGAAGAGGTAGATGAAACC & A24.727T \\
DtoVRv & GGTTTCATCTACCTCTTCAACATAGTTCATAGCTCTGG & A24.727T \\
\hline
\end{tabular}

Table 9: Primers for sequencing

\begin{tabular}{|l|l|l|}
\hline Primer name & Vector & Primer sequence \\
\hline T7 Sequencing primer & $\begin{array}{l}\text { pGADT7 } \\
\text { pGBKT7 pET23aT7 } \\
\text { pcDNA3.1 } \\
\text { pGEX6P-1 } \\
\text { pGEX-fw }\end{array}$ & TAATACGACTCACTATAGGG \\
PGEXRv & CTEX6P-1 & CCTCTGACACATGCAGCTC \\
\hline
\end{tabular}

\subsubsection{Antibodies}

Table 10: Primary antibodies

\begin{tabular}{|l|l|l|l|}
\hline Antibody & Description & Supplier & Catalog No. \\
\hline HA-Tag & Mouse monoclonal $\mathrm{IgG}_{1}$ & Sigma & H9658 \\
c-MYC-Tag & Mouse monoclonal $\mathrm{IgG}_{1}$ & Sigma & M5546 \\
T7-Tag & Mouse monoclonal $\mathrm{IgG}_{2 \mathrm{~b}}$ & Novagen & 69522 \\
GST-Tag & Mouse monoclonal $\mathrm{IgG}_{1}$ & Novagen & 71097 \\
HIS-Tag & Mouse monoclonal $\mathrm{IgG}_{1}$ & Santa Cruz & sc-8036 \\
MAP1B (LC1) & Mouse monoclonal $\mathrm{IgG}_{1}$ against aa & BD & 612680 \\
& $2257-2357$ & Santa Cruz & sc-25729 \\
MAP1B (H-130) & Rabbit polyclonal $\mathrm{IgG}_{\text {against aa } 2221-2350}$ & A7811 \\
Sarcomeric $\alpha$-actinin EA-53 & Mouse monoclonal $\mathrm{IgG}_{2 \mathrm{~b}}$ & Biotrend & $4699-9555$ \\
GAPDH & Mouse monoclonal & & \\
\hline
\end{tabular}

Table 11: Secondary antibodies

\begin{tabular}{|l|l|l|l|}
\hline Antibody & Description & Supplier & $\begin{array}{l}\text { Catalog } \\
\text { No. }\end{array}$ \\
\hline ECL Anti-mouse IgG & $\begin{array}{l}\text { HRP conjugated to sheep anti-mouse polyclonal } \\
\text { IgG antibody linked whole antibody }\end{array}$ & Amersham & NA391V \\
ECL Anti-rabbit IgG & $\begin{array}{l}\text { HRP conjugated to sheep anti-mouse polyclonal } \\
\text { IgG antibody linked whole antibody } \\
\text { GAM IgG1-TXRD }\end{array}$ & Amersham & NA394V \\
\hline
\end{tabular}




\begin{tabular}{|l|l|l|l|}
\hline GAR IgG-Cy & Goat Anti-Mouse Ig G + Ig M conjugated with & Jackson & $115-165-$ \\
& $\mathrm{Cy}^{3}$ & ImmunoResearch & 068 \\
\hline
\end{tabular}

\subsubsection{Software and statistics}

For the alignment analysis of cDNA sequences and the primer design the BioEdit Sequence Alignment Editor (Ibis Biosciences, Carlsbad, CA, USA) was used. The BLAST (http://blast.ncbi.nlm.nih.gov/Blast.cgi) was applied to find sequence homologies. For the image processing Adobe Photoshop CS3 extended software was used. For the prediction of the motifs EML (http://elm.eu.org/) and for the phosphorylation sites the Phospho.ELM (http://phospho.elm.eu.org) internet tools were applied. Annealing temperatures of primers were calculated with the program "Primer Calculator" available on the Internet (http://www.williamstone.com). The statistical analysis was performed using Microsoft's Exel software. The statitical significance of two groups of measurements was proved using Student's T-Test. The P-Value $<0.05$ was considered as statistically significant.

\subsection{Methods}

\subsubsection{Molecularbiological methods}

\subsubsection{Polymerase chain reaction (PCR)}

Polymerase chain reaction is a method of in vitro enzymatic amplification of DNA by thermal cycling. PCR allows to make millions of copies of the desired DNA-fragment and to add restriction sides or to exchange a nucleotide using specific oligonucleotides (primers).

For the amplification of DNA with the purpose of plasmid generation Pfu DNA polymerase was used. Each PCR reaction mixture of genomic DNA contained the following reagents (Table 12): 
Table 12: Components of the PCR using Pfu DNA polymerase

\begin{tabular}{|l|l|l|}
\hline Reagnet & Final concentration & Amount \\
\hline Genomic DNA template & $100 \mathrm{ng}$ & $0.5-2 \mu \mathrm{l}$ \\
dNTP mix (10mM) & $1 \mu \mathrm{M}$ & $1 \mu \mathrm{l}$ \\
Downstream primer & $1 \mu \mathrm{M}$ & $0.5 \mu \mathrm{l}$ \\
Upstream primer & $1 \mu \mathrm{M}$ & $0.5 \mu \mathrm{l}$ \\
$10 x$ Pfu puffer with $\mathrm{MgSO}_{4}$ & $1 \mathrm{x}$ & $5 \mu \mathrm{l}$ \\
$P f u$ DNA Polymerase & $1.25 \mathrm{U} / 50 \mu \mathrm{l}$ & $0.5 \mu \mathrm{l}$ \\
$\mathrm{ddH}_{2} \mathrm{O}$ & & To $50 \mu \mathrm{l}$ \\
\hline
\end{tabular}

As a negative control $1 \mu \mathrm{l}$ of water was added to the reaction mixture instead of DNA.

The following scheme was used for the amplification. The annealing temperature was usually chosen $5^{\circ} \mathrm{C}$ lower than the average melting temperature of the primer pair. In case of problematic amplification, a gradient PCR with stepwise increase $\left(0.5-1{ }^{\circ} \mathrm{C}\right)$ in annealing temperature was applied. The extension time of 0.75 to $2 \mathrm{~min}$ for DNA-fragments of up to 1000 bp was sufficient.

\section{Table 13: PCR-amplification steps}

\begin{tabular}{|l|l|l|l|}
\hline Step & Temperature, ${ }^{\circ}$ C & Time, min. & $\begin{array}{l}\text { Number of } \\
\text { cycles }\end{array}$ \\
\hline $\begin{array}{l}\text { Initial denaturation } \\
\begin{array}{l}\text { Denaturation } \\
\text { Annealing } \\
\text { Extension }\end{array} \\
\text { Final extension }\end{array}$ & 95 & 3 & 1 \\
\hline & 95 & 0.5 & \\
\hline
\end{tabular}

The PCR reaction was carried out in an automated thermal cycler. To check the PCR efficiency, aliquots of $10 \mu \mathrm{l}$ were analysed by agarose gel electrophoresis.

\subsubsection{Electrophoretic DNA separation}

Agarose gel electrophoresis is used for the separation, purification and identification of plasmid DNA and DNA fragments. Because of the negative charge of its phosphate groups, the DNA moves towards the positive pole in an electric field. Under constant voltage, the migration speed of linear, double-stranded DNA in agarose gels is proportional to the logarithm of its molecular weight. The size of a DNA fragment can be determined by 
comparison with standard DNA marker fragments of identified size. A rough estimation of the DNA concentration can be made by comparing the band intensity of the sample and a reference marker DNA band upon staining with ethidium bromide. Depending on the size of the DNA molecules, the agarose concentration chosen was between 1 and $2 \%$ (w/v). DNAsamples were mixed with 6xDNA loading buffer and applied to the wells of the gel. In parallel, a marker was loaded. The TAE buffer was used for the agarose solution and as an electrophoretic buffer. The electrophoretic separation was done at 5 volts $/ \mathrm{cm}$. Separated fragments were visualized by UV-light.

\subsubsection{DNA sequencing}

DNA sequencing relies on the dideoxynucleotide-method developed by Sanger (1992). This technique utilizes 2', 3'-dideoxynucleotide triphosphates (ddNTPs), molecules that differ from deoxynucleotides by having a hydrogen atom attached to the $3^{\prime}$ carbon rather than an $\mathrm{OH}$ group. These molecules terminate the DNA chain elongation because they cannot form a phosphodiester bond with the next deoxynucleotide. A sequencing reaction contains a mixture of fluorescently labeled ddNTPs with the normal dNTPs. The logic behind this ratio is that after DNA polymerase is added, the elongation will take place and will terminate whenever a ddNTP is incorporated into the growing strand. If the ddNTP is only $1 \%$ of the total concentration of dNTP, a whole series of labeled strands will result. The DNA mixture can be separated by cappilary gel electrophoresis and is analysed base-specifically due to the four differently labelled ddNTPs on an Abi Prism Genetic Analyser. DNA sequencing was done in-house by the service group of our department and at AGOWA (Berlin, Adlershof).

\subsubsection{Ligation}

The respective DNA fragment and the plasmid were mixed in equimolar amounts with ligation buffer and $0.5 \mathrm{U}$ of T4 DNA-ligase (Stratagene) in a total volume of $10 \mu \mathrm{l}$. The ligation mixture was incubated either at room temperature for $3 \mathrm{~h}$ or at $16^{\circ} \mathrm{C}$ for $20 \mathrm{~h}$. The ligated product was transformed into E.coli (XL-1 Blue) as described in section 2.2.1.5.

\subsubsection{Transformation of E. coli by heat shock method}

Competent cells were thawed on ice for $15 \mathrm{~min}$ and gently mixed with $10 \mathrm{ng}$ of plasmid-DNA or $10 \mu \mathrm{l}$ of ligation product. After incubation on ice for $1 \mathrm{~h}$, bacteria were heat shocked at $42^{\circ} \mathrm{C}$ for $80 \mathrm{~s}$ and cooled on ice for another $2 \mathrm{~min}$. Then, $1 \mathrm{ml}$ of pre-warmed SOC-medium (Invitrogen) was supplied to the heat shocked cells and incubated at $37^{\circ} \mathrm{C}$, rotating for $1 \mathrm{~h}$. 
These cells were subsequently spun down at $5000 \mathrm{rpm}$ for $5 \mathrm{~min}$, resuspended in $100 \mu \mathrm{l}$ medium and plated on LB-plates with appropriate antibiotic supplement.

\subsubsection{Transformation of E. coli by electroporation}

Elctrocompetent cells $(50 \mu \mathrm{l})$ were thawed on ice for $15 \mathrm{~min} .1 \mathrm{ng}$ of the plasmid-DNA or 1.5 $\mu l$ of the ligation product was added directly to the competent cells and mixed well by flicking gently. The mixture was transferred in a pre-chilled $0.1 \mathrm{~cm}$ electrode Gene Pulser Cuvette (Bio-Rad). The electroporation was performed using Electroporator (EasyjecT) with the following setting: $1.8 \mathrm{kV}$ voltage, $200 \Omega$ resistance, $25 \mu \mathrm{F}$ capacitance. Afterwards, $1 \mathrm{ml}$ prewarmed SOC-medium was immediately supplied to the electroporated E. coli for recovery. The cells were incubated at $37^{\circ} \mathrm{C}$ with $250 \mathrm{rpm}$ rotating for 1 hour, followed by plating on appropriate LB-antibiotic plates.

\subsubsection{Plasmid-DNA isolation from E. coli}

DNA from E. coli was purified using QIAGEN Plasmid Mini, Midi, Maxi Kit (Qiagen), as described by the manufacturer.

\subsubsection{DNA extraction from yeast cells}

Selected yeast colonies were cultured in $5 \mathrm{ml}$ of selection medium overnight, pelleted by centrifugation at 13,000 rpm for about $10 \mathrm{~s}$ and vortexed vigoursly for $5 \mathrm{x} 1 \mathrm{~min}$ in extraction solution $(0.3 \mathrm{ml}$ of lysis buffer, $0.3 \mathrm{ml}$ of phenol/choloroform/isoamylalcohol at a 25:24:1 ratio containing $0.3 \mathrm{ml}$ volumes of glass beads of $0.2 \mathrm{~mm}$ in diameter) to rupture the cells. After centrifugation (13000 rpm, $5 \mathrm{~min}$ ) the upper, aqueous phase containing the DNA was transferred to fresh tubes, and the DNA was precipitated by addition of 0.2 volumes of $3 \mathrm{M}$ $\mathrm{NaCl}$ and 0.75 volumes of isopropanol. Precipitated DNA was pelleted by centrifugation (13,000 rpm, $10 \mathrm{~min}$ ), washed with $70 \%$ ethanol, air dried and resuspended in $20 \mu \mathrm{l}$ sterile $\mathrm{ddH}_{2} \mathrm{O}$. For the isolation of a certain plasmid, $1 \mathrm{ng}$ of the extracted DNA was electroporated into $E$. coli and selected on an ampicillin plate.

\subsubsection{Site-directed mutagenesis}

The QuickChange Site-Directed Mutagenesis system (Stratagene) was employed for PCRmediated, site-directed mutagenesis. A wild-type Titin Kinase pGBKT7 construct was employed as a template with complementary oligonucleotides listed above (Table 8). The PCR cycles were performed in a $50 \mu \mathrm{l}$ reaction containing $50 \mathrm{ng}$ of circularized template, 125 
ng of each oligonucleotide, $500 \mu \mathrm{M}$ dNTPs, and 2.5 U Pfu DNA polymerase (Fermentas). PCR reaction conditions were $95{ }^{\circ} \mathrm{C}$ for $30 \mathrm{~s}, 55{ }^{\circ} \mathrm{C}$ for $1 \mathrm{~min}$ and $68{ }^{\circ} \mathrm{C}$ for $15 \mathrm{~min}(2$ minutes/kb of plasmid) for 18 successive rounds of PCR amplification. The entire $50 \mu 1$ reaction was digested with $\mathrm{DpnI}(10 \mathrm{U})$ to remove methylated, non-mutated template plasmid, and $1 \mu \mathrm{l}$ of DpnI-digested amplified DNA was used for transformation in competent XL-1 Blue E. coli. Resulting bacterial colonies were screened by DNA sequencing.

\subsubsection{Yeast two hybrid: A system for detection of protein interactions}

\subsubsection{Principle of GAL4 based yeast two hybrid system}

The assay is conducted in yeast (S. cerevisiae) and uses transcription of yeast reporter genes to measure the protein interaction. One of the two proteins is expressed as a fusion to a DNAbinding domain from a transcription factor, and the other is expressed as a fusion to a transcription activation domain. If the fusion proteins interact, they activate the transcription of specially designed reporter genes that carry binding sites for the DNA binding partner.

The GAL4 Matchmaker yeast two-hybrid system 3 (Clontech) was used to identify titin kinase interacting proteins. The GAL4-titinkinase fusion protein binds to GAL4-binding sites upstream of a reporter gene, which is driven by a minimal promoter. The reporter will be transcribed if a library protein fused to the GAL4 activation domain (AD) interacts with GAL4-titinkinase (C). The reporter will not be transcribed in the sole presence of GAL4-titin kinase or library-AD fusion proteins $(\mathrm{A}, \mathrm{B})$ : 
A

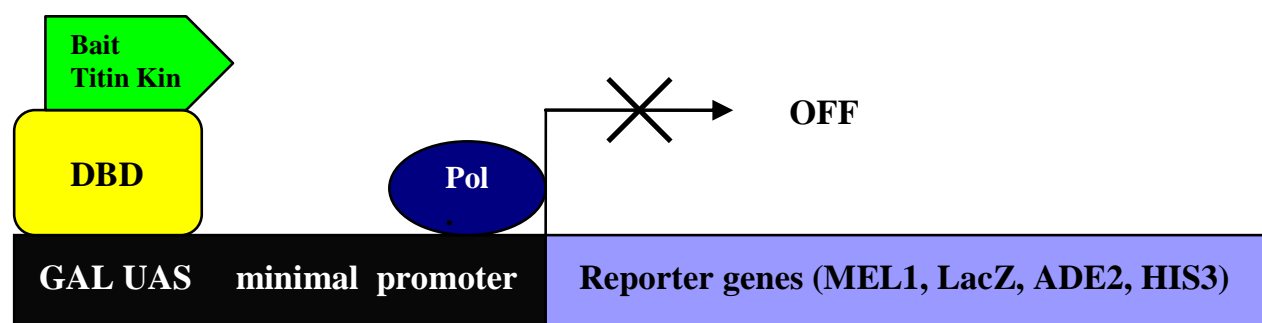

B

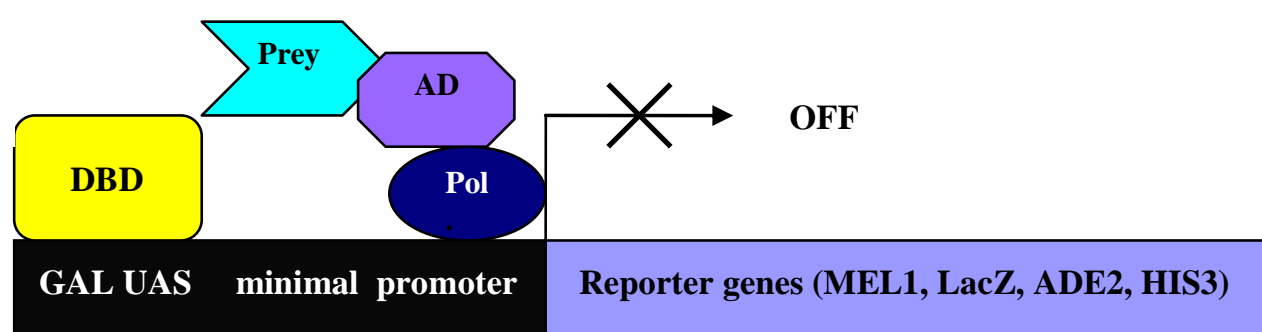

C

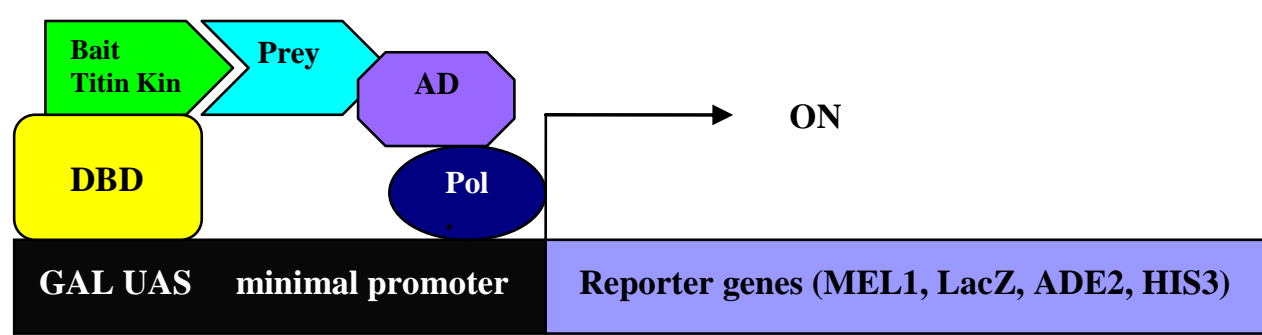

Figure 4: Principle of GAL4 based yeast two hybrid system (explanations in text)

The Titin Kinase Yeast two hybrid library screen procedure included following steps:

1. Construction Gal4 DNA-BD/target plasmid (bait)

2. Transformation of AH109 with bait plasmid and test for autonomous reporter gene activation (HIS3 and LacZ) and cell toxicity

3. Mating the pretransformed bait and library cultures

4. Streaking the transformants that can grow on TDO onto QDO selection plates

5. Performing $\beta$-gal colony-lift filter assay

6. Isolation of plasmid DNA from positive yeast clones

7. Identification and isolation of AD/library plasmids from E. coli transformants

8. Selection positive clones by restriction digest and check their library DNA sequence

\subsubsection{Construction of the "target" or "bait"}

A BamHI/SalI cDNA fragment of titin, which encodes the catalytic core of titin kinase and the interdomain region $\mathrm{N}$-terminal from kinase domain, was cloned in frame with the GAL4 DNA-binding domain in vector pGBKT7. Yeast strain Y109, which carrys Gal4-dependant 
lacZ and HIS3 genes, was cultured to $\mathrm{OD}_{600}=0.5$, pelleted at $1,000 \mathrm{rpm}$ for $5 \mathrm{~min}$ at room temperature, washed in 10 volumes of $\mathrm{dH} 2 \mathrm{O}$, and pelleted again. Yeast cells were made competent by resuspending in $1.5 \mathrm{ml}$ of sterile TE/LiAc, and $0.1 \mathrm{ml}$ competent cells were mixed with $0.1 \mu \mathrm{g}$ of TKin-pGBKT7 or Kin2-pGBKT7 and $0.1 \mathrm{mg}$ of herring testes DNA in $600 \mu \mathrm{PEG} / \mathrm{LiAc}$ solution. The cells were mixed by vortexing and incubated at $30^{\circ} \mathrm{C}$ for 30 min. After addition of $70 \mu \mathrm{l}$ DMSO cells were subsequently transformed by heat shock at $42^{\circ} \mathrm{C}$ for $15 \mathrm{~min}$. Yeast transformants were cooled on ice for $2 \mathrm{~min}$, pulse-centrifuged, resuspended in $0.5 \mathrm{ml}$ sterile TE-buffer and plated on SD-selection agar plates lacking tryptophan. The plates were incubated with $30^{\circ} \mathrm{C}$ for 3 to 5 days. The transformation efficiency was calculated for every plate utilizing following formula:

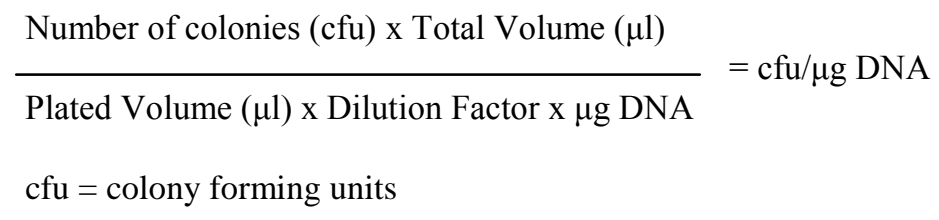

The cloning and the expression of recombinant protein in yeast were verified by sequencing and western blot analysis, respectively.

\subsubsection{Yeast mating}

A major advantage of this approach is the possibility of using frozen human heart cDNA library harbored in the pGADT7 vector (Clontech) pre-transformed into Y187 yeast strain to be expressed as a transactivation domain fusion protein. The mating of two haploid yeast strains of the opposite mating types, AH 109 MATa and Y187 MAT $\alpha$, each harboring one of the respective plasmids, results in the formation of doubly transformed diploid zygotes.

After an autoactivation test of HIS3 and LacZ reporter genes, one large colony of AH109 pretransformed with titin kinase was inoculated into $50 \mathrm{ml}$ of SD/-Trp and incubated overnight at $30{ }^{\circ} \mathrm{C}$, shaking with $250 \mathrm{rpm}$. Grown cells $\left(\mathrm{OD}_{600} \geq 0.8\right)$ were centrifuged at $1000 \mathrm{rpm}$ for $5 \mathrm{~min}$ and resuspended in $5 \mathrm{ml}$ of residual medium. Thawed at room temperature, a water bath $1 \mathrm{ml}$ library aliquot was combined with the entire AH109 culture, which enabled us to reach a MATa: MATa ratio of 2.5:1 for optimal mating efficiency. Mating was performed in 21 flask in a total volume of $50 \mathrm{ml}$ YPDA/Kanamycin overnight by $30{ }^{\circ} \mathrm{C}$, swirling gently $(35 \mathrm{rpm})$. The mating mixture was spun down by $1,000 \mathrm{rpm}$ for $10 \mathrm{~min}$, resuspended in $10 \mathrm{ml}$ of YPDA and plated on $50150 \mathrm{~mm}$ TDO plates. As a mating efficiency controls dilution, series of a 1:10000, 1:1000, 1:100 and 1:10 were plated on SD/-Leu, SD/-Trp and DDO $100 \mathrm{~mm}$ plates. The plates were incubated at $30{ }^{\circ} \mathrm{C}$ until yeast colonies appeared. 
Calculation of viablity $\mathrm{cfu} / \mathrm{ml}$ on each type of SD medium:

$\frac{\mathrm{cfu} \times 1000 \mathrm{ul}}{\text { Plated Volume }(\mu \mathrm{l}) \times \text { Dilution Factor }}=\mathrm{cfu} / \mathrm{ml}$

Calculation of mating efficiency:

$$
\frac{\text { No. } \mathrm{cfu} / \mathrm{ml} \text { of diploids }}{\text { No. } \mathrm{cfu} / \mathrm{ml} \text { of limiting partner }} \times 100=\% \text { Diploid }
$$

Limiting partner $=$ strain with the lower viability

\subsubsection{Forced two hybrid}

Forced two hybrid experiments were performed in order to confirm the yeast two hybrid library screen result. At first the sequences of the fished out proteins: ANP, Filamin C, MAP1B-LC1, MLC2 and HSP27, were cloned into the pGBKT7 bait vector. The desired PCR product for cloning was amplified from adult human heart cDNA library generated in our laboratory.

The pre-transformation of the AH109 with FilC24-pGBKT7, MAP1B-LC1pGBKT7, MLC2pGBKT7 or empty pGBKT7 was performed as described. The yeast was finally plated into the tryptophan dropout medium. After autoactivation check, a single colony of the pretransformed yeast was cultured in $50 \mathrm{ml}$ of tryptophan dropout medium at $30^{\circ} \mathrm{C}$ overnight. The co-transformation of the pre-transformed yeast cells with Tkin-pGADT7 plasmid was performed using the same protocol. The cells were plated on DDO agar and selected on TDO and QDO agar plates. The Colony-Lift Filter $\beta$-galactosidase assay was performed to analyse the interaction strength.

\subsubsection{5 $\beta$-galactosidase assays}

The colorimetric reporter lac Z encoding $\beta$-galactosidase, which cleaves substrates such as $\mathrm{X}$ Gal or ONPG to produce pigment, is used in yeast two hybrid screens for the detection and the selection of protein-protein interactions.

B-galactosidase is responsible for lactose hydrolysis into glucose and galactose. It occurs in bacteria, fungi and yeasts. The lacZ gene encodes an open reading frame of 1024 amino acids, and it is one of the first large genes to be completely sequenced. $\beta$-galactosidase is the most commonly used reporter gene for yeast and other systems because its activity can be semiquantitatively assayed on plates or quantitatively determined in cells grown in liquid cultures. 


\subsection{Liquid phase B-galactosidase assay with ONPG as a substrate}

The o-nitrophenyl- $\beta$-D-galactopyranoside (ONPG) is the most widely used substrate in assays for B-galactosidase in bacteria and yeasts (Bignon et al.1993; Schneider et al. 1996). This substrate is suitable for the measurement of enzymatic activity. As ONPG is unable to enter the intact cells, they have to be permeabilized prior to determination of enzyme activity.

Overnight cultures of selected yeast colonies were resuspended in fresh SD double dropout medium to an $\mathrm{OD}_{600}$ of approximately $0.2 \AA$ and grown at $30^{\circ} \mathrm{C}$ on a rotation wheel to an $\mathrm{OD}_{600}$ of 0.5 to 0.8 . The cell pellets were resuspended in $5 \mathrm{ml}$ of Z-buffer containing $50 \mathrm{mM}$ $\beta$-mercaptoethanol. Then, $20 \mu \mathrm{l} 0.1 \%$ SDS and $40 \mu \mathrm{l}$ of chloroform were added and the cells were vortexed at the highest setting for $30 \mathrm{~s}$. Before starting the reaction, temperature of the samples had been equilibrated in a water bath at $30^{\circ} \mathrm{C}$ for $15 \mathrm{~min}$. Samples were incubated with $160 \mu \mathrm{l}(4 \mathrm{mg} / \mathrm{ml})$ pre-warmed ONPG solution in a water bath $\left(30^{\circ} \mathrm{C}\right)$ until yellow coloration became visible. The reaction was quenched by adding $400 \mu \mathrm{l}$ of $1 \mathrm{M}$ sodium carbonate. Cell debris was pelleted $(13,000 \mathrm{rpm}, 15 \mathrm{~min})$, and $\mathrm{OD}_{420}$ of triplicates was determined on 96 well plates. A likewise treated sample without yeast cells was used as a blank. The $\beta$-galactosidase activity was calculated using the following formula (Miller JH 1972):

$\beta$-galactosidase activity $=[1000 * \AA 420] /\left[\mathrm{V}(\mathrm{ml}) * \mathrm{~T}(\mathrm{~min}) * \AA_{600}\right]$, where

$\AA 420$ is the absorbance units at $420 \mathrm{~nm}$, $\AA 600$ is the absorbance units at $600 \mathrm{~nm}$,

$\mathrm{T}(\mathrm{min})$ is the reaction time in minutes, and $\mathrm{V}(\mathrm{ml})$ is the reaction volume in $\mathrm{ml}$.

\subsection{Colony-lift filter $\beta$-galactosidase assay}

Yeast colonies were assayed qualitatively for blue/white selection according to the method described by Schneider et al. (1996). Fresh yeast colonies (i.e. grown at $30^{\circ} \mathrm{C}$ for $2-4$ days) were transferred onto a nitrocellulose membrane. This membrane was subjected to three freeze-thaw cycles (completely submerged into the pool with liquid nitrogen for $10 \mathrm{sec}$, removed from the liquid nitrogen and left to thaw completely at room temperature). Then the membrane was carefully placed, colony side up, onto the pre-soaked (with $5 \mathrm{ml}$ of Zbuffer/X-gal solution) Whatman filter in a $100 \mathrm{~mm}$ plate to allow the X-Gal solution to get into contact with yeast colonies. The plate was incubated at $37^{\circ} \mathrm{C}$, and the appearance of blue colour was checked periodically. Replicas of the corresponding blue colonies were picked from the original plates in order to isolate the prey plasmid from the yeast cells or for quantitative ONPG assay. 


\subsubsection{Biochemical methods}

\subsubsection{Expression of GST fusion proteins}

TKin, MAP1B-LC1, FLNC-D24 and MLC2 cDNAs were inserted into pGEX6P-1 vectors (GE Healthcare) between EcoRI and SalI sites in frame with GST coding sequence. BL21 CodonPlus competent bacterial cells transformed with GST-fusion expression constructs were cultured in $5 \mathrm{ml}$ of LB medium with $100 \mu \mathrm{g} / \mathrm{ml}$ of carbenicillin and $34 \mu \mathrm{g} / \mathrm{ml}$ chloramphenicol at $37^{\circ} \mathrm{C}$ and $250 \mathrm{rpm}$ agitation overnight. Overnight cultures were diluted 1:200 with fresh LB medium and cultured until $\mathrm{OD}=0.5$ (approximately $3 \mathrm{~h}$ ). Protein expression was induced via the addition of IPTG at a final concentration of $0.2 \mathrm{mM}$, and cells were cultured for an additional $6 \mathrm{~h}$ at $37^{\circ} \mathrm{C}\left(12 \mathrm{~h}\right.$ at $28^{\circ} \mathrm{C}$ with an addition of $10 \mathrm{ml} 0.2 \mathrm{M}$ glucose for titin kinase) at a rate of 250 rpm. The cells were collected by centrifugation at $6000 \mathrm{rpm}$ for $10 \mathrm{~min}$ and used for protein purification immediately or stored at $-80^{\circ} \mathrm{C}$.

\subsubsection{Expression of recombinant 6xHis- and T7-tagged proteins}

The cDNA, which encodes the titin kinase catalytic domain (Kin2), was cloned into the pETW2 (modified pET23a) expression vector. The pETW2-Kin2 construct was transformed into the host strain BL21 ( $\lambda$ DE3 lysogen), in which the T7 RNA polymerase is under control of the IPTG-inducible lacUV5 promoter. Therefore, the target gene is under control of the T7 promotor. Kin2 was constructed with His-tag located in the N-terminal and T7-tag located in the C-terminal. The expression of the 6xHis-tagged Kin2 was performed as described in section 2.2.3.1.

\subsubsection{Purification of recombinant GST-and His-tagged proteins}

Frozen cell pellets were thawn on ice, resuspended in Lysis buffer and sonicated to reduce viscosity. Cell debris was removed by centrifugation $(20,000 \mathrm{x} \mathrm{g}, 30 \mathrm{~min})$, and the supernatant was collected. $500-1000 \mu \mathrm{l}$ of pre-equilibrated $\mathrm{Ni}^{2+}$-beads or $500 \mu \mathrm{l} \mathrm{GSH}$ Agarose were added to His-tagged or GST-tagged fusion protein respectively. The beads were incubated with the protein solution for approximately $1 \mathrm{~h}$. The fusion protein-bound beads were washed thoroughly in wash buffer, and the fusion proteins were eluted by the addition of the respective elution buffers. 


\subsubsection{Protein isolation from mammalian cells}

The medium from $30 \mathrm{~mm}$ cell culture dishes was aspirated, and cells were washed once with ice-cold PBS. After adding $100 \mu$ of RIPA lysis buffer supplied with a complete Mini protease inhibitor cocktail (Roche) the cells were scraped off from the plates, transferred into microcentrifuge tubes and incubated for $15 \mathrm{~min}$ on ice. The lysed cells were centrifuged for $15 \mathrm{~min}$ at $14,000 \mathrm{x} \mathrm{g}$ at $4{ }^{\circ} \mathrm{C}$ and the supernatant containing protein extract was collected into fresh tube. The protein extracts were used immediately for pull-down assays or were flash frozen and stored at $-80^{\circ} \mathrm{C}$.

\subsubsection{Determination of protein concentration}

The protein concentration was determined using the BCA Protein Assay (PIERCE) according to the recommendations of the supplier.

\subsubsection{SDS-polyacrylamide gel electrophoresis}

SDS-polyacrylamide gel electrophoresis was performed using the discontinuous buffer system (Laemmli 1970). Discontinuous polyacrylamide gels (10-12\% resolving gel, $4.5 \%$ stacking gel) were prepared using glass-plates $(10 \mathrm{~cm} \times 7.5 \mathrm{~cm})$ and spacers of $0.75 \mathrm{~cm}$ thickness. A 10 -well comb was generally used for the formation of the wells in the stacking gel. The protein samples were resuspended in SDS sample buffer. The samples were denatured by heating at $95^{\circ} \mathrm{C}$ for $5 \mathrm{~min}$ and loaded into the wells in the stacking gel. A molecular weight marker, which was run simultaneously on the same gel in an adjacent well, was used as a standard to establish the apparent molecular mass of proteins resolved on SDSpolyacrylamide gels. After loading the samples onto the gel, electrophoresis was performed in running buffer at a constant voltage of $70 \mathrm{~V}$, until the bromophenol blue dye front had reached the resolving gel with following increasing to 100-120 V. After the electrophoresis, the resolved proteins in the gel were either observed by Coomassie blue staining or transferred onto a nitrocellulose membrane.

\subsubsection{Protein transfer (Western blotting)}

Proteins were transferred onto a nitrocellulose membrane via the semi-dry blotting procedure. The two sheets of filter paper and nitrocellulose membrane were pre-soaked in transfer puffer and subsequently placed on the anode of the blotting apparatus as follows: filter paper, SDSgel, nitrocellulose membrane, filter paper, and covered with the cathode. The transfer of the proteins was performed for 1 hour at $1 \mathrm{~mA} / \mathrm{cm}^{2}$. The nitrocellulose membrane was stained 
with Ponceau S ready solution for $5 \mathrm{~min}$ on a shaker for the visualization of the proteins and the labeling of the protein marker.

\subsubsection{Western blot overlay assays}

This technique is similar to Western blot techniques developed for antibody detection of proteins immobilized on membranes by gel blotting or spotting. In a Western Blot overlay, the antibody is replaced by a recombinant protein, and the interaction of this protein with a protein on the membrane is assayed by a subsequent overlay with an antibody that detects the recombinant protein probe. Through this antibody, bands or spots of proteins, which the probe protein has bound, can be visualized on the membrane, thereby identifying an interaction with an immobilized protein.

The recombinant proteins MAP1B-LC1, FLNC-D24, and MLC2 were expressed in BL-21 CP E. coli strain as GST fusion proteins. The samples containing $2 \mathrm{mg} / \mathrm{ml}$ purified protein were boiled for 5 minutes in SDS sample buffer. The protein was separated by SDS-PAGE on 10\% acrylamide gels, $4 \mu \mathrm{g}$ of the total protein were loaded on each lane. The proteins were transferred onto the nitrocellulose membranes via the Bio-Rad transblot semi-dry transfer system. The blot membrane was stained with Ponceau red, to identify and mark overexpressed fusion proteins, and blocked with blocking buffer overnight at $4^{\circ} \mathrm{C}$. The membrane was washed briefly with PBST and overlaid with $100 \mu \mathrm{g}$ of purified recombinant His- and T7tagged Titin Kinase (Kin2) diluted in $5 \mathrm{ml}$ of blocking buffer (4\% (w/v) low fat milk powder in PBST) for 1-2 $\mathrm{h}$ at room temperature. The overlaid protein, which was bound to the blotted proteins, was immunodetected with monoclonal His- and T7-tag antibodies.

\subsubsection{GST-pulldown assay}

COS7 cells were transiently transfected with T7 epitope-tagged MAP1B-pCMVT7 and FLNC-D24-pCMVT7 constructs utilizing $3 \mu \mathrm{g}$ of plasmid DNA by applying the lipofection method (FuGENE HD). Cell extacts were prepared $48 \mathrm{~h}$ after transfection as described. GSTtagged titin kinase was expressed in E. coli BL-21 CP strain and purified as described (the elution step was omitted). For the pull-down assay $90 \mu \mathrm{l}$ of total COS7 lysate were mixed with $50 \mu \mathrm{l}$ of GST beads bound to titin kinase in $500 \mu \mathrm{l}$ of RIPA buffer and incubated for $3 \mathrm{~h}$ on rotator by $4{ }^{\circ} \mathrm{C}$. Next, the beads were pelleted with $2000 \mathrm{rpm}$ at $4{ }^{\circ} \mathrm{C}$ and washed 5 times with ice-cold RIPA buffer. SDS samples were prepared by addition of 2xLaemmli buffer to the beads and boiling at $95{ }^{\circ} \mathrm{C}$ for $5 \mathrm{~min}$. For detection of pulled titin kinase bindig partners with T7-immunotag $80 \%(\mathrm{v} / \mathrm{v})$ of the sample was loaded onto $10 \%$ SDS gel and western 
blotted. The rest was used to detect GST-fused Titin Kinase or GST with anti-GST tag antibody.

\subsubsection{In vitro kinase assay}

At first, COS7 cells were transiently transfected with plasmid containing the titin kinase cDNA, which has an N-terminally located T7-tag. The COS7 cells were lysed with the kinase lysis buffer, as described below. For immunoprecipitation of the kinase, $10 \mu \mathrm{g}$ of T7-tag monoclonal antibody (Novagen) were added to the $500 \mu \mathrm{l}$ aliquot of total cell lysate and incubated overnight with $40 \mu 1$ of protein A-sepharose. The protein A-sepharose bound T7tag recombinant protein was centrifuged at $12,000 \mathrm{x}$ g for $5 \mathrm{~min}$. The beads were washed 3 times with ice cold kinase buffer without ATP and protease inhibitors. Precipitated kinase was divided into four equal portions for the kinase assay.

The substrates for the kinase assay were expressed in E.coli and affinity purified using GST fusion tag, and excised or purchased dephosphorylated MBP. The kinase reaction mixture was prepared to a total volume of $30 \mu 1$ to enable the complete loading of the mixture onto the $1 \mathrm{~mm}$ thick SDS gel. After adding radioactivity, $3 \mu \mathrm{Ci}\left[\gamma_{-}{ }^{32} \mathrm{P}\right] \mathrm{dATP} /$ reaction and $3-5 \mu \mathrm{g}$ of protein substrate, the mixture was incubated for $30 \mathrm{~min}$ at $30{ }^{\circ} \mathrm{C}$ and later quenched with $4 \mathrm{x}$ loading buffer. The entire reaction mixture was separeted on a $10 \%$ SDS gel by PAGE. The gel was dried, and autoradiography was performed with a Fujifilm FLA-9000 phopho-imager.

\subsubsection{Cell biology methods}

\subsubsection{Tissue culture and transfection assays}

COS-7 and C2C12 cells were maintained at $37^{\circ} \mathrm{C}$ in Dulbecco's modified Eagle's medium (DMEM) supplemented with $10 \%$ and $20 \%$ heat-inactivated fetal bovine serum, respectively (Life Technologies, Inc.), $2 \mathrm{mM}$ glutamine, $100 \mathrm{U} / \mathrm{ml}$ penicillin, and $100 \mathrm{U} / \mathrm{ml}$ streptomycin in a humidified environment with $5 \% \mathrm{CO}_{2}$.

Transient transfections were performed with the corresponding eukaryotic expression plasmid using the lipofection method (FuGENE HD), following the instructions of the manufacturer.

The $\mathrm{C} 2 \mathrm{C} 12$ cell line was selected for co-localization experiments due to their well characterized abilities to differentiate into skeletal muscle cells that form contractile myotubes and produce characteristic muscle proteins.

$\mathrm{C} 2 \mathrm{C} 12$ cells grown on glass cover slips of $1.2 \mathrm{~cm}$ diameter in $35 \mathrm{~mm}$ cell culture dishes were transient transfected at 50-60\% confluence using FuGENE HD transfection reagent (Roche 
Diagnostics): $6 \mu$ of FuGENE transfection reagent suspended in $94 \mu 1$ fresh DMEM without serum were mixed with $1 \mu \mathrm{g}$ of plasmid DNA and incubated for $15 \mathrm{~min}$ to allow complex formation; the mixture was immediately transferred to the proliferating $\mathrm{C} 2 \mathrm{C} 12$ cells. Transfected $\mathrm{C} 2 \mathrm{C} 12$ cells were induced to differentiate after attaining 70-80\% confuence by changing from the high nutrition proliferation medium containing $20 \%$ serum to a differentiation medium containing 0.4\% Ultroser G (Benders et al. 1991). Cover slips were either fixed with $3.7 \%$ formaldehyde in PBS and immunostained or used for cell extract preparation and Western blot analysis.

\subsubsection{Immunochemical staining procedures}

C2C12 myotubes grown on coverslips were fixed either with methanol/acetone $1: 1 \mathrm{v} / \mathrm{v}$ at $-20^{\circ} \mathrm{C}$ for $5 \mathrm{~min}$ or with $3.7 \%$ paraformaldehyde $(0.37 \mathrm{~g}$ paraformaldehyde, $1 \mathrm{ml} \mathrm{10x} \mathrm{PBS}, 10$

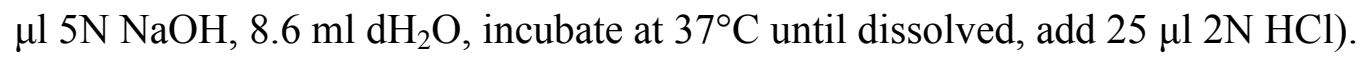

PFA-fixed cells were permeabilized for 10 min with $0.5 \%$ Triton X-100 in PBS. After the permeabilization, cover slips were washed three times in PBS and incubated with $4 \%(\mathrm{w} / \mathrm{v})$ BSA for 1 hour to minimize non-specific antibody binding. The cells were subsequently incubated with a primary antibody or combination of primary antibodies ( $\alpha$-actinin a653 1:75; MAP1B (LC1) 1:100; tubulin 1:100 in PBST) for $1 \mathrm{~h}$ at room temperature in the staining chamber (large plate with damp Whatmann paper overlaid with parafilm). Labelled with primary antibody cells were washed three times with PBS and then incubated with the appropriate secondary antibodies coupled to Cyanine dye 3 (Cy3) or Texas Red sulfonyl chloride (TXRD) for 1 hour at room temperature. To visualize nuclei by MAP1B-LC1 stainings 4', 6-diamidine-2'-phenylidole dihydrochloride (DAPI) (1:5000 in PBS) was exposed to the cells for $5 \mathrm{~min}$. Finally, the cells were washed three times with PBS and mounted in MOWIOL. An Olympus BX51 fluorescence microscope with DVC-1310C digital color camera and Image-ProPlus 4.1 software were used for imaging. 


\section{Results}

\subsection{Identification of titin kinase interacting partners in yeast two hybrid library screen}

Protein interaction plays a major role in almost all functions of the cell. The characterization of protein interaction networks elucidates the function of the protein of interest. We decided to screen the C-terminal region of titin, including titin kinase for novel binding partners. I conducted a yeast two hybrid library screen using adult human heart cDNA library as a pray, which was pretransformed in pGADT7 vector. The bait was designed and inserted in pGBKT7 vector as described bellow.

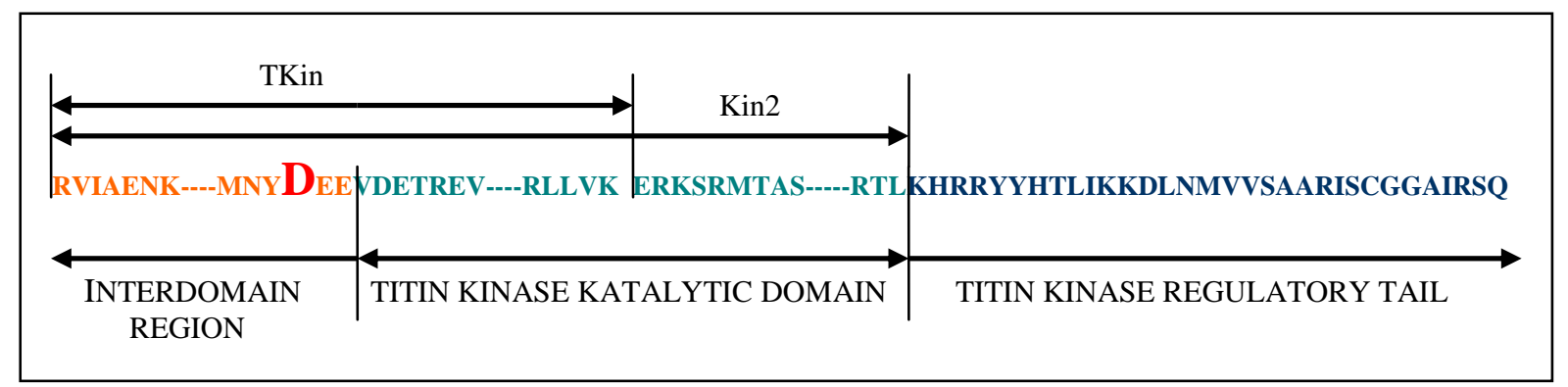

\section{Figure 5: Titin kinase constructs used for protein-protein interactions studies}

TKin and Kin2 clones both include a C-terminal part of the interdomain region between titin kinase and the Fn170 domain with the Asp24.727Val titin kinase mutation identified in our laboratory. Kin2 includes the titin kinase catalytic domain without its C-terminal regulatory tail. Additionally, TKin lacks on the part of the catalytic domain from its $\mathrm{C}$-terminus.

Truncated at its carboxy-terminus titin kinase constructs including the kinase catalytic domain and the N-terminal interdomain region were inserted into the EcoRI/BamHI restriction sites of the pGBKT7 vector in-frame with the DNA binding domain. This approach was adopted to create titin kinase bait, which includes the interdomain region with the Asp24.727Val mutation and covers the catalytic domain of the molecule without the C-terminal inhibitory tail, so that the kinase domain possibly remains in a semi-open state to facilitate protein binding and function. Secondly, the TKin clone lacking a few amino acids at the C-Terminus of the kinase catalytic domain, i.e. the regulatory tail of titin kinase, did not report for the $\beta$-galactosidase activity when assayed in absence of co-transformants in the yeast two-hybrid system. The presence of insert 
coding for titin kinase was verified by restriction digestion and bidirectional sequencing using specific primers located in the vector backbone.

A yeast strain (AH190) that is auxotrophic for the tryptophan, leucine, and histidine was successively transformed with Gal4 DNA-binding domain - titin kinase fusion construct (TKinpGBKT7) carrying TRP1 gene, which makes it capable of growth on tryptophan deficient medium. The expression of the protein in the host strain was verified by western blotting throgh probing the N-terminally located $m y c$-epitope, as shown in Figure 6. Furthermore, a filter lift assay was performed to verify the expression of $\beta$-galactosidase, i.e. self-activation test. The pretransformants did not exhibit the expression of $\beta$-galactosidase in the AH109 yeast strain. A single clone with robust expression of the fusion protein was chosen as a bait candidate to carry out further studies.

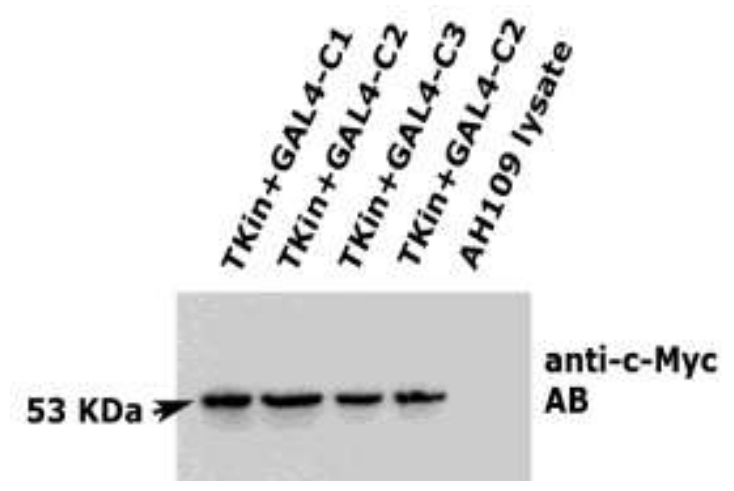

\section{Figure 6: TKin expression in AH109 yeast strain}

TKin was detected $(53 \mathrm{KDa})$ in a whole yeast protein lysate prepared from cultures of an individual yeast colony (TKin-C1, 2, 3, and 4) in WB using N-terminal c-myc antibody. Untransformed AH109 yeast lysate served as a negative control.

A yeast mating experiment was performed as described (2.2.2.3). The transformants, capable of growth on TDO agar plates, were subsequently transferred on QDO agar plates with higher stringent selection media. Surviving yeast colonies were screened for in situ $\beta$-galactosidase activity using the colony-lift filter assay. To ensure that protein-protein interactions in resulting diploid cells were specific, analogous mating experiments were performed with Y187 cells transformed with plasmids carrying only the Gal4-DNA-binding domain fused with p53 and the Gal4-AD "activation domain" fused to partial lamin C gene, which served as a negative control.

The yeast two hybrid screen mating efficiency (number of colonies currying both plasmids) came to $3.6 \times 10^{5} \mathrm{cfu}$ per $\mathrm{ml}$ of plated yeast suspension (2.2.2.3): 


$$
\frac{36 \mathrm{cfu} \times 1000 \mu \mathrm{l}}{100 \mu 1 \times 0.001}=3.6 \times 10^{5} \mathrm{cfu} / \mathrm{ml}
$$

The total amount of plated yeast suspension of $10 \mathrm{ml}$ allows the assumption that ca. $3.6 \times 10^{6}$ cardiac proteins participated in the screen, of which only 30 candidates showed an activation of all four reporter genes in the GAL4 Matchmaker yeast two-hybrid system 3 and were further analyzed (Table 14).

Prey plasmids from the positive colonies were obtained using the phenol chloroform isoamylalcohol extraction procedure (2.2.1.8) after selection on leucine drop out medium. The extracted plasmids were transformed into $E$. coli to get a better concentration and purity of the DNA. Plasmid-DNA was extracted using the spin column method (Qiagen), and sequenced using the standard automated DNA sequencing methods. The 37 derived sequences were analysed using nucleotide BLAST (NCBI database). Some of the sequences repeatedly appeared in the screen. Finally, sequencing results revealed only ten potential interacting partners. A search for homologues proteins in all the reading frames was performed. A subsequent sequence analysis made sure that all clones except decorin and mitochondrial DNA sequences were in frame with the GAL4 trans-activation domain and were translated into a protein listed in the table 14.

\section{Table 14: Overview of the titin kinase potential binding partners}

$\beta$-Galactosidase activity was determined by filter lift assay for the TKin co-transformed with the indicated plasmids. +++, ++, and + represent colonies that turned strongly blue, moderately blue, and weakly blue, respectively. The homologies represent the BLAST search that gave the smallest eValue.

\begin{tabular}{|l|l|l|l|l|l|}
\hline Nr & $\begin{array}{l}\text { Number } \\
\text { of clones }\end{array}$ & $\begin{array}{l}\boldsymbol{\beta} \text {-gal } \\
\text { test }\end{array}$ & Gene & Homologies & $\begin{array}{l}\text { NCBI-Accession } \\
\text { Number }\end{array}$ \\
\hline 1 & 1 & + & PCBD2 & HNF1-alpha dimerization cofactor & NT_034772 \\
2 & 10 & + & $T R N F$ & mitochondrially encoded tRNA & NC_001807 \\
3 & 8 & +++ & $M A P 1 B$ & microtubule-associated protein 1B & NT_006713 \\
4 & 2 & ++ & FLNC & $\begin{array}{l}\text { filamin C (actin binding protein 280) } \\
\text { myosin, light polypeptide 2, regulatory, }\end{array}$ & NT_007933 \\
5 & 1 & ++ & NYL2 & $\begin{array}{l}\text { NT_009775 } \\
\text { heat shock 27kDa protein family, } \\
\text { member (cardiovascular) }\end{array}$ & NM_014424 \\
6 & 6 & +++ & HSPB7 & Decorin & NT_019546 \\
7 & 1 & ++ & $D C N$ & &
\end{tabular}




\begin{tabular}{|l|l|l|l|l|l|}
\hline 8 & 1 & nPPA & natriuretic peptide precursor A & NT_021937 \\
9 & 1 & + & COL3A1 & Collagen type 3, alpha 1 preproprotein & NT_005403 \\
10 & 1 & + & - & $\begin{array}{l}\text { Homo sapiens chromosome 15 } \\
\text { genomic contig }\end{array}$ & NT_010194.16 \\
\hline
\end{tabular}

By analyzing the obtained potential interacting partner proteins, I could not ascertain any sequence homologies among the obtained prey protein sequences. The two extracellular matrix proteins, collagen and decorin, were not considered as they are localized outside the cell. I regarded collagen and decorin as false positive clones. Heat shock protein 27 has an autoactivation potential when transformed into the AH109 yeast strain alone and hence was not considered in the further course of this study. Four clones revealed homology with atrial natriuretic peptide (ANP). ANP is produced by myoendothelial cells of the atrial myocardium in response to stretch, and is secreted out of the cell after posttranslational modifications. Although involvement of titin kinase based pathway on regulation of ANP secretion could be assumed, the direct interaction of ANP protein precursor and titin kinase due to their different intracellular localization is unlikely.

Three potential interacting proteins from this library screen were chosen for further investigation: filamin C (FLN C), microtubule associated protein 1B (MAP1B-LC1) and myosin regulatory light chain (MLC2). The nucleotide sequences of these three potential interacting partners presented in Appendix 1.

\subsection{Sequence and structure of three potential interacting partners}

\subsubsection{Microtubule-associated protein 1B}

The nucleotide and amino acid sequence of clone 3 corresponds to the human microtubuleassociated protein 1B light chain 1 (MAP1B-LC1). The gene is located in chromosome 5q13 in humans. MAP1B is synthesized as a polyprotein precursor, which is post-translationally cleaved into a $300 \mathrm{kDa}$ heavy chain (HC) and a $32 \mathrm{kDa}$ light chain (LC1). Both HC1 and LC1 are noncovalently linked to form a HC-LC1 complex. Further, both HC1 and LC1 of MAP1B contain an actin binding sequence $(\mathrm{AB})$ and a microtubule binding sequence (MB) (Figure 7).

A nearly complete sequence of MAP1B-LC1 was obtained in the yeast two hybrid library screen. The identified clone represents a $27 \mathrm{kDa}$ C-terminal part of MAP1B-LC1. While analyzing the sequence of MAP1B-LC1 clone a single nucleotide polymorphism introducing E2279G point 
mutation was detected in the adult human heart cDNA library provided by Clontech. Interestingly, the point mutation introduces a new BamH1 endonuclease restriction site within the MAP1B-LC1 coding sequence. Additionally, I could identify the same point mutation for the second time in the PCR product derived from human non-failing heart cDNA prepared in our laboratory. The mutation has not been notified in the NCBI SNP-database and was out of my research focus.

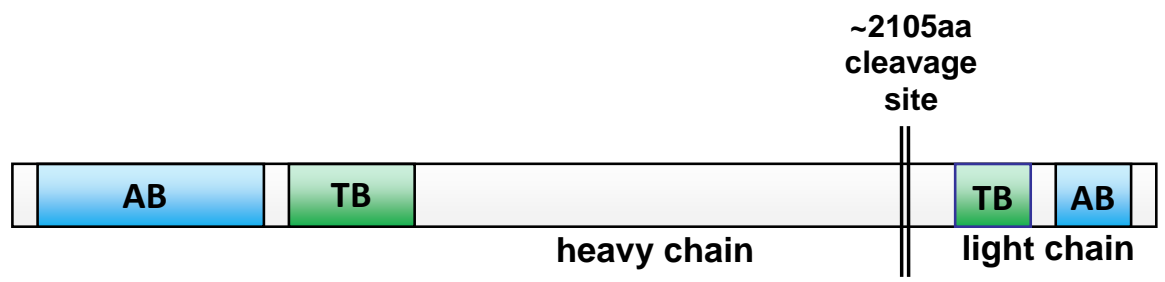

\begin{tabular}{|c|c|c|}
\hline MAP1B-LC1-Y2H & 1 & 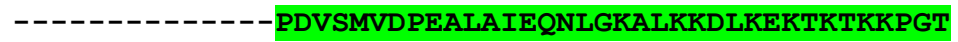 \\
\hline NP 005900 & 2201 & PPAPVQDRSPSPRHPDVSMVDPEALAIEQNLGKALKKDLKEKTKTKKPGT \\
\hline MAP1B-LC1 - Y2H & 37 & KTKSSSPVKKSDGKSKPLAASPKPAGLKGSSDKVSRVA PKKKESVEKAA \\
\hline NP 005900 & 2251 & KTKSSSPVKKSDGKSKPLAASPKPAGLKESSDKVSRVA SKKKESVEKAA \\
\hline MAP1B-LC1-Y2H & 87 & KPTTTPEVKAARGEEKDKETKNAANASASKSAK ATAGPGTTKTTKSSAV \\
\hline NP 005900 & 2301 & KPTTTPEVKAARGEEKDKETKNAANASASKSAK ATAGPGTTKTTKSSAV \\
\hline MAP1B-LC1-Y2H & 137 & PPGLPVYLDLCYIPNHSNSKNVDVEFFKRVRSSYYVVSGNDPAAEEPSRA \\
\hline NP 005900 & 2351 & PPGLPVYLDLCYIPNHSNSKNVDVEFFKRVRSSYYVVSGNDPAAEEPSRA \\
\hline MAP1B-IC1-Y2H & 187 & VLDALLEGKAQWGSNMQVTLIPTHDSEVMREWYQETHEKQQDLNIMVLAS \\
\hline NP 005900 & 2401 & VLDALLEGKAQWGSNMQVTLIPTHDSEVMREWYQETHEKQQDLNIMVLAS \\
\hline MAP1B-LC1-Y2H & 237 & SSTVVMQDESFPACKIEL \\
\hline NP 005900 & 2451 & SSTVVMQDESFPACKIEL \\
\hline
\end{tabular}

\section{Figure 7: Schematic presentation and protein sequence alignment of MAP1B-LC1}

The protein is expressed as a precursor and cleaved at amino acid 2105 by unknown protease into $300 \mathrm{kD}$ heavy chain and 32kD light chain. Both heavy and light chains have Tubulin (TB) and F-actin (AB) binding sequenses. The MAP1B-LC1 sequence obtained in the Y2H-screen compared with human MAP1B isoform from NCBIdatabase (NP_005900). It has two most favourable potential serine-threonine kinase phosphorylation sites (orange). The tubulin and F-actin binding sequences of LC1 are marked green and blue, respectively. The newly identified E2279G point mutation (red) is located at the N-terninus of the LC1. 


\subsubsection{Filamin C}

Two Filamin C clones were found in yeast two hybrid screens performed with titin kinase as bait. By analysing the amino acid sequences of the Filamin C clone isolated in yeast-two-hybrid library screening, and by aligning it with the human filamin $\mathrm{C}$ homologous sequence from the database (NCBI GenBank accession number NT_007933), I could specify the clone obtained in screen as a C-terminal part of Filamin C, which includes the complete self-association domain 24, the second hinge region and a few amino acids that belong to domain 23. Bioinformatical analysis of the obtained prey clone revealed that the second hinge region contained several potential serinethreonine phosphorylation sites (Figure 8).

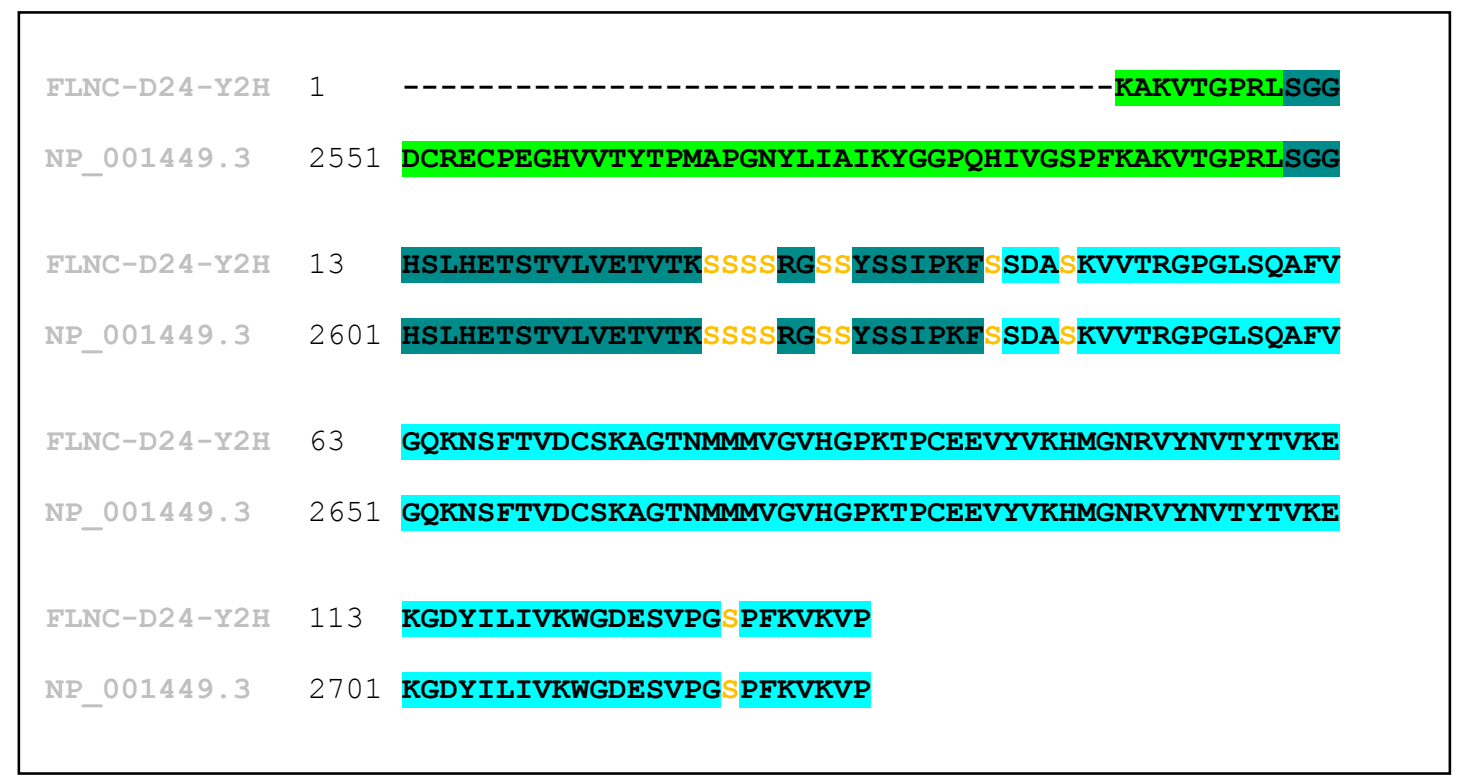

Figure 8: Protein sequence alignment of $\mathbf{C}$-terminal portion of Filamin $\mathbf{C}$

The protein sequence of $\mathrm{Y} 2 \mathrm{H}$-clone of Filamin C is identic with human Filamin C isoform from NCBI-database (NP_001449.3) and includes domain 24 (light blue), the hinge region between the domains 23 and 24 (dark blue), and a small C-terminal part of domain 23 (green). The potential serine-threonine kinase phosphorylation sites are indicated in orange.

\subsubsection{Myosin regulatory light chain}

A complete open reading frame representing MYL2 was identified in the high throughput library screen. It is a small polypeptide with theoretical molecular weight of $19 \mathrm{kDa}$. Myosin regulatory light chain (RLC) is a well known substrate of titin kinase homolog - myosin light chain kinase. The predicted serine-threonine kinase phosphorylation sites S15 und S19 in cardiac muscle 
isoform of RLC probably correlate with MLCK phosphorylation sites in smooth/skeletal muscle RLC (Sanbe et al. 1999).

\begin{tabular}{|lll|}
\hline MLC2-Y2H & 1 & MAPKKAKKRAGGANSNVF MFEQTQIQEFKEAFTIMDQNRDGFIDKNDLR \\
NP_000423.2 & 1 & MAPKKAKKRAGGANSNVF MMFEQTQIQEFKEAFTIMDQNRDGFIDKNDLR \\
MLC2-Y2H & 51 & DTFAALGRVNVKNEEIDEMIKEAPGPINFTVFLTMFGEKLKGADPEETIL \\
NP_000423.2 & 51 & DTFAALGRVNVKNEEIDEMIKEAPGPINFTVFLTMFGEKLKGADPEETIL \\
MLC2-Y2H & 101 NAFKVFDPEGKGVLKADYVREMLTTQAERFSKEEVDQMFAAFPPDVTGNL \\
NP_000423.2 & 101 NAFKVFDPEGKGVLKADYVREMLTTQAERFSKEEVDQMFAAFPPDVTGNL \\
MLC2-Y2H & 151 DYKNLVHIITHGEEKD \\
NP_000423.2 & 151 DYKNLVHIITHGEEKD \\
\end{tabular}

Figure 9: Protein sequence alignment of MLC2 clone

A complete protein sequence MLC2 Y2H-clone is identic with human cardiac isoform of MLC2 from NCBIdatabase (NP_000423.2). Potential serine-threonine kinase phosphorylation sites indicated in orange.

\subsection{Forced two hybrid confirm yeast two hybrid library screen interaction results}

To confirm as well as to validate the $\mathrm{Y} 2 \mathrm{H}$ library screen result, forced two hybrid experiments were performed. The clones obtained from the screen were used as the template for PCR amplification with compatible endonulcease restriction sites. The PCR products encoding the MAP1B-LC1, FLNC-D24, and MLC2 were re-cloned in both vectors, pGBKT7 (GAL4-DNABD) and pGADT7 (GAL4-AD), respectively. After sequence verification the generated plasmids were transformed into the AH109 yeast reporter strain. Additionally, TKin sequence was cloned into pGADT7 and co-transformed with each of the potential interacting partners. First, single transformants were assayed for self activation, and were found to be negative. Empty plasmids were used as negative controls and were also tested for $\beta$-galactosidase expression. After four days of growth on double dropout plates with less stringency, four to six colonies were transferred onto the triple and quadruple dropout agar plates. Clearly, yeast colonies containing both the bait and the prey vector with MAP1B-LC1, FLNC-D24 and titin kinase grew vigorously on the selection agar plates (Figure 10). Interestingly, I observed a weak growth of colonies cotransformed with MLC2 and empty vectors in all the agar selection plates. Therefore, we reasoned 
that the MLC2 interaction must be unspecific in our initial $\mathrm{Y} 2 \mathrm{H}$ library screen. Moreover, the same individual colonies picked from the double dropout plates were tested for $\beta$-galactosidase expression after cracking the yeast cell by the freeze-thaw procedure as described in 2.2.2.5.2. The results derived from the forced yeast two hybrid studies summarized in Table 15.

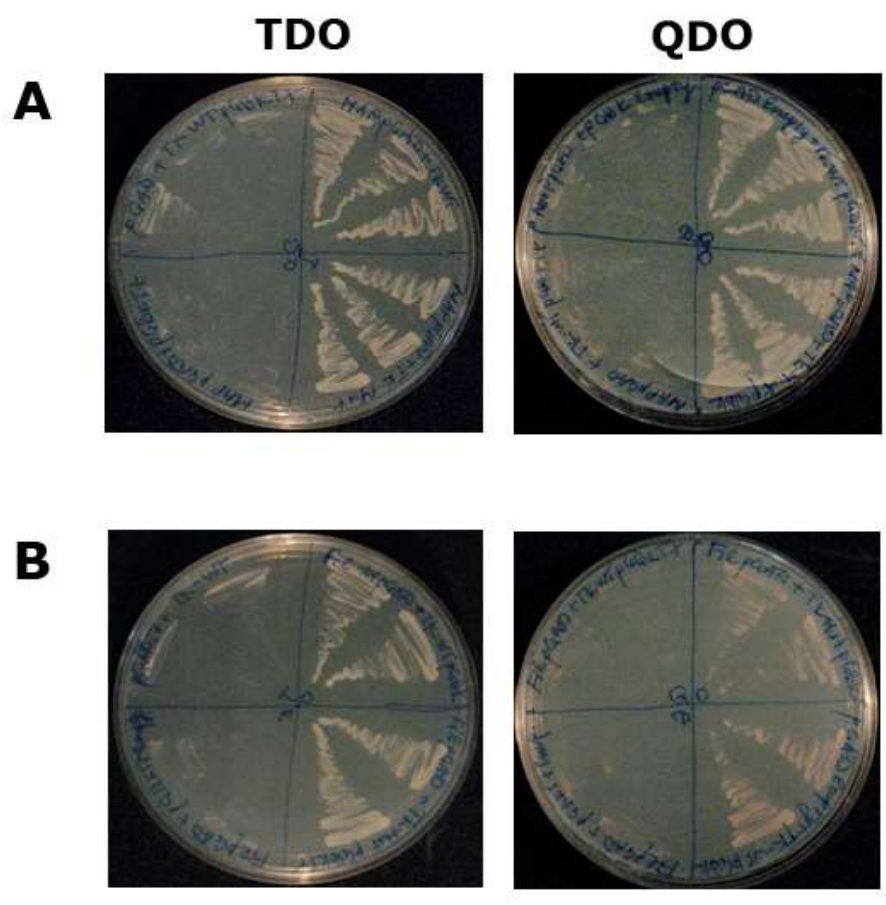

Figure 10: Interaction of TKin and MAP1B-LC1 (A) and TKin and FLNC-D24 (B) in Forced two hybrid Left column: the yeast growth after three days on TDO plate; right column: after five days on QDO plate. As negative controls served pGBKT7 and pGADT7 vectors without insert co-transformed MAP1B-LC1-pGADT7 and TKin-pGBKT7, respectively (left half of each plate).

Table 15: Forced two hybrid interaction results

\begin{tabular}{|c|c|c|c|c|}
\hline & $\begin{array}{l}\text { TKin-pGBKT7 } \\
\text { TDO/QDO/ß-Gal }\end{array}$ & $\begin{array}{l}\text { TKin-pGADT7 } \\
\text { TDO/QDO/ } \beta-G a l\end{array}$ & $\begin{array}{c}\text { pGBKT7 } \\
\text { TDO/QDO/ } \beta-G a l\end{array}$ & $\begin{array}{c}\text { pGADT7 } \\
\text { TDO/QDO/ } \beta-G a l\end{array}$ \\
\hline FLNC-D24-pGADT7 & $+/+/++$ & $N / A$ & $-/-/-$ & $N / A$ \\
\hline MAP1BLC1-pGADT7 & $+/+/+++$ & $N / A$ & $-/-/-$ & $N / A$ \\
\hline MLC2-pGADT7 & $+/+/++$ & N/A & $+/+/-$ & $N / A$ \\
\hline pGADT7 & $-/-/$ & N/A & $-/-$ & $N / A$ \\
\hline FLNC-D24-pGBKT7 & $N / A$ & $+/++$ & $N / A$ & $-/-/-$ \\
\hline MAP1BLC1-pGBKT7 & N/A & $+/+/+++$ & N/A & -/-/- \\
\hline
\end{tabular}




\begin{tabular}{|l|c|c|c|c|}
\hline MLC2-pGBKT7 & N/A & $+/+/++$ & N/A & $+/+/-$ \\
pGBKT & N/A & $-/-/$ & N/A & $-/-/-$ \\
\hline
\end{tabular}

\subsection{TKin interacts with FLNC-D24 but not with MAP1B-LC1 or MLC2 in Far Western Blot assay}

For further characterization of potential interacting partners of titin kinase the Far Western Blot assay was chosen. It is the standard method to study protein interactions in a solid phase: this technique involves fractionating of proteins on SDS-PAGE, blotting to the nitrocellulose membrane, and then incubation with a probe of interest. Due to reduction and denaturation of the proteins during preparation for SDS-PAGE weak transient interactions could be barely dertected. Nevertheless, as many types of protein - protein interactions still occur on overlays, it can still help to assume about the type of interaction (Hall 2004).

We used the Far Western Blot to confirm the yeast two hybrid interactions trying to detect binding of western-blotted GST-fused MAP1B-LC1, FLNC-D24 or MLC2 to soluble Hisand T7-tagged Kin2 recombinant protein overexpressed in E. coli and purified using pET expression and purification system (2.2.3.2).

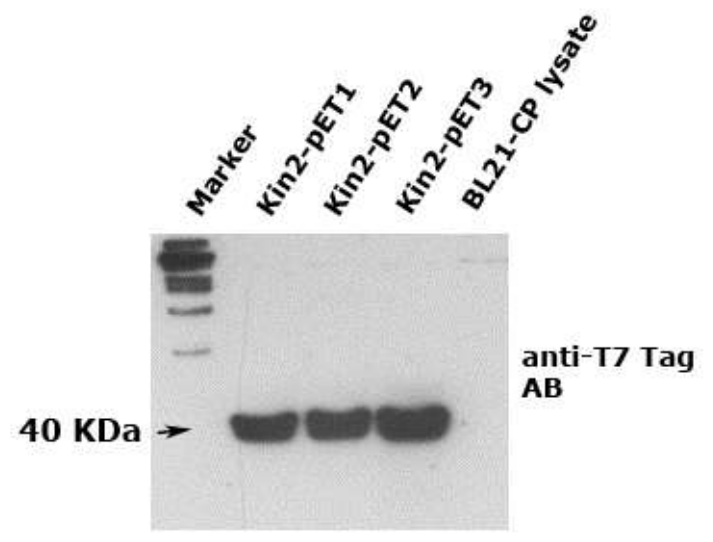

Figure 11: Kin2 expressed in E.coli and purified by Ni-NTA affinity chromatography

Recobinant His- and T7-tagged Kin2-pET (expression culture 1, 2 and 3) of approx. 40 kDa was immunodetected with T7-tag antibody (1:5000). On each line $4 \mu \mathrm{g}$ of protein was loaded. Exposure time: $1 \mathrm{~min}$.

In the first experiment, total E.coli extracts containing recombinant MAP1B-LC1, FLNC-D24 and MLC2 (4 $\mu \mathrm{g}$ of each) were prepared. The extracts were separated on SDS-PAGE and western blotted. Additionaly, GST-alone was taken as a negative control. After overlay with 
$100 \mu \mathrm{g}$ of recombinant purified His- and T7-tagged Kin2 probe, the binding to proteins immobilized on the nitrocellulose membrane was visualized using His-tag antibody. In this Far Western Blot overlay, an unspecific band of approximately $35 \mathrm{kDa}$ in size was detectable in all lines. We observed an interaction between Kin2 and FILNC-D24. The 40 kDa GSTFILNC-D24 fusion protein was detected with His-tag antibody. Two different negative controls were used for this experiment: the membrane was incubated with primary (His-tag) and secondary goat anti-mouse ECL antibody or secondary antibody alone. The $35 \mathrm{kDa}$ but not the $40 \mathrm{kDa}$ bands appeared in both negative controls, suggesting that the $35 \mathrm{kDa}$ band appeared through unspecific binding of the secondary antibody.

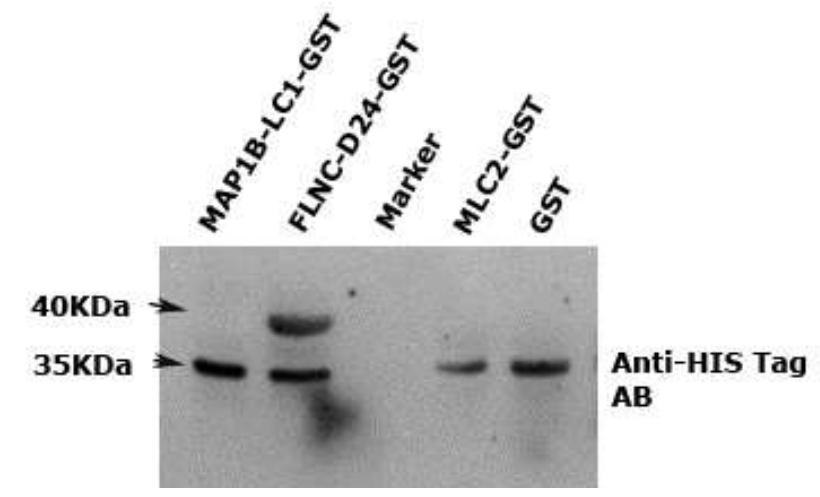

Figure 12: Western Blot overlay of GST-fused binding partners with Kin2 recombinant protein FILNC-D24-GST 40kDa protein detected with anti-His-Tag antibody after overlay with His-tagged Kin2 probe (lane 2). GST-fused MAP1B-LC1 (lane 1), MLC2 (lane 4) and GST-alone (lane 5) are not detectable. The 35 kDa unspecific band appears ubiquitary. Lane 3 represents protein marker.

The positive interacting result for FILNC-D24-GST and Kin2 in the Far Western Blot was followed by an additional Far Western Blot experiment, in which purified FILNC-D24 protein was cut from GST-fusion protein by precision protease. In this approach, we used purified recombinant FILNC-D24 free from GST fusion protein to answer the question of binding of Kin2 to GST-fused FILNC-D24 or to FILNC-D24 peptide alone and to clearly show the absence of binding of Kin2 to GST fusion protein.

Recombinant proteins FLNC-D24-GST and GST alone were purified from E. coli extracts as described (2.2.3.3). The elution step of FLNC-D24-GST was omitted and the recombinant protein was bound to sepharose beads, which were incubated with $3 \mu \mathrm{g}$ of precision protease in cleavage buffer by $4{ }^{\circ} \mathrm{C}$ overnight. The FILNC-D24 recombinant protein in the liquid phase was easily taken by pipeting after centrifugation for $5 \mathrm{c}$ at 13,000 rpm. The GST fusion protein bound to the beads remained in the solid phase. After that, $4 \mu \mathrm{g}$ of each purified 
recombinant protein were separated on SDS-PAGE, western blotted and overlaid with Hisand T7-tagged Kin2 as described above.

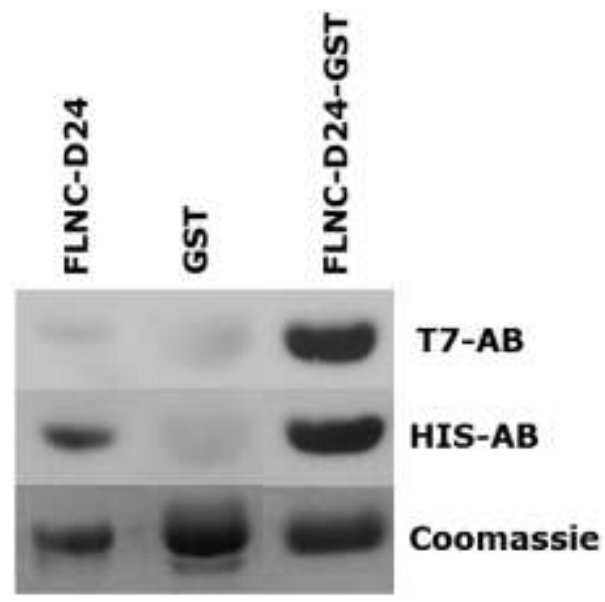

Figure 13: Western Blot overlay of purified FILN-D24 with titin kinase

Purified recombinant immobilized FILNC-D24 (15 kDa) and FLNC-D24-GST (40 kDa), but not the GST fusion protein alone $(26 \mathrm{kDa})$, were detected with His-tag antibody after the membrane was probed with His-tagged titin kinase (level 2; lane 1 and 3). Only FLNC-D24-GST was clearly detectable on the same western blot probed with anti-T7 Tag antibody (level 3; lane 3). Exposure time: $30 \mathrm{~min}$. The recombinant proteins loaded in equal to the western blot amounts and visualized by Coomassie blue staining (level 1).

We were able to detect FILNC-D24-GST as well as FILNC-D24 with His-tag antibody alone. Using N-terminal T7-tag antibody, only GST-fused FILNC-D24 could be detected. The presence and expression of T7-tag of Kin2-pET23a construct was confirmed by sequencing and western blots of overexpressed Kin2-recombinant protein.

These data suggest that FILNC-D24 binds to the N-teminal part of Kin2. The interaction with the very N-terminal part of Kin2 could possibly disable the binding of the T7-tag antibody to the T7-tagged Kin2 by changing the protein conformation in absence GST-fusion protein. In conclusion, the Far Western Blot gave a positive interaction result for FILNC-D24, but the other potential interacting partners could not be excluded based on this experiment.

\subsection{MAP1B-LC1 binds to TKin in GST-pulldown assay}

C-terminally truncated TKin sequence was re-cloned by restriction digest using EcoRI and SalI restriction sites into pGEX4T-1 glutathione S-transferase fusion expression vector, which enables prokaryotic overexpression of the recombinant protein and subsequent purification from bacterial extracts using affinity chromatography. 
The cDNAs of FLNC-D24 and MAP1B-LC1 were generated by polymerase chain reaction using a Pfu-proof reading DNA polymerase and primers that give the desired restriction sites (EcoRI and SalI) from human heart cDNA library and cloned into pGEX6P-1 E. coli expression vector. From this vector, sequences were re-cloned in modified pCMV5 mammalian expression vector carrying N-terminal T7-tag (Appendix 2) using BamHI and SalI restriction sites for expression in eukaryotic (here COS7) cells. The sequences of all constructs were confirmed by sequencing.

GST-pulldown assays were performed with GST-fused TKin and COS7 cells lysates containing overexpressed FLNC-D24 and MAP1B-LC1. The pulldown experiments were performed as described (2.2.3.9). The presumable binding partners could be detected on immuno-blots with T7tag antibody. The T7-tag presence and subsequently binding on TKin-GST-beads could be shown only for MAP1B-LC1. Henceforth, the pulldown assays revealed that MAP1B-LC1 binds to titin kinase (Figure 14).

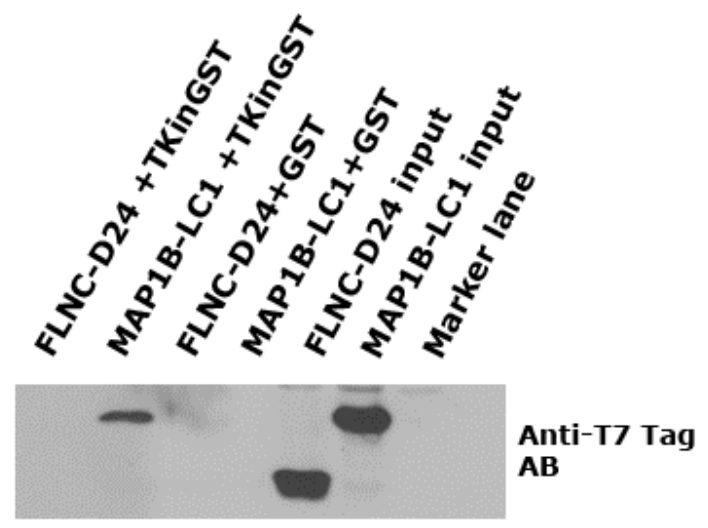

Figure 14: MAP1B-LC1 pulled down by TKin-GST

COS7 cell lysates transiently transfected with MAP1B-LC1-T7-tagged, or FLNC-D24-T7-tagged were incubated with purified GST, or GST-TKin-fusion proteins were bound to glutathione-Sepharose beads. After washing, bound proteins were separated on $10 \%$ SDS-gel, western blotted and detected using anti-T7-Tag antibody. MAP1B-LC1 pulled down by TKin-GST but not by GST; FLNC-D24 is neither detectable with TKin-GST nor with GST alone. Inputs of FLNC-D24 and MAP1B-LC1 show equal amounts. Monoclonal anti-T7 Tag antibody (Novagen) was used in a dilution of 1:5000 (Western Blot).

\subsection{Mapping of MAP1B-LC1 and TKin interaction}

Having obtained evidence for interaction between titin kinase and MAP1B-LC1, we examined with which portion of MAP1B-LC1 the interaction is taking place. Two additional clones of MAP1B-LC1 divid the molecule into two parts, one of which encloses N-terminal 
Tubulin Binding (TB) domain and another - C-terminal Actin Binding (AB) domain. The DNA sequences were obtained using PCR from the human heart cDNA library and inserted in pCMV5 modified vector using appropriate restriction sites (Figure 15).

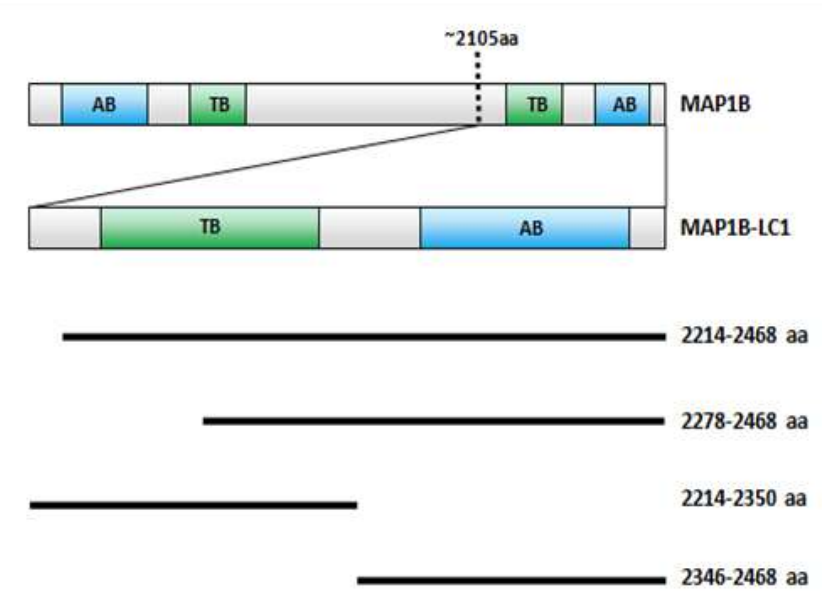

Figure 15: Schematic presentation of MAP1B constructs

MAP1B-LC1 with its tubulin (green) and actin (blue) binding sequences is a product of posttranstational modificatition of MAP1B. A C-terminal part of MAP1B-LC1 containing amino acids (aa) 2214-2468 appeared in Y2H library screen. N-terminal (2214-2350 aa) and C-terminal parts (2346-2468 aa) of LC1 were generated for mapping of TKin interaction site. N-terminaly truncated clone (2278-2468 aa) was generated additionally.

The clone with aa 2278-2468 was additionally generated, thanks to the newly identified MAP1B point mutation, which introduces an additional BamH1 endonuclease restriction site. For these interaction studies the GST-pulldown method was successfully used. The peptides were expressed in the eukaryotic system (COS7 cells). The overexpressed GST-fusion protein alone bound to glutathione sepharose beads was used as a negative control.

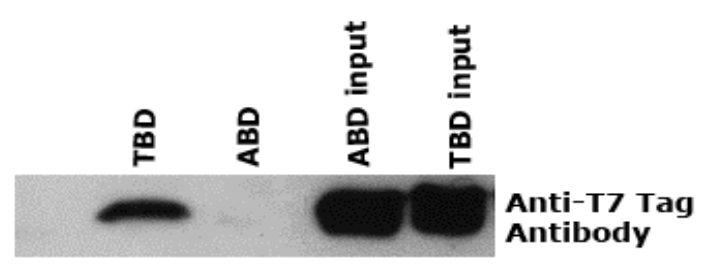

\footnotetext{
Figure 16: GST-Pulldown of MAP1B-LC1 tubulin and actin binding portions by Tkin

The MAP1B-LC1 N-terminal tubulin binding part (TBD) but not the F-actin binding part (ABD) was pulled down by TKin. The inputs of MAP1B-LC1-TBD and MAP1B-LC1-ABD are shown. Proteins were detected with the T7-tag antibody in a dilution of 1:5000 (Western blot).
} 
The GST-pulldowns suggest that TKin interaction with MAP1B-LC1 takes place between amino acids 2278 and 2350, where also predicted serine-threonine kinase phosphorylation sites are located (Figure 7).

Table 16: Interaction result of different portions of MAP1B-LC1 with TKin

\begin{tabular}{|l|l|}
\hline MAP1B-LC1 Clone & Interaction result \\
\hline $2214-2468$ aa - Y2H & + \\
$2278-2468$ aa - truncated & + \\
$2214-2350$ aa - TBD & + \\
$2346-2468$ aa - ABD & - \\
\hline
\end{tabular}

\subsection{MAP1B in developing and adult muscle cell}

Since the expression of MAP1B-LC1 in cardiac tissue at the level of mRNA and its role in the development and elongation of axons in the central nervous system was previously shown, it is of major importance here to investigate the role of MAP1B-LC1 in the development of muscle cell and also to scrutinize the role of its interaction with titin kinase.

To study MAP1B-LC1 localization in muscle cell, the protein was immunocytochemically visualized $\mathrm{C} 2 \mathrm{C} 12$ myoblasts. These cells are able to differentiate into mature myotubes and thereby express all sarcomeric proteins and even show contractile activity in vitro. In order to investigate whether the MAP1B-LC1 is actually expressed in adult muscle tissue (origin of $\mathrm{C} 2 \mathrm{C} 12$ cells) and in order to roughly compare the expression levels with brain tissue, the protein expression analysis was performed with MAP1B specific antibody on adult mouse tissues. The recognition was done with anti-MAP1B-LC1 mouse monoclonal antibody against aa 2257-2357 of human origin. The mouse sequence of this portion is almost completely identical with the human one. It allows successful recognition of the MAP1B-LC1 in mouse tissues. 


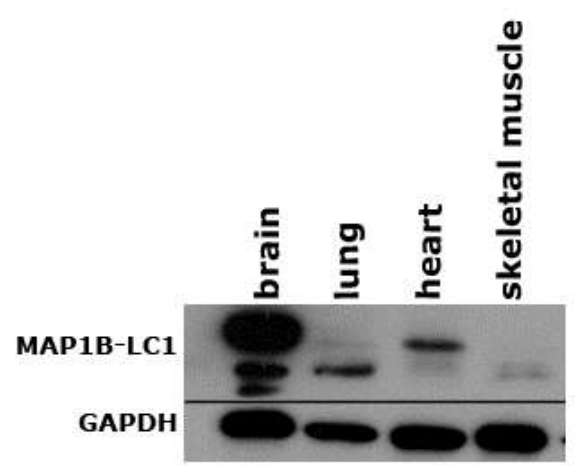

Figure 17: MAP1B-LC1 protein expression in adult mouse tissues

MAP1B-LC1 shows high levels of expression in mouse brain, it is expressed in the lung and heart and detectable in skeletal muscle. MAP1B-LC1 was detected with LC1-specific muse monoclonal antibody (BD) as a $34 \mathrm{kDa}$ protein. Anti-GAPDH antibody was used as a loading control (Western Blot).

To visualize the process of myoblast differentiation and to make sure at which stage of the myofibrillogenesis the cell extacts were prepared, we performed immunostainings with $\alpha$ actinin antibody. The stainings of proliferating or differentiating $\mathrm{C} 2 \mathrm{C} 12$ cells were performed from the dish which at the same time was used for the prepation of total protein extract. C2C12 cells differented into mature muscle cells within about 5 to 7 days. The percentage of cells that went into differentiation process as well as the speed of differentiation was considerably improved with Ultroser $\mathrm{G}$ as a supplement to the differentiation medium. $\mathrm{C} 2 \mathrm{C} 12$ cells were forming nicely aligned myofibrils on the fifth day and started to contract at the end of first week of cultivation. Longer cultivation of the cells led to increased cell death and to destruction of the myofibrils.

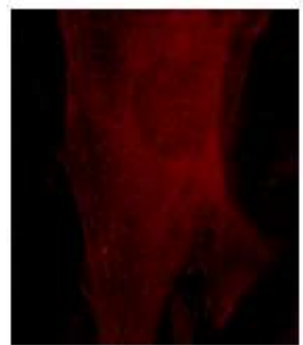

proliferation

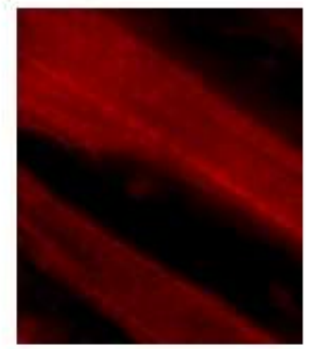

second day

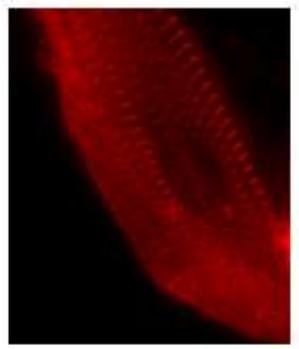

fourth day

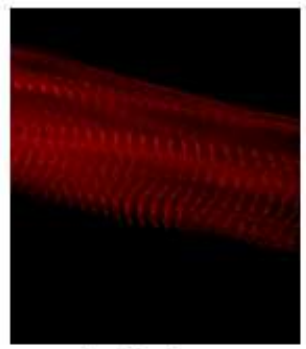

sixth day

\section{Figure 18: $\mathrm{C2C12}$ cells stained with $\alpha$-actinin specific antibody}

Proliferating $\mathrm{C} 2 \mathrm{C} 12$ myoblasts show distribution of $\alpha$-actinin in the cytoplasm. The differentiation process leads to the formation of typical cross striated myotubes on the sixth day. Rabbit polyclonal $\alpha$-actinin antibody was used to a dilution of 1:75. 


\subsubsection{Staining of native MAP1B-LC1 in C2C12 myoblasts}

The MAP1B-LC1 is a small protein of $32 \mathrm{kDa}$ localizing freely in the cytoplasm of the cell (cytoplasmic fraction), and it is bound to microtubuli fraction in neurons (Noiges et al. 2002). To study MAP1B-LC1 localization in muscle cell, stainings of $\mathrm{C} 2 \mathrm{C} 12$ myoblasts were performed. A single staining with polyclonal anti-MAP1B-LC1 (H-130) antibody without costaining with tubulin or a differentiation marker, like $\alpha$-actinin, was performed to get a clear MAP1B-LC1 distribution pattern. MAP1B-LC1 was truly observed in the cytosole with high density in the perinuclear area and organized in filamentous structures directing from the center of the cell to its periphery (Figure 19). This subcellular localization probably coincides with the microtubules (tubulin). The differentiating $\mathrm{C} 2 \mathrm{C} 12$ cells fixed on the fifth day represented up to $70 \%$ of the multinuclear myotubes with typical cross striations visualized by $\alpha$-actinin staining. These myotubes display MAP1B-LC1 in the filamentous structures. The localization of these filaments was observed along the longitudinal axis of the myotubes. The negative controls with secondary Cy3-conjugated antibody didn't show any unspecific stain.

\section{A}
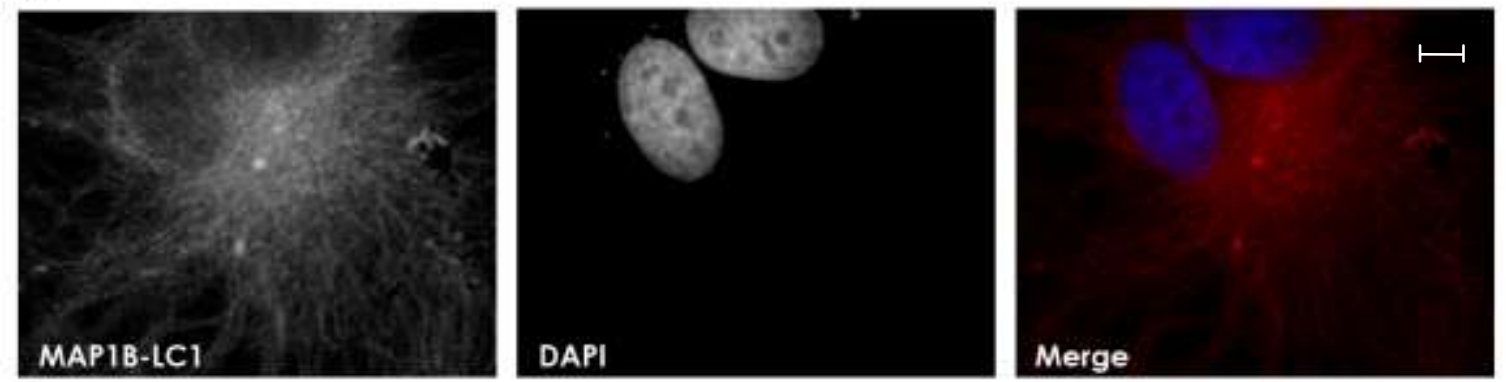

B
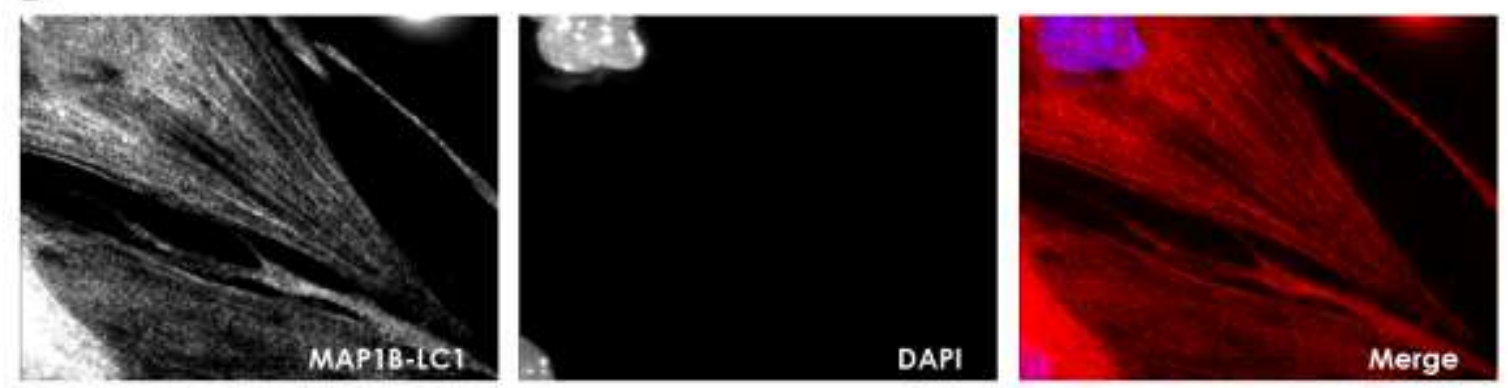

\section{Figure 19: Endogenous distribution of MAP1B-LC1 in C2C12 myoblasts}

MAP1B-LC1 observed perinuclear in cytosole and filamentous structures in proliferating C2C12 myoblasts (A). In differentiating $\mathrm{C} 2 \mathrm{C} 12$ myotubes ( $5^{\text {th }}$ day of differentiation), protein filaments appeared aligned parallely along the longitudinal axis of the cell (B). Staining performed with MAP1B-LC1 specific antibody (H-130) in a dilution of 1:200. DAPI staining performed to visualize nuclei. Scale bar, $10 \mu \mathrm{m}$. 
MAP1B-LC1 presence in the nucleus was observed in some of the proliferating and differentiating $\mathrm{C} 2 \mathrm{C} 12$ cells. Due to the small size of the protein, passive translocation to the nucleus can probably occur. The sequence identical to the nuclear receptor box (sequence motif, which binds to nuclear receptor), which was identified using bioinformatical methods, indicates the possibility of the active transport as well. The role of the protein in the nucleus is as yet unknown.

\subsubsection{MAP1B-LC1 is downregulated in proliferating $\mathrm{C} 2 \mathrm{C} 12$ myoblasts and induced during myogenesis}

Previous studies have shown that MAP1B-LC1 expression is induced in elongating axons. Having hypothesized that MAP1B-LC1 will be upregulated during the myotube elongation and sarcomere alignment along with increased network of microtubules; we examined the kinetics of expression of MAP1B-LC1 in differentiating $\mathrm{C} 2 \mathrm{C} 12$ myoblasts. Whole cellextracts taken at various points in time during the myoblast differentiation were probed with specific anti-MAP1B-LC1 antibody.

MAP1B-LC1 was expressed within 24 hours of inducing the differentiation and appeared to reach a maximum between 48 and 72 hours after the onset of the myogenic conversion. The level of MAP1B-LC1 was again decreasing after completing the myoblast fusion and after forming the myotubes (Figure 20).

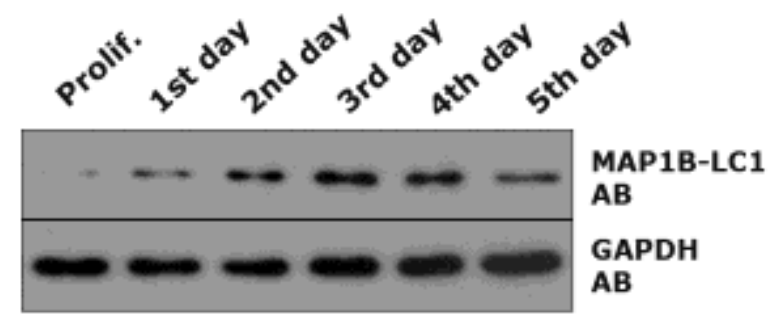

Figure 20: Expression profile of MAP1B-LC1 in differentiating C2C12 myoblasts

Myoblasts were placed in differentiation media upon $80 \%$ confluency and allowed to differentiate for the time periods indicated. Whole cell extracts were separated by SDS-PAGE and immunoblotted using MAP1B-LC1specific antibody. A total of $8 \mathrm{mg}$ of whole cell extract was used for each lane. GAPDH antibody was used as a loading control. 


\subsection{Titin Kinase phosphorylates MAP1B-LC1 and FLNC-D24}

In-vitro kinase assays are the most common and the first approach to study posttranslational modifications to understand the function as well as signaling mechanisms. The in vitro kinase assay was performed with the positively interacting protein substrate FLNC-D24 and TBD (tubulin binding domain of MAP1B-LC1) with the titin kinase immunoprecipitates. First, the protein substrates were expressed in E.coli as GST-fusion proteins and subsequently cleaved the GST fusion part with precession protease to obtain purified FLNC-D24 and TBD of MAP1B-LC1 proteins. The protein concentration was estimated by using the BCA protein assay kit. GST-fused proteins were either frozen after addition of $10 \%$ glycerol or immediately used for the kinase assay. Secondly, the titin kinase was immunoprecipitated using $10 \mu \mathrm{g}$ of T7-tag antibody as described and finally washed in the kinase buffer.

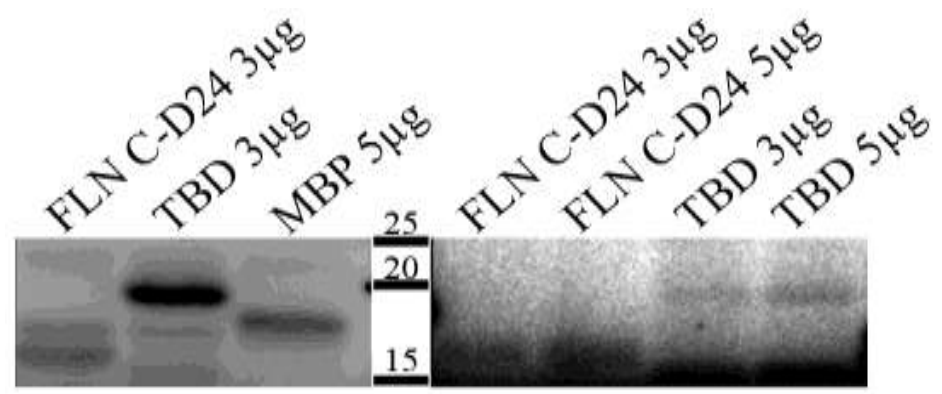

Figure 21: In vitro kinase assay

FLNC-D24, TBD of MAP1B-LC1 and MBP phosphorylated by unknown kinases from COS7 cell lysate (left picture). FILNC-D24 and TBD phosphorylated by eukaryoticly expressed titin kinase (right picture). Note: FLNC-D24 is small polypeptide $16 \mathrm{kDa}$ seen just above the $15 \mathrm{kDa}$ protein marker.

For the kinase activity assay, 3 or $5 \mu \mathrm{g}$ of FLNC-D24or TBD were used along with the purified titin kinase. In vitro phosphorylation assay with total COS7 cell lysate and FNLCD24, TBD and MBP was performed. The protein substrates were found to be phosphorylated directly by titin kinase in the reaction mixture containing only titin kinase, substrate and ATP. The identified titin kinase substrates were phosphorylated weakly (Figure 21: lane 1, 2, 3 and 4 ) in comparison to the total lysate used as a positive control (Figure 21: lane 5 and 6). 


\subsection{Asp24.727Val-mutated titin exhibit altered binding to MAP1B-LC1}

A point mutation of the titin kinase region has been identified in our laboratory in a DCM patient. This mutation was introduced into TKin-pGBKT7 using the Quick Change Sidedirected Mutagenesis Kit according to the instructions of manufacturer. To introduce this mutation, a single basepair exchange was generated, which resulted in an amino acid exchange of asparagine to valine.
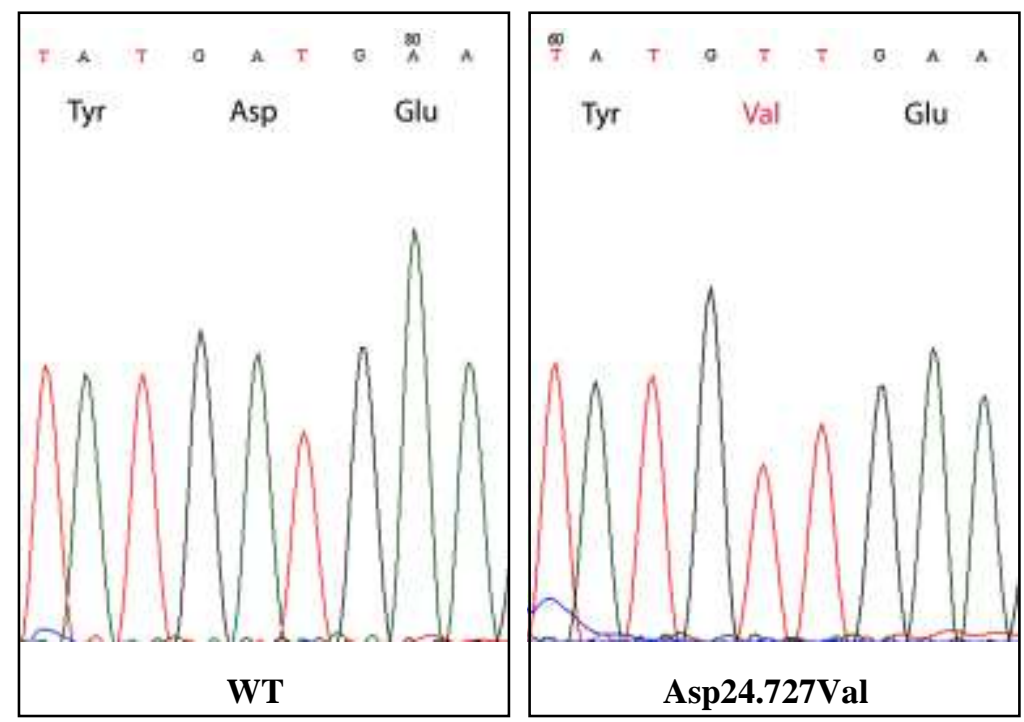

Figure 22: Chromatogramm of wildtype and Asp24.727Val-mutated titin

A single basepare exchange from adenine to thymine applied in site-directed mutagenesis assay results in Asp24.727Val point mutation in giant titin (right picture).

$\beta$-galctosidase activity in this assay is a quantitative parameter, which can give information about the interaction strength of two proteins in the yeast two hybrid system. TKin-WT and TKin-mut were co-transformed with MAP1B-LC1 or FLNC-D24 in the AH109 yeast strain and grown on TDO agar plates. Ten different colonies from each co-transformation were used for a quantitative liquid phase $\beta$-galactosidase activity assay. The $\beta$-galactosidase assay was performed as described (2.2.2.5). $\beta$-galactosidase activity was calculated for each single colony culture in Miller units (arbitrary units). 


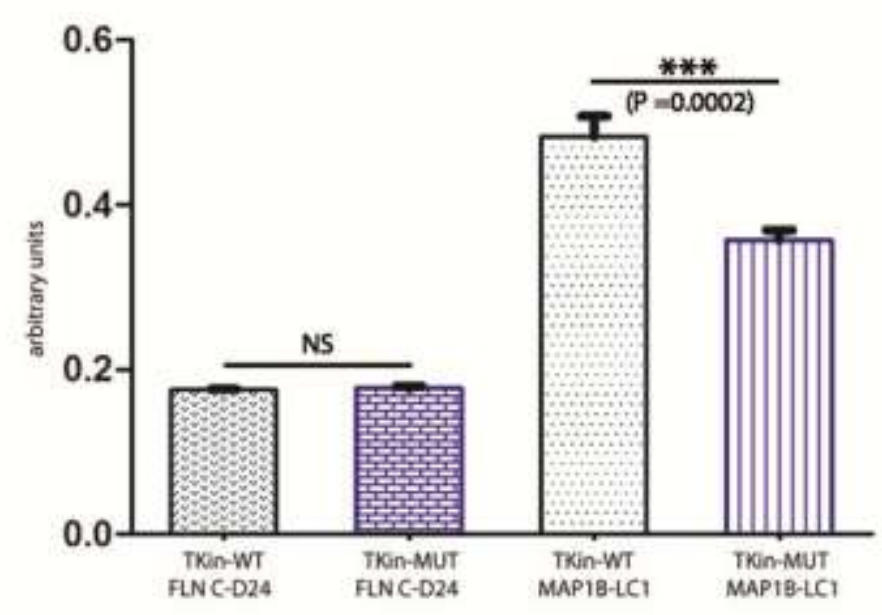

Figure 23: Graphic presentation of $\beta$-galactosidase activity mesured for MAP1B-LC1 and TKin-WT/-Mut interaction and FLNC-D24 and TKin-WT/-Mut-interaction

The $\beta$-galactosidase activity measured for TKin-WT and FLNC-D24-interaction was equal to the activity measured for TKin-Mut and FLNC-D24-interaction ( $p$-value $=0.39$, not significant). The $\beta$-galactosidase expression measured for TKin-WT and MAP1B-LC1-interaction showed a high level with respect to the TKinMut and MAP1B-LC1-interaction ( $p$-value=0.0002, significant). P-value was derived by the unpaired test $(n=10)$.

The cultures containing FILNC-D24 co-transformed with WT-titin kinase as well as with mutant titin kinase showed low $\beta$-galactosidase expression levels with connected less sensitive measurements and greater deviations in OD values. The incubation time needed for the appearance of yellow coloration before stopping the reaction was $1 \mathrm{~h}$ for TKin-MAP1B transformants and $2.5 \mathrm{~h}$ for TKin-FLNC-D24 transformants. In conclusion, the quantitative ONPG assay displayed lower interaction strength between TKin-mut and MAP1B-LC1 than TKin-WT and MAP1B-LC1, evidently shown by lower levels of $\beta$-galactosidase expression of TKin-mut-MAP1BLC1 co-transformants. The result in the cases of MAP1B, TKin-WT, and TKin-mut is statistically significant. Analyzing the data of this assay, we can assume that MAP1B indeed interacts with the N-terminal part of titin kinase or interdomain region $\mathrm{N}$ terminal of titin kinase domain. 


\section{Discussion}

Our knowledge on interacting partners and signaling pathways of giant modular muscle protein titin is constantly evolving. Responsible for the development of some cardiac and skeletal muscle diseases, titin-mutations open a new avenue for the investigation of sarcomeric organization and function. My search for novel titin kinase region interacting partners was initiated by the newly identified Asp24.727Val mutation in titin gene which is possibly responsible for development of hereditary DCM in a small family. The yeast two hybrid library screen yielded interesting interacting partners for the titin kinase region. This thesis presents mainly the analysis of two previously unidentified potential candidates interacting with the titin kinase region, one of which shows significant defect in binding to the Asp24.727Val mutant titin.

\subsection{Challenges with the giant titin and large-scale protein interaction studies}

In adult muscle cells, titin is a filamentous protein, whose $\mathrm{N}$-terminal end is fixed in the Zdisc, and the C-terminal part is tightly bound to the thick filament and is integrated into the M-line. To study protein-protein interaction in vitro, the giant modular protein has to be considered as the sum of its parts and split into its functional elements or domains. To study an isolated domain interactions its physiological conformation and functional activity has to be maintained. The titin kinase domain at the C-terminus of titin is flanked by FnIII and Iglike domains. The physiological conformation could probably be achieved through inclusion of flanked domains or a partial sequence of the domains to the titin kinase conctruct. In this study, the titin kinase construct includes a partial sequence of the FnIII domainlocated at the $\mathrm{N}$-terminal, the interdomain amino acid sequence-wherein the mutation Asp24.727Val was identified - followed by the complete kinase domain without the regulatory tail sequence. Absence of the regulatory tail confers the designed construct to be constitutively active (Mayans et al. 1998).

The widely used system for discovery of new protein-protein interactions in vivo is the yeast two hybrid system (Fields and Song 1989). Other available methods are: in vivo pull-down and native co-immunopercipitation based protein screens with subsequent mass spectrometric 
analysis. All approaches have high rates of false positives. Furthermore, of all interactions detected, only $3 \%$ are found by more than one approach (von Mering et al. 2002).

An advantage of the yeast two hybrid system is the eukaryotic expression of the proteins of interest, although not all necessary posttranslational modifications could probably occur in the non-muscle low ranged eukaryotic cell. The proteins of interest are tagged with relatively heavy GAL4-AD or BD, which could change the conformation of whole complex and reveal new interacting properties or cause the autoactivation of the system.

Some of technically determined problems of the yeast two hybrid library screen could not be influenced by a change in internal conditions but has to be considered while analyzing the experimental results. The yeast two hybrid library screen with titin kinase as bait was performed using adult human heart cDNA library. In the process of the preparation of precloned in pGADT7 human heart cDNA library the pool of synthesized cDNA is randomly cut with endonucleases and cloned downstream the GAL4 activation domain into the pGADT7 expression vector. The cDNA fragments cloned not in-frame with GAL4 could not be translated into encoded muscle protein. In that way clone 7 (Table 12) was excluded from the list of potential titin kinase interacting partners. Thus this established method of cDNA library preparation leads to isolation of some possible interacting partners out of the yeast two hybrid screen. It makes usage of different cDNA libraries or combined approaches in proteinprotein interactions studies indispensable.

While analyzing yeast two hybrid library screen result interesting fact was noticed: most of the fished out sequences representC-terminal parts of the corresponding encoded proteins. The explanation for this finding may be connected to the cDNA library preparation procedure.

\subsection{Titin kinase region and its interacting partners}

The yeast two hybrid library screen with titin kinase was performed in order to identify new interacting partners of the titin kinase region which includes newly identified Asp24.727Val mutation. The large scale yeast two hybrid library screen revealed relatively less (32) positive clones. Nevertheless, the analysis of fished out proteins requires methodical approach. The examination using nucleotide BLAST (NCBI) disclosed several repetitions of the obtained sequences. It allowed narrowing down the screen result to nine poteintial interacting partners (Table 12). The binding partners were divided in subgroups like cardiac specific proteins/ protein isoforms (MLC2, filamin C, ANP); extracellular matrix proteins/ hormones (collagen, decorin, ANP); intracellular non-cardiac proteins (HSP27, MAP1B-LC1). Many of the fished out proteins have immediate connection to the intra- or extracellular cytoskleleton: filamin $\mathrm{C}$, 
MAP1B, collagen, decorin. The analysed proteins did not display any significant structural similarities among each other or with previously described interacting partners of titin kinase region like MURF's, telethonin or Nbr1.

Remarkably, none of previously described interacting partners appear in this screen. The previously described R279W-mutated titin kinase failed to bind $\mathrm{Nbr1}$, which leads to development of skeletal muscle disorder without clinically dominant cardiac phenotype (Lange et al. 2005). This fact might suggest that titin kinase substrates or titin kinase stretch activated pathway in the cardiac muscle could differ from the same in the skeletal muscle.

Since not all fished out proteins could be analyzed in this study, the greater importance was given to cardiac cytoskeletal protein filamin C. An outstanding candidate MAP1B-LC1 awoke the interest due to connection to microtubule as well as actin cytoskeleton and participation in microtubule network stabilisation during axonal growth. Analogous role could be proposed for LC1 or its possible cardiac homolog in cardiomyocytes or cardiac pacemaker cells during myofibrillogenesis, in which microtubules, actin cytoskeleton and titin molecule play a key role.

\subsubsection{Filamin C: interacting partner of titin kinase region}

The C-terminal immunoglobulin-like domain 24 along with part of second hinge region was identified in the library screen as an interacting partner of titin kinase. After re-cloning the obtained filamin $\mathrm{C}$ short transcript, forced yeast two hybrid experiments with interchanging bait and prey were applied to prove the interaction. The positive result of yeast two hybrid library screen was confirmed. However, the biochemical studies brought two different results: the solid phase western blot overlay assay indicated the interaction of filamin $\mathrm{C}$ with titin kinase but liquid phase assay showed a negative result. Western blot overlay assay were considered to be sensitive but less specific, since conformation of proteins of interest and their electrical load could be changed by SDS PAGE. The negative result in the liquid phase assay is arguably due to the dimerization of domain 24 and its subsequent binding to membraneassociated proteins, such as integrin, when expressed in COS7 cells. The isolated Ig24, failed to perform the F-actin crosslinking function, probably easier associates with membrane proteins and is not available in soluble cytoplasmic fraction.

We speculated that the binding of titin kinase to filamin $\mathrm{C}$ could occur similar to the previously identified titin kinase-telethonin interaction during early myofibrilogenesis (Mayans et al. 1998). Cardiac or skeletal muscle development is complex and several distinct 
steps have to occur before attaining the full functionality of the muscle cell. In the early $\mathrm{C} 2 \mathrm{C} 12$ differentiating myotubes on the first or second day titin expression begins. It can be observed as it aggregates in the early differentiating muscle cells with titin epitope specific antibodies. These aggregates of titin colocalizes with dense body like structures, which later develops into the Z-discs. The titin epitopes, which initially colocalise at Z-bodies, separate during the process of myofibrillogenesis (Mayans et al. 1998; Van der Loop et al.1996), indicating that stretching of the titin molecule, and possibly exposure of binding sites for other myofibrillar proteins, is an essential process for the assembly of sarcomeres. Filamin $\mathrm{C}$ is upregulated in differentiating myoblast with a simultaneous down-regulation of filamin $\mathrm{A}$, a non muscle specific isoform (van der Ven et al. 2000b). During the early phase of myofibrillogenesis filamin $\mathrm{C}$ is seen to be distinctly distributed in a punctate manner along the stress fibers, which are dense body structures. In that stage of sarcomerogenesis filamin $\mathrm{C}$ and C-terminal titin with titin kinase domain are co-localized and the interaction could probably occur.

We further considered that the filamin C-titin kinase interaction may potentially contribute significantly during the remodeling processes and the unfolding of titin in close cooperation with dynamic actin cytoskeleton.

\subsubsection{MAP1B-LC1 performing specific function in muscle cell and associates with titin kinase}

The second interesting binding partner identified in the yeast library screen was MAP1B. The initial forced yeast two-hybrid assay, performed in both directions revealed MAP1B to be a likely binding partner of titin kinase. Biochemical assays confirmed the interaction, and subsequently, the binding was narrowed down to the tubulin binding region of MAP1B-LC1 in GST-pull down assays. The bioinformatic sequence analysis data allowed speculation that the LC1 might be a substrate of titin kinase. The phosphorylation of LC1 might affect its binding to tubulin and thereby contribute to reorganization of microtubules. Phosphorylation of MAP1B is described to be involved in the modulation of microtubule stability and the interaction with microfilaments (Mansfield et al. 1991).

MAP1B was first discovered in neurons and is considered to be a major cytoskeletal protein in neuronal tissue essential for neurite outgrowth. It is especially abundant in developing axons. Its appearance predominantly in neuronal tissue gives rise to a question about abundance and functional importance of the protein in the cardiac/skeletal muscle tissue. It 
was shown that MAP1B mRNA transcripts of exon 1 to 5 are expressed in levels comparable with brain tissue also in adult cardiac, skeletal muscle and lung tissue (Kutschera et al. 1998). The protein expression of MAP1B-LC1 analyzed by western blot in adult mouse tissues probed with MAP1B-LC1 specific monoclonal antibody shows prominent expression levels of LC1 in brain in comparison to low levels of expression in other tissues (cardiac and skeletal muscle). In spite of low levels of protein expression the LC1 could perform specific function in the heart. It could occur in contractile cardiomyocytes, cells of electrical conduction system or nervous systems of the heart. The preformed immunocytochemical localization studies of native LC1 in differentiating and proliferating $\mathrm{C} 2 \mathrm{C} 12$ myoblasts showed characteristic distribution pattern of LC1 in cytosol of the muscle cell and in filamentous structures. Like it is observed for LC1 in neurons (Noiges et al. 2002), distribution of LC1 in undifferentiated myoblasts dominates in perinuclear areas in punctate manner und in filamentous structures spreading from centre to the periphery of the cell. In the differentiating myotubes LC1 distributes in parallel aligned filamentous structures, probably along with microtubules. The function of microtubules in myofibrillogenesis and maintenance of the sarcomeric structure is poorly understood. It is known that the number of microtubules increases, and they rearrange parallel to myofibrillar axis during myogenesis. The induction of cardiac hypertrophy and thereby formation of new sarcomeres leads to rapid increase in microtubules and their major rearrangements (Rappaport et al. 1984; Rappaport et al. 1985; Saitoh et al. 1988; Samuel et al. 1984). Moreover, the microtubules were shown to play a direct role in integration of myosin into nascent sarcomeres (Guo et al. 1986). The myocytes treated with microtubule-stabilizing drug taxol were exhibiting defective sarcomerogenesis with the formation of pseudo-sarcomeres lacking normal actin filaments (Antin et al. 1981; Toyama et al. 1982).

The cardiomyocyte mechanosensation and transduction of mechanical stimuli is necessary for maintenance of structure and function of pre-existing sarcomeres but also for initiation and process of sarcomerogenesis. The sarcomeric cytoskeleton and its associated proteins play a central role in this process. The light chain of MAP1B is involved in microtubule stabilization, self-dimerization and actin filament binding. MAP1B-LC1 stabilizes microtubules, but such that microtubules remain flexible. The LC1 could probably affect interaction of giant titin with microtubules by participation in reorganization of microtubule network. The direct association of MAP1B with F-actin links it to the mechanotransduction pathways of the cell. 
Another piece of evidence in support of LC1 performing specific function in muscle cell was obtained by observation of increase in protein expression levels of MAP1B-LC1 during course of $\mathrm{C} 2 \mathrm{C} 12$ myoblasts differentiation. The expression level was increasing during first days of differentiation when the fusion and elongation of myotubes occurs. At the later stages of differentiation levels of LC1 appeared slightly decreasing. The change in protein expression levels itself suggests physiological importance of LC1 in myocytes.

In conclusion, MAP1B-LC1 could possibly interact with the titin kinase region. Although the expression level in cardiac and skeletal muscle tissue is low, MAP1B in association with microtubules, actin cytoskeleleton and giant titin could probably play a role in the processes of mechanosensing, sarcomerogenesis and maintenance of the sarcomeric structures.

\subsubsection{MLC2: a false substrate of titin kinase?}

The small protein is a substrate for the myosin light chain kinase, a structural analogue of titin kinase. In spite of the report about phosphorylation of RLC by titin kinase homolog from mollusc (Hierhorst et al. 1995), this interaction might be considered as based on structural similarity of titin kinase with MLCK unspecific interaction. MLCK is a $\mathrm{Ca}^{2+1}$ calmodulindependent serine/threonine kinase responsible for the phosphorylation of myosin RLC (Gallagher et al. 1997; Kamm and Stull 2001). The Fn III and Ig modules as well as the elastic PEVK motifs are present in smooth muscle/nonmuscle MLCK, like in vertebrate titins (Champagne et al. 2000; Fyrberg et al. 1992; Labeit et al. 1990; Labeit et al. 1992). There are also actin-bindingdomains. The high similarity of the Stretchin-MLCK and the titin-like protein superfamily allowed its identification as a member of this family of giant proteins (Champagne et al. 2000).

Phosphorylation of MLC2 in Drosophila IFM has been shown to be critical for the stretch activation response required for flight (Tohtong et al. 1995). The target residues of MLCK in MLC2 are located in the N-terminal part of the protein and surrounded by hydrophobic amino acid residues. The residues, which are phosphorylated by MLCKs, are S14 and S15 in sketetal muscle isoform (Gao et al. 1995), conserved S19 and probably S1-2 or Th9 in smooth muscle isoform (Ikebe and Hartshorne 1986). The N-terminal sequence of MLC2 should be probably used for comparison with any identified titin kinase binding partner in order to find structural similarity. 


\subsection{Analysis of phosphorylation of FilC-D24 and MAP1B-LC1 by titin kinase}

Protein phosphorylation has been traditionally studied by in vitro assays.The potential substrates of titin kinase were first identified in yeast two hybrid screen and studied in in vitro radioactive kinase assay. Unfortunately, kinases often show promiscuous activity in vitro, necessitating additional experimental approaches. In vitro assays have a comparative character, where the activity of the kinase towards a potential substrate is compared with a known substrate or unspecific control substrate. Phosphorylation studies with isolated titin kinase domain exclude stretch activation with participation of the whole sarcomere and the complete giant molecule. The titin kinase, when overexpressed in a different from muscle cell system, may lack the necessary posttranslational modifications and activation mechanisms, and possibly exhibit changes in its catalytic activity and specificity.The in vivo approach for the identification of titin kinase substrates is desirable under most conditions, where the kinase and the substrate with their associated proteins are appropriately compartmentalized.

Titin kinase is an autoinhibited serine-threonine protein kinase, which has a dual activation mechanism in the muscle cell along with a possible additional stretch-dependent activation mechanism (Mayans et al. 1998). Titin kinase phosphorylation activity towards the substrate telethonin was previously shown through an in vitro phosphorylation assay (Mayans et al. 1998). Interaction of titin kinase with telethonin was proposed to take place during muscle development. In comparison to telethonin, which is expressed at embryonic day 15.5 in mice (Weinert et al. 2006), when formed sarcomeres already exist, filamin C and MAPIB expressed very early during embyogenesis (Aoki et al. 1995; Chiang et al. 2000). Furthermore, both substrates showed several potential phosphorylation sites determined using the online server:http://www.cbs.dtu.dk/services/NetPhos/. The in vitro kinase assay with the immunoprecipitated titin kinase, i.e. an active kinase without regulatory tail, and with the protein substrates filamin $\mathrm{C}$ domain 24 and the tubulin binding region of MAP1B-LC1, were studied. The $\left[\gamma_{-}{ }^{32} \mathrm{P}\right]$ ATP was seen to be incorporated in the substrates after SDS-PAGE and autoradiographic analysis. By using equal amounts of FilC-D24 and TBD we showed, that TBD was phosphorylated more prominently by kinases from COS7 cell extract. The COS7 cell extract probably contains specific kinases, which are able to phosphorylate MAP1B-LC1, but doesn't contain specific kinase, which phosphorylates filamin C. The in vitro kinase assay with titin kinase showed equally low levels of MAP1B-LC1 and filamin C domain 24 phosphorylation. The phosphorylation of the substrates additionally supports our interaction studies. Although what could not be excluded is the fact that weak phosphorylation of the 
substrates is a result of the catalytic activity of kinases from COS7 cell extract, which are probably still present in a very small amount even after immunoprecipitation and purification of titin kinase. It could also indicate that the titin kinase is not fully active, or that both substrates are not specific for the titin kinase.

The previously described substrates, like telethonin and Nbr1, as well as the identified in this study MLC2 could be used in the kinase assay as controls. In order to get an in vitro active titin kinase, Y170E mutant kinase could be used. The mutant titin kinase was shown to be catalytic active through simulation of Y170 phosphorylation and thereby abolishing kinase autoinhibition (Mayans et al. 1998). The specificity of titin kinase in vitro phosphorylation studies has to be critically looked at, since changes in function of isolated titin kinase are probably far more drastic in comparison to other kinases studied in vitro.

\subsection{Relevance of Asp24.727Val mutation}

The C-terminal titin mutation (see 1.8) was speculated to influence titin kinase domain function and thereby cause cardiomyopathy in a small family. In the present study only two newly identified binding partners of titin kinase region were used to explore a role of the mutation. The titin kinase binding partners MAP1B-LC1 and FilC-D24 showed different $\beta$ galactosidase expression levels in a semi-quantitative colony-lift filter $\beta$-galactosidase assay (Table 12). The experiment allows the assumption, that titin kinase region interactions with MAP1B-LC1 or FilC-D24 could differ in strength. These two titin kinase yeast two hybrid interacting partners were used to investigate the importance of the titin mutation. The quantitative $\beta$-galactosidase assay was chosen to analyze interaction strength of the mutant titin with the newly identified yeast two hybrid interacting partners in comparison to wild type titin. In the forced two hybrid assay of FilC-D24 and MAP1B-LC1 with TKin-WT as well as TKin-Mut showed colony growth without any detectable difference in growth kinetics. In the quantitative $\beta$-galactosidase expression assay, the newly identified binding partner of titin kinase region MAP1B-LC1 showed a decreased binding to Asp24.727Val-mutated titin kinase. This experiment gives indirect evidence of MAP1B-LC1 physiological importance in cardiac muscle and a first evidence of possible participation of the described mutation in the development of cardiomyopathy. To give an additional strength to this experimental result another comparative assays already successfully used in this study could be performed with mutated and wild type titin kinase (region), for example, GST-pulldown assay. In vitro 
comparison of MAP1B-LC1 phosphorylation by mutated and wild type titin kinase could confirm the $\beta$-gal ONPG assay result as well.

One possible assumption is that mutant titin kinase is probably unable to incorporate/attach to the sarcomeric M-band due to alteration of MAP1B-LC1 binding. Future immunocytochemical localization studies could give additional evidence of physiological importance of the Asp24.727Val mutation and opens up the possibilities to study signaling pathways involved in the development of DCM with possible participation of MAP1B-LC1 and sarcomeric cytoskeleton from early stages to the adult stage.

\subsection{Outlook and future experimental directions}

The main future goal and futher clinical implication is to identify cardiac specific pathways leading to development of cardiomyopathy and heart failure with involvement of titin kinase and subsequently to find suitable inhibitors of such pathway. Titin kinase domain is a part of giant molecule which has been recognized as a "molecular ruler" indispensable for the assembly of the sarcomere and maintenance of the sarcomere structure. Giant titin is thought to be involved in intrasarcomeric mechanosensation and regulation of passive stiffness, particularly important in cardiac muscle. Titin kinase as an activated by mechanical stress mechanosensor is probably important for reorganization of the sarcomere structures during adaptation to mechanical stress or in the process of sarcomerogenesis. The kinase probably participates in microtubule network reorganization and sarcomere proteins degradation through its association with microtubule associated proteins like MURFs and MAP1 light chains. Future studies will be needed to address whether the different titin signaling complexes, i.e. the Z-disc titin-MLP pathway, the I-band titin N2A-CARP pathway, and the titin kinase signaling pathways act independently or in coordinated fashion.

The identification of two proteins directly associated to cytoskeleton and upregulated during embryogenesis - LC1 and filamin C - supports the current direction in titin kinase domain research. The titin kinase-filamin $\mathrm{C}$ interaction didn't find sufficient biochemical support in this study. For the further confirmation and finding of new interacting partners an additional GST-pulldown or Co-IP screen in muscle cells, for example, in $\mathrm{C} 2 \mathrm{C} 12$ differentiating myotubes could be performed. To provide a structural foundation for proteomic studies crystallization of the LC1-titin kinase or filamin C-titin kinase complex followed by NMR structural analysis is the next possible investigation approach. 
The downstream signaling of titin kinase in connection to sarcomeric cytoskeleton (microtubules) and its associated proteins MAP1 light chains, MURFs, Nbr1 and p62 has to be studied in vivo. In cardiac cell culture model with knocked down MAP1B or with ablated by specific drugs microtubules the process of myofibrillogenesis and the downstream signaling pathways could be further investigated. The involvement of LC1, titin and microtubules in sarcomerogenesis could be studied via MAP1B-LC1-GFP knock in model system utilizing immunohistochemical and other approaches. The previously proposed signaling pathways involving hypertrophic signaling via SRF (Lange et al. 2005), and atrophic signaling via protein degradation pathways (Pankiv et al. 2007; Waters et al. 2009) should be included in these studies.

The influence of titin kinase region mutation on LC1 binding and its signaling pathways could be investigated with help of knock in cell culture or animal models.

All the above proposed experiments and directions are outside the limits of this thesis. 


\section{Summary}

The giant filamentous muscle protein titin spans half of the sarcomere. Through its tight association with the thick filament, its elastic elements at the I-band, its connection to the cytoskeleton components, and its anchorage at the Z-disc and M-line, the protein is proposed to participate in the mechanosensation and -transduction, to provide mechanical stability to the sarcomere as well as to possibly serve as a "molecular ruler," providing the basis for the incorporation of the thick filament and other components into the sarcomere during myofibrillogenesis, where mechanosensory processes also play an important role.

Cardiomyopathies are frequently caused by mutations in structural sarcomeric proteins, which are known to perturb a variety of different functions, such as mechanical stability, contractility, mechanosensation, and transduction. A number of mutations in the giant sarcomeric protein, which is associated with familial HCM, DCM or skeletal muscle disorders, were identified in the past. We focused on unravelling the function of the kinase domain of titin located at its carboxyterminus in close proximity to the M-band. A single nucleotide polymorphism causing Asp24.727Val mutation, which is located 20 amino-acids upstream of the kinase domain, was identified in a small family suffering from severe DCM. It is a first mutation of the titin kinase region that leads to the development of the cardiac phenotype. We assume that the function of the kinase domain and its signalling pathways of the heart muscle could be affected by the mutation.

To get more insight into the underlying molecular mechanisms, a yeast two hybrid screen was performed, using the titin kinase with the $\mathrm{N}$-terminal interdomain region as bait as well as a human heart cDNA library. We identified several different prey clones and were able to confirm interaction with the light chain of microtubule-associated protein 1B (tubulin- and actin-binding protein) in GST pull-down assay and interaction with the filamin $\mathrm{C}$ domain 24 (actin-binding and bundling protein) in a far western blot assay. We were able to narrow down the interaction of MAP1B-LC1 to the titin kinase region to amino acids 2278-2350, where potential serine-threonine phosphorylation sites are also located. The interaction with titin kinase was narrowed down to the tubulin-binding sequence of MAP1BLC1. The MAP1B-LC1, known to be upregulated and functionally active during embryogenesis in neuronal tissue, mostly in developing and elongating axons, was shown to be expressed in differentiating $\mathrm{C} 2 \mathrm{C} 12$ myoblasts and to organize in filamentous structures along the longitudinal axis of the cells and in the cytoplasm. The low levels of protein 
expression, in comparison to brain tissue, are detectable even in adult mouse heart, skeletal muscle and lung tissue. The expression analysis of MAP1B-LC1 on different stages of C2C12 myoblast differentiation suggests that MAP1B-LC1 is functionally active in developing muscle tissue as well. MAP1B-LC1 is upregulated during fusion and elongation of the myoblasts and downregulated after having completed the differentiation course.

The feature of the interaction of MAP1B-LC1 or Filamin C domain 24 with the titin kinase region has yet to be discovered. In the yeast two hybrid based B-galactosidase expression assay binding of Asp24727Val titin kinase to MAP1B-LC1 was compromised. This finding suggests that the mutation possibly disturbs the kinase function, or that MAP1B-LC1 binds upstream of the kinase domain $\mathrm{N}$-terminal from the kinase interdomain region. The Asp24727Val mutation does not affect binding of the Filamin C domain 24 to titin kinase in the same assay.

This study provides data about potentially new interacting partners of the titin kinase region in the heart. With the help of the newly identified genetic variant in the titin gene, we want to investigate functions of titin kinase and involvement of the sarcomeric cytoskeleton and its associated proteins in the titin kinase-associated pathogenetic pathways leading to DCM. 


\section{Appendices}

\subsection{Appendix 1}

Titin kinase clone used for yeast two hybrid screen (TKin):

A. Nucleotide sequence

CGGGTAATAGCTGAAAATAAATTTGGTCTGAGCAAGCCTTCAGAGCCTTCAGAAC CAACCATAACCAAAGAAGATAAGACCAGAGCTATGAACTATGATGAAGAGGTAG ATGAAACCAGGGAAGTCTCCATGACTAAAGCATCTCACTCTTCAACCAAGGAACT CTATGAGAAATATATGATTGCTGAAGATCTTGGGCGTGGTGAGTTTGGAATTGTC CATCGTTGTGTTGAAACATCCTCAAAGAAGACATACATGGCCAAATTTGTTAAAG TCAAAGGGACTGATCAGGTTTTGGTAAAGAAGGAAATTTCCATTCTGAATATTGC TAGGCATAGAAACATCTTACACCTCCATGAATCATTTGAAAGCATGGAAGAATTA GTTATGATCTTTGAGTTTATATCAGGACTTGACATATTTGAGCGCATTAACACAAG TGCTTTTGAACTTAATGAAAGAGAAATTGTAAGTTATGTTCACCAGGTCTGTGAA GCACTTCAGTTTTTACACAGTCATAATATTGGACACTTTGACATTAGACCAGAAA ATATCATTTACCAAACCAGAAGAAGCTCTACCATTAAAATCATAGAATTTGGTCA AGCCCGTCAGCTGAAACCAGGGGACAACTTCAGGCTTCTATTCACTGCCCCAGAA TACTATGCACCTGAAGTCCACCAGCATGATGTTGTCAGCACAGCCACAGACATGT GGTCACTTGGAACACTGGTATATGTGCTATTGAGTGGTATCAACCCATTCCTGGCT GAAACTAACCAACAGATCATTGAGAATATCATGAATGCTGAATATACTTTCGATG AGGAAGCATTCAAAGAGATTAGCATTGAAGCCATGGATTTTGTTGACCGGTTGTT AGTGAA

B. Protein sequence

RVIAENKFGLSKPSEPSEPTITKEDKTRAMNYDEEVDETREVSMTKASHSSTKELYEK YMIAEDLGRGEFGIVHRCVETSSKKTYMAKFVKVKGTDQVLVKKEISILNIARHRNIL HLHESFESMEELVMIFEFISGLDIFERINTSAFELNEREIVSYVHQVCEALQFLHSHNIG HFDIRPENIIYQTRRSSTIKIIEFGQARQLKPGDNFRLLFTAPEYYAPEVHQHDVVSTAT DMWSLGTLVYVLLSGINPFLAETNQQIIENIMNAEYTFDEEAFKEISIEAMDFVDRLLV $\mathrm{K}$

Titin kinase clone used for in vitro studies (Kin 2):

A. Nucleotide sequence

TCCGGGTAATAGCTGAAAATAAATTTGGTCTGAGCAAGCCTTCAGAGCCTTCAGA ACCAACCATAACCAAAGAAGATAAGACCAGAGCTATGAACTATGATGAAGAGGT AGATGAAACCAGGGAAGTCTCCATGACTAAAGCATCTCACTCTTCAACCAAGGA ACTCTATGAGAAATATATGATTGCTGAAGATCTTGGGCGTGGTGAGTTTGGAATT GTCCATCGTTGTGTTGAAACATCCTCAAAGAAGACATACATGGCCAAATTTGTTA AAGTCAAAGGGACTGATCAGGTTTTGGTAAAGAAGGAAATTTCCATTCTGAATAT 
TGCTAGGCATAGAAACATCTTACACCTCCATGAATCATTTGAAAGCATGGAAGAA TTAGTTATGATCTTTGAGTTTATATCAGGACTTGACATATTTGAGCGCATTAACAC AAGTGCTTTTGAACTTAATGAAAGAGAAATTGTAAGTTATGTTCACCAGGTCTGT GAAGCACTTCAGTTTTTACACAGTCATAATATTGGACACTTTGACATTAGACCAG AAAATATCATTTACCAAACCAGAAGAAGCTCTACCATTAAAATCATAGAATTTGG TCAAGCCCGTCAGCTGAAACCAGGGGACAACTTCAGGCTTCTATTCACTGCCCCA GAATACTATGCACCTGAAGTCCACCAGCATGATGTTGTCAGCACAGCCACAGACA TGTGGTCACTTGGAACACTGGTATATGTGCTATTGAGTGGTATCAACCCATTCCTG GCTGAAACTAACCAACAGATCATTGAGAATATCATGAATGCTGAATATACTTTCG ATGAGGAAGCATTCAAAGAGATTAGCATTGAAGCCATGGATTTTGTTGACCGGTT GTTAGTGAAAGAGAGGAAATCTCGCATGACAGCATCGGAGGCTCTCCAGCACCC ATGGTTGAAGCAGAAGATAGAAAGAGTCAGTACTAAAGTTATCAGAACATTA

\section{B. Protein sequence}

RVIAENKFGLSKPSEPSEPTITKEDKTRAMNYDEEVDETREVSMTKASHSSTKELYEK YMIAEDLGRGEFGIVHRCVETSSKKTYMAKFVKVKGTDQVLVKKEISILNIARHRNIL HLHESFESMEELVMIFEFISGLDIFERINTSAFELNEREIVSYVHQVCEALQFLHSHNIG HFDIRPENIIYQTRRSSTIKIIEFGQARQLKPGDNFRLLFTAPEYYAPEVHQHDVVSTAT DMWSLGTLVYVLLSGINPFLAETNQQIIENIMNAEYTFDEEAFKEISIEAMDFVDRLLV KERKSRMTASEALQHPWLKQKIERVSTKVIRTL

\section{Clone 5 (myosin regulatory light chain):}

\section{A. Nucleotide sequence}

CTCGGGAGGCAGTGCTGGGTCCTTTCCACCATGGCACCTAAGAAAGCAAAGAAG AGAGCCGGGGACGCCAACTCCAACGTGTTCTCCATGTTCGAACAGACCCAAATCC AGGAATTTAAGGAGGCCTTCACTATCATGGACCAGAACAGGGATGGCTTCATTGA CAAGAACGATCTGAGAGACACCTTTGCTGCCCTTGGGCGAGTGAACGTGAAAAA TGAAGAAATTGATGAAATGATCAAGGAGGCTCCGGGTCCAATTAACTTTACTGTG TTCCTCACAATGTTTGGGGAGAAACTTAAGGGAGCGGACCCTGAGGAAACCATTC TCAACGCATTCAAAGTGTTTGACCCTGAAGGCAAAGGGGTGCTGAAGGCTGATTA CGTTCGGGAAATGCTGACCACGCAGGCGGAGAGGTTTTCCAAGGAGGAGGTTGA CCAGATGTTCGCCGCCTTCCCCCCTGACGTGACTGGCAACTTGGACTACAAGAAC CTGGTGCACATCATCACCCACGGAGAAGAGAAGGACTAGGAGGGGGCTCGCTGC TGCGCCCTGGGCTCGTCTTTGCAGAGTGGTCCCTGCCCTCATCTCTCTCCCCCGAG TACCGCCTCTGTCCCTACCTTGTCTGTTAGCCATGTGGCTGCCCCATTTATCCACC TCCATCTTCTTTGCAGCCTGAGTGGCTATGGGTACTTCGTGGCCGCACATCCTACA GTTGGAAATCCATCCAGAGGCCATGTTCCAATAAAACAGGAGTCGTGTATTTGGT CACGACATTTCTCTGACGAAAGGAATATAAAGACACATACTAAATAAGTGAAGA AGGACACAGACAGAAAATAAAGAATAATGATGGAGCACTAGATTATAAAAACCT GTCGCGCCCTCGCCTCTAAGAGGTGGCTCAGATCCGGATATCATTC

\section{B. Protein sequence}

LGRQCWVLSTMAPKKAKKRAGDANSNVFSMFEQTQIQEFKEAFTIMDQNRDGFIDK NDLRDTFAALGRVNVKNEEIDEMIKEAPGPINFTVFLTMFGEKLKGADPEETILNAFK 
VFDPEGKGVLKADYVREMLTTQAERFSKEEVDQMFAAFPPDVTGNLDYKNLVHIIT HGEEKD

\section{Clone 3 (MAP1B):}

A. Nucleotide sequence

CACCCAAGCAGTGGTATCAACGCAGAGTGGCCATTATGGCCTGATGTGTCCATGG TGGACCCAGAGGCCTTGGCCATTGAGCAGAACCTGGGCAAAGCTCTAAAGAAAG ATCTGAAAGAGAAGACCAAAACCAAAAAGCCAGGTACAAAGACAAAGTCATCTT CACCTGTCAAAAAGAGTGATGGGAAGTCTAAGCCCTTGGCAGCTTCACCAAAACC AGCGGGCTTGAAAGGATCCTCGGATAAAGTGTCCAGGGTGGCTTCTCCTAAGAAG AAAGAATCTGTGGAAAAGGCAGCAAAACCCACCACCACTCCTGAGGTCAAAGCT GCACGTGGGGAAGAGAAAGACAAGGAGACCAAGAATGCTGCCAATGCCTCTGCA TCCAAGTCGGCCAAGACCGCCACTGCAGGACCAGGAACTACCAAGACGACCAAG TCATCTGCTGTGCCCCCAGGCCTCCCTGTGTATTTGGACCTGTGCTACATTCCTAA CCACAGCAATAGTAAGAATGTTGATGTGGAATTTTTCAAGAGAGTGCGGTCTTCC TACTACGTGGTGAGTGGGAATGACCCTGCTGCTGAGGAGCCCAGCCGGGCTGTCC TGGACGCTTTGTTGGAAGGAAAGGCTCAGTGGGGCAGCAACATGCAGGTGACAC TGATCCCAACTCATGACTCAGAAGTGATGAGGGAATGGTACCAGGAGACCCATG AGAAACAGCAAGATCTCAACATCATGGTTTTAGCAAGCAGCAGCACAGTGGTTAT GCAAGATGAATCCTTCCCTGCATGCAAGATTGAACTGTAAAAACCAAGGCCAGCC ACACCACAGGATCTGAACTTTGTTTCCAGAAATCTCAATTTGAAATCACCTTTTCT AAAAAGTCATTCATCTAGTAGTCGCTGACATTACTGCAAATGCTATACTGTGTCA TGTGATGCAGTCACTAAATTTCTCAGTTTTGCTGAATGCTAAGG

B. Protein sequence

EFHPSSGINAEWPLWPDVSMVDPEALAIEQNLGKALKKDLKEKTKTKKPGTKTKSSS PVKKSDGKSKPLAASPKPAGLKGSSDKVSRVASPKKKESVEKAAKPTTTPEVKAARG EEKDKETKNAANASASKSAKTATAGPGTTKTTKSSAVPPGLPVYLDLCYIPNHSNSK NVDVEFFKRVRSSYYVVSGNDPAAEEPSRAVLDALLEGKAQWGSNMQVTLIPTHDS EVMREWYQETHEKQQDLNIMVLASSSTVVMQDESFPACKIEL

\section{Clone 4 (Filamin C):}

A. Nucleotide sequence

AAGGCCAAGGTCACTGGTCCGAGGCTGTCCGGAGGCCACAGCCTTCACGAAACA TCCACGGTTCTGGTGGAGACTGTGACCAAGTCCTCCTCAAGCCGGGGCTCCAGCT ACAGCTCCATCCCCAAGTTCTCCTCAGATGCCAGCAAGGTGGTGACTCGGGGCCC TGGGCTGTCCCAGGCCTTCGTGGGCCAGAAGAACTCCTTCACCGTGGACTGCAGC AAAGCAGGCACCAACATGATGATGGTGGGCGTGCACGGCCCCAAGACCCCCTGT GAGGAGGTGTACGTGAAGCACATGGGGAACCGGGTGTACAATGTCACCTACACT GTCAAGGAGAAAGGGGACTACATCCTCATTGTCAAGTGGGGTGACGAAAGTGTC CCTGGAAGCCCCTTCAAAGTCAAGGTCCCT 
B. Protein sequence

KAKVTGPRLSGGHSLHETSTVLVETVTKSSSSRGSSYSSIPKFSSDASKVVTRGPGLSQ AFVGQKNSFTVDCSKAGTNMMMVGVHGPKTPCEEVYVKHMGNRVYNVTYTVKEK GDYILIVKWGDESVPGSPFKVKVP

\subsection{Appendix 2}

\section{pET23a-T7 vector:}

Size: $3.7 \mathrm{~kb}$

Supplier: Novagen (pET23a)

T7 Promotor

T7-Immunotag, HIS6-Tag

F1 Origin

Ampicillin resistance

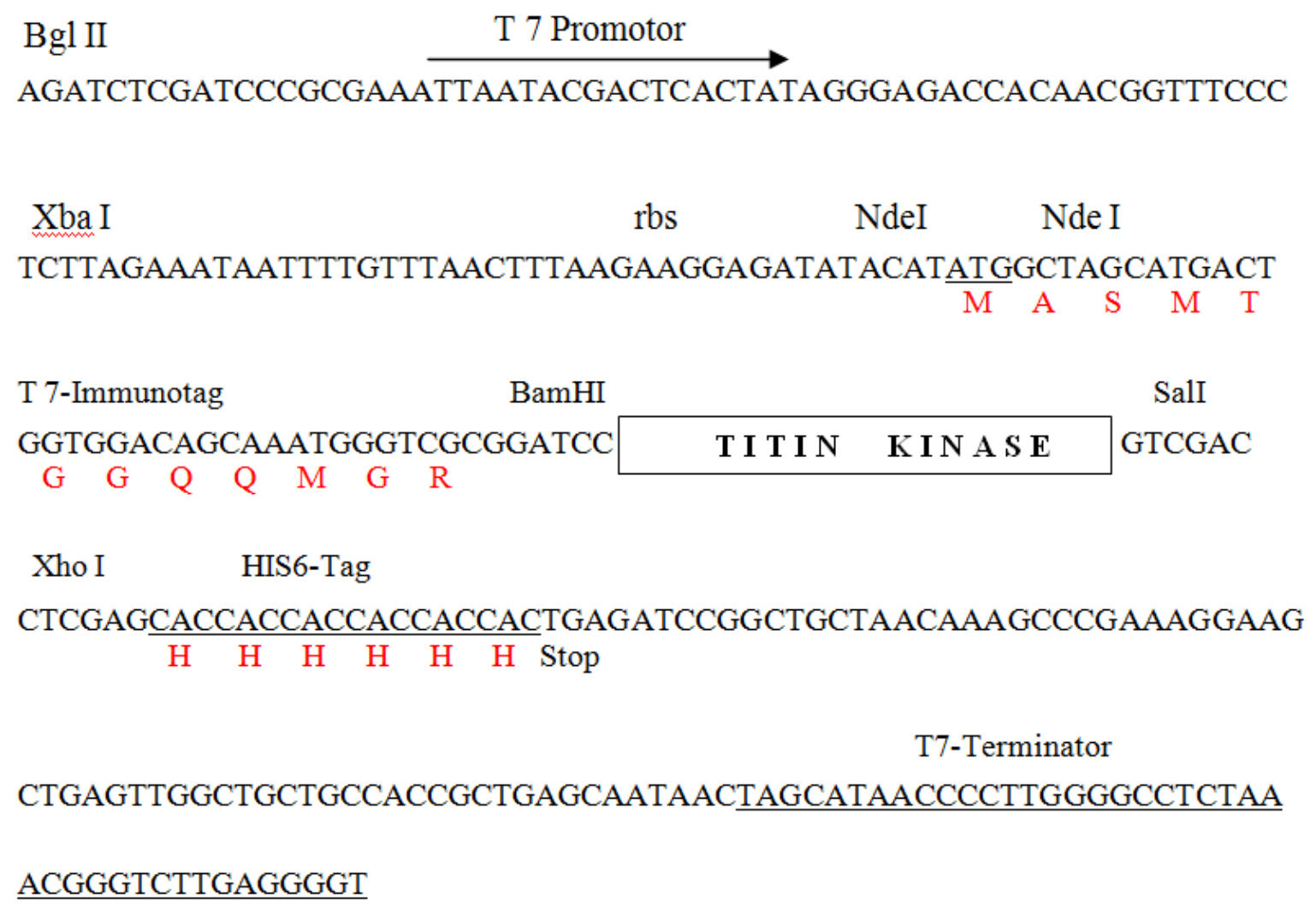




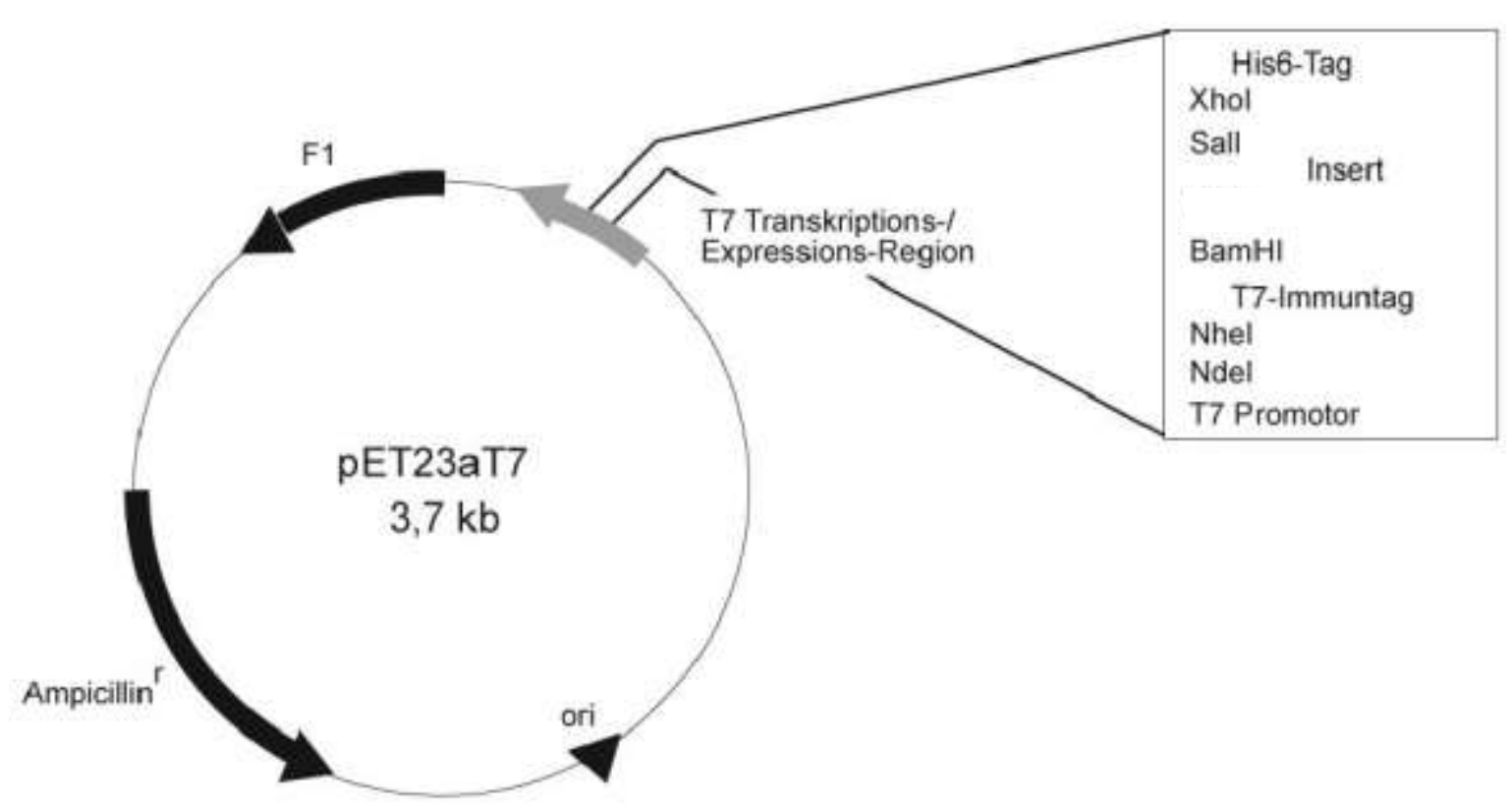

Figure 24: Vector map of pET23aT7 prokaryotic expression vector

pCMV5-T7 mammalian expression vector:

Size: $4.7 \mathrm{~kb}$

CMV promoter

T7-Immunotag

CV40 ori

Ampicillin resistance

F1 origin

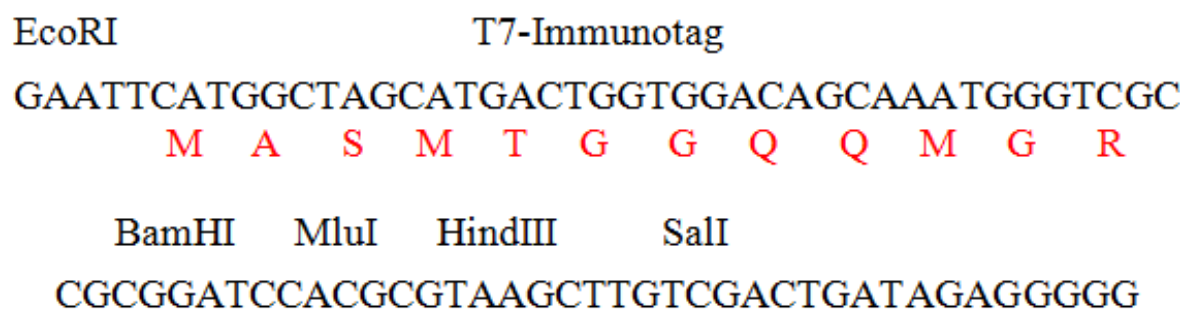




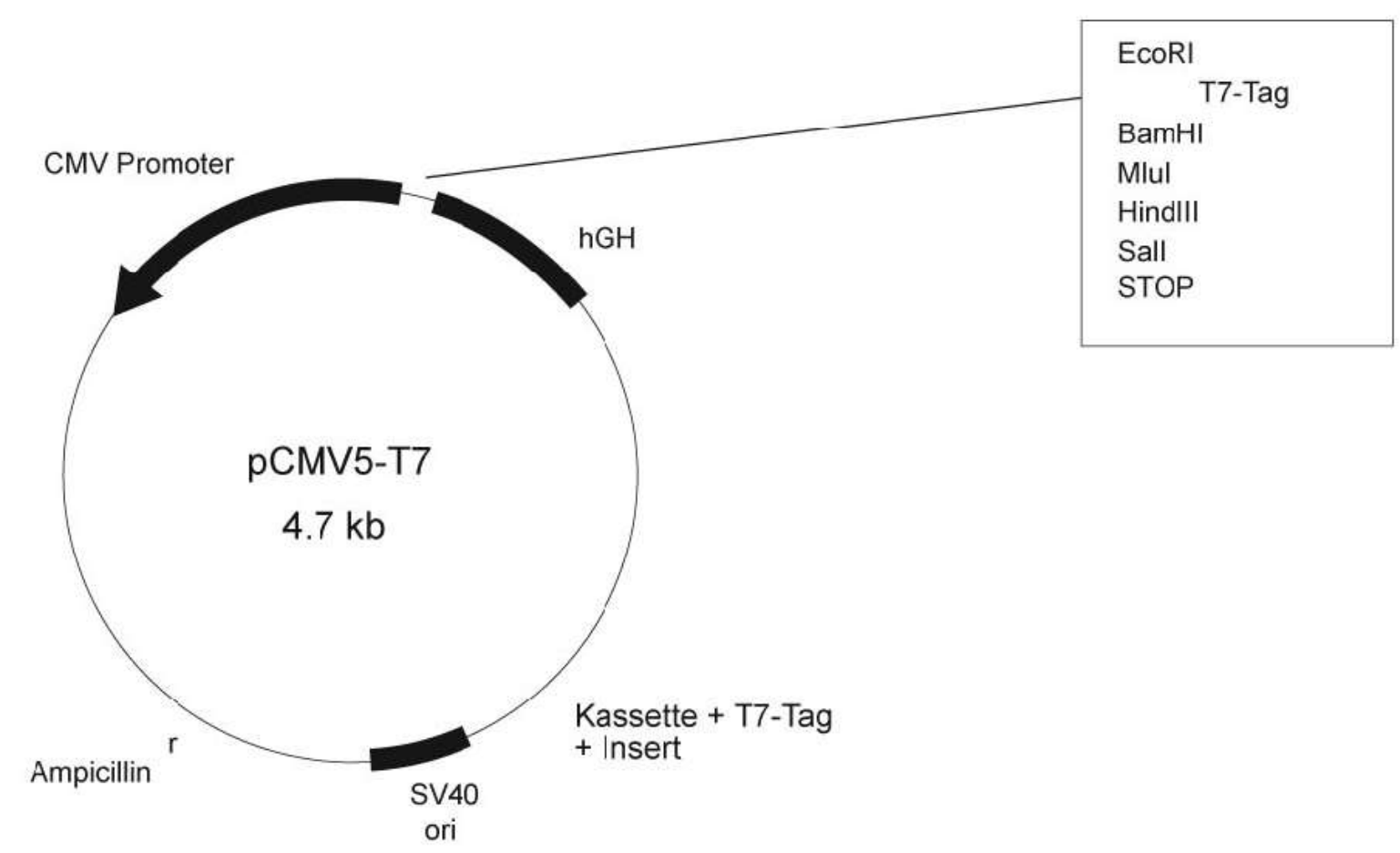

Figure 25: Vector map of pCMV5-T7 mammalian expression vector

\subsection{Appendix 3}

\section{Abbreviations}

$\mathrm{ADH}$

Ankrd2

ANP

APS

ARVD

AV

BLAST

BSA

CARP

Casq2

$\mathrm{Cdc} 42$

CK

CMV

$\mathrm{Cy} 3$
Alcohol dehydrogenase

Ankyrin-repeat domain protein-2

Atrial natriuretic peptide

Ammonium peroxo disulphate

Arrhythmogenic right ventricular dysplasia

Atrioventricular

Basic local alignment search tool

Bovine serum albumin

Cardiac ankyrin repeat protein

Calsequestrin 2

Cell division cycle 42

Creatine kinase

Cytomegalovirus

Cyanine dye 3 
DAPI 4',6-diamidino-2-phenylindole, dihydrochloride

DARP Diabetes-related ankyrin repeat protein

DCM Dilated cardiomyopathy

dd

Double distillated

DDO

Double dropout

DMEM

Dulbecco's modified Eagle medium

DMSO

Dimethylsulfoxide

DNA

Deoxyribonucleic acid

dNTP

Deoxyribonucleotide triphosphate

DTT

Dithiothreitol

ECG

Electrocardiography

ECL

Enhanced chemiluminescene

EDTA

Ethylenedinitrilotetraacetic acid

ERK

Extracellular signal-regulated protein kinase

ES cells

Embryonic stem cells

FAK

Focal adhesion kinase

FCS

Fetal calf serum

FHL1

Four and half LIM domain protein 1

FITC

Fluorescein

FITC

Fluorescein isothiocyanate

Fn III

Fibronectin type III

GAPDH

Glyceraldehyde 3-phosphate Dehydrogenase

GPCR

$G$ protein-coupled receptor

GST

Glutathione S-transferase

HCM

Hypertrophic cardiomyopathy

HDAC

Histone deacetylase

HMERF

Hereditary myopathy with early respiratory failure

HRP

Horseradish Peroxidase

IFM

Indirect flight muscles

$\mathrm{Ig}$

Immunoglobulin

ILK

Integrin-linked kinase

IPTG

Isopropyl- $\beta$-D-thiogalactoside

IPTG

Isopropyl-1-thio- $\beta$-D-galactopyranoside

LiAc

Lithium acetate

LV

Left ventricle

LVOT

Left ventricular outflow tract

MAP

Microtubule associated protein 
MAPK

MARP

MEK1/2

MLC

MLCK

MLP

MRF4

MuRF

MyoD

Nbr1

NCBI

NEAA

NFAT

NF-kB

OD

PAGE

PBS

PBST

PCR

PEG

$\mathrm{PINCH}$

PKC

PMSF

QDO

Rho

RLC

RNA

SDS

SOC

SRF

TAC

TAE

TDO

TE

TEMED

TXRD

UV
Mitogen-activated protein kinase

Muscle ankyrin repeat protein

Mitogen-activated protein kinase kinase 1/2

Myosin light chain

Myosin-light-chain kinase

Muscle LIM domain protein

Muscle-regulatory-factor-4

Muscle-specific RING finger protein

Myogenic-differentiation-antigen

Neighbor of BRCA1 gene 1

National center for biotechnology information

Non-essential amino acids

Nuclear-factor-of-activated-T-cells

Nuclear factor kB

Optical density

Polyacrylamide gel electrophoresis

Phosphate buffered saline

Phosphate buffered saline with Tween 20

Polymerase chain reaction

Polyethylene glycol

Particularly interesting new cysteine - histidine - rich protein

Protein kinase C

Phenylmethylsulfonylfluorid

Quadruple dropout

Rhodopsin

Regulatory light chain

Ribonucleic acid

Sodium dodecylsulfate

Super Optimal broth with Catabolite repression

Serum response factor

Trans-aortic constriction

Tris-acetate-EDTA

Triple dropout

Tris-EDTA

$\mathrm{N}, \mathrm{N}, \mathrm{N}$ ', N'-tetramethyl-ethylendiamine

Texas Red sulfonyl chloride

Ultraviolet 
VEGF

$\mathrm{X}-\mathrm{Gal}$

YPD

ZASP
Vascular endothelial growth factor

5-bromo-4-chloro-3-indolyl-[beta]-D-galactopyranosidecrystal

Yeast peptone dextrose

Z-band alternatively spliced PDZ motif 


\section{References}

Antin PB, Forry-Schaudies S, Friedman TM, Tapscott SJ, Holtzer H (1981): Taxol induces postmitotic myoblasts to assemble interdigitating microtubule-myosin arrays that exclude actin filaments. J Cell Biol 90, 300-308.

Aoki K, Osumi-Yamashita N, Ninomiya Y, Eto K (1995): Proteolysis and actin-binding properties of $10 \mathrm{~S}$ and $6 \mathrm{~S}$ smooth muscle myosin: identification of a site protected from proteolysis in the $10 \mathrm{~S}$ conformation and by the binding of actin. Biochemistry $\underline{25}, 6177-6185$.

Arber S, Hunter JJ, Ross J Jr, Hongo M, Sansig G, Borg J, Perriard JC, Chien KR, Caroni P (1997): MLP-deficient mice exhibit a disruption of cardiac cytoarchitectural organization, dilated cardiomyopathy, and heart failure. Cell $\underline{88}, 393-403$.

Au Y (2004): The muscle ultrastructure: a structural perspective. Cell Mol Life Sci 61, 30163033 .

Ayme-Southgate A, Vigoreaux J, Benian G, Pardue ML (1991): Drosophila has a twitchin/titin-related gene that appears to encode projectin. Proc Natl Acad Sci USA $\underline{88}$, 7973-7977.

Bachou T, Giannakopoulos A, Trapali C, Vazeou A, Kattamis A (2009): A novel mutation in the G4.5 (TAZ) gene in a Greek patient with Barth syndrome. Blood Cells Mol Dis $\underline{42}, 262-264$.

Bähler M, Wallimann T, Eppenberger HM (1985): Myofibrillar M-band proteins represent constituents of native thick filaments, frayed filaments and bare zone assemblages. J Muscle Res Cell Motil $\underline{6}, 783-800$.

Bang ML, Centner T, Fornoff F, Geach AJ, Gotthardt M, McNabb M, Witt CC, Labeit D, Gregorio CC, Granzier H et al. (2001): The complete gene sequence of titin, expression of an unusual approximately $700-\mathrm{kDa}$ titin isoform, and its interaction with obscurin identify a novel Z-line to I-band linking system. Circ Res $\underline{89}$, 1065-1072.

Bell SP, Nyland L, Tischler MD, McNabb M, Granzier H, LeWinter MM (2000): Alterations in the determinants of diastolic suction during pacing tachycardia. Circ Res $\underline{87}$, 235-240.

Benders AA, van Kuppevelt TH, Oosterhof A, Veerkamp JH (1991): The biochemical and structural maturation of human skeletal muscle cells in culture: the effect of the serum substitute Ultroser G. Exp. Cell Res 195, 284-294.

Bendig G, Grimmler M, Huttner IG, Wessels G, Dahme T, Just S, Trano N, Katus HA, Fishman MC, Rottbauer W (2006): Integrin-linked kinase, a novel component of the cardiac mechanical stretch sensor, controls contractility in the zebrafish heart. Genes Dev 20, 2361-2372.

Benian GM, Kiff JE, Neckelmann N, Moerman DG, Waterston RH (1989): Sequence of an unusually large protein implicated in regulation of myosin activity in C. elegans. Nature $\underline{342}, 45-50$.

Bienengraeber M, Olson TM, Selivanov VA, Kathmann EC, O'Cochlain F, Gao F, Karger AB, Ballew JD, Hodgson DM, Zingman LV et al. (2004): ABCC9 mutations identified in human dilated cardiomyopathy disrupt catalytic KATP channel gating. Nat Genet $\underline{36}, 382-387$. 
Bignon C, Daniel N, Djiane J (1993): Beta-galactosidase and chloramphenicol acetyltransferase assays in 96-well plates. Biotechniques 15, 243-246.

Blount P (2003): Molecular mechanisms of mechanosensation: big lessons from small cells. Neuron 37, 731-734.

Boyer HW, Roulland-Dussoix D (1969): A complementation analysis of the restriction and modification of DNA in Escherichia coli. J Mol Biol 41, 459-472.

Brancaccio M, Guazzone S, Menini N, Sibona E, Hirsch E, De Andrea M, Rocchi M, Altruda F, Tarone G, Silengo L (1999): Melusin is a new muscle-specific interactor for beta(1) integrin cytoplasmic domain. J Biol Chem 274, 29282-29288.

Brancaccio M, Fratta L, Notte A, Hirsch E, Poulet R, Guazzone S, De Acetis M, Vecchione C, Marino G, Altruda F et al. (2003): Melusin, a muscle-specific integrin beta1interacting protein, is required to prevent cardiac failure in response to chronic pressure overload. Nat Med $\underline{9}$, 68-75.

Brancaccio M, Hirsch E, Notte A, Selvetella G, Lembo G, Tarone G (2006): Integrin signalling: the tug-of-war in heart hypertrophy. Cardiovasc Res $\underline{70}, 422-433$.

Bullock WO, Fernandez JM und Short JM (1987): XL-1-blue: A high efficiency plasmid transforming recA E. coli strain with ß-galactosidase selection. Bio-Techniques $\underline{5}, 376$.

Carmignac V, Salih MA, Quijano-Roy S, Marchand S, Al Rayess MM, Mukhtar MM, Urtizberea JA, Labeit S, Guicheney P, Leturcq F et al. (2007): C-terminal titin deletions cause a novel early-onset myopathy with fatal cardiomyopathy. Ann Neurol 61, 340-351

Carniel E, Taylor MR, Sinagra G, Di Lenarda A, Ku L, Fain PR, Boucek MM, Cavanaugh J, Miocic S, Slavov D et al. (2005): Alpha-myosin heavy chain: a sarcomeric gene associated with dilated and hypertrophic phenotypes of cardiomyopathy. Circulation $\underline{112}, 54-59$.

Centner T, Yano J, Kimura E, McElhinny AS, Pelin K, Witt CC, Bang ML, Trombitas K, Granzier H, Gregorio CC et al. (2001): Identification of muscle specific ring finger proteins as potential regulators of the titin kinase domain. J Mol Biol 306, 717-726.

Champagne MB, Edwards KA, Erickson HP, Kiehart DP (2000): Drosophila stretchinMLCK is a novel member of the Titin/Myosin light chain kinase family. J Mol Biol $\underline{300,}$, 759777.

Chiang W, Greaser ML, Lyons GE (2000): Filamin isogene expression during mouse myogenesis. Dev Dyn 217, 99-108.

Clerk A, Sugden PH (1999): Activation of protein kinase cascades in the heart by hypertrophic G protein-coupled receptor agonists. Review. Am J Cardiol 푸, 64H-69H.

Collins JH (2006): Myoinformatics report: myosin regulatory light chain paralogs in the human genome. J Muscle Res Cell Motil 27, 69-74.

Craelius W, Chen V, el-Sherif N (1988): Stretch activated ion channels in ventricular myocytes. Biosci Rep $\underline{8}, 407-414$.

Daehmlow S, Erdmann J, Knueppel T, Gille C, Froemmel C, Hummel M, Hetzer R, Regitz-Zagrosek V (2002): Novel mutations in sarcomeric protein genes in dilated cardiomyopathy. Biochem Biophys Res Commun 298, 116-120.

Dehmelt L, Halpain S (2004): Actin and microtubules in neurite initiation: are MAPs the missing link? J Neurobiol $\underline{58}, 18-33$. 
Ding P, Huang J, Battiprolu PK, Hill JA, Kamm KE, Stull JT (2010): Cardiac myosin light chain kinase is necessary for myosin regulatory light chain phosphorylation and cardiac performance in vivo. J Biol Chem 285, 40819-40829.

Ehler E, Horowits R, Zuppinger C, Price RL, Perriard E, Leu M, Caroni P, Sussman M, Eppenberger HM, Perriard JC (2001): Alterations at the intercalated disk associated with the absence of muscle LIM protein. J Cell Biol $\underline{153}$, 763-772.

Ervasti JM (2003): Costameres: the Achilles' heel of Herculean muscle. J Biol Chem 278, 13591-13594.

Fatkin D, MacRae C, Sasaki T, Wolff MR, Porcu M, Frenneaux M, Atherton J, Vidaillet HJ Jr, Spudich S, De Girolami U et al. (1999): Missense mutations in the rod domain of the lamin A/C gene as causes of dilated cardiomyopathy and conduction-system disease. N Engl J Med 341, 1715-1724.

Feng J, Yan J, Buzin CH, Towbin JA, Sommer SS (2002): Mutations in the dystrophin gene are associated with sporadic dilated cardiomyopathy. Mol Genet Metab 그, 119-126.

Fields S, Song O (1989): A novel genetic system to detect protein-protein interactions. Nature $\underline{340}, 245-246$.

Freiburg A, Trombitas K, Hell W, Cazorla O, Fougerousse F, Centner T, Kolmerer B, Witt C, Beckmann JS, Gregorio CC et al. (2000): Series of exon-skipping events in the elastic spring region of titin as the structural basis for myofibrillar elastic diversity. Circ Res $\underline{86}, 1114$.

Fukuzawa A, Shimamura J, Takemori S, Kanzawa N, Yamaguchi M, Sun P, Maruyama K, Kimura S (2001): Invertebrate connectin spans as much as 3.5 microm in the giant sarcomeres of crayfish claw muscle. EMBO J 20, 4826-4835.

Fürst DO, Vinkemeier U, Weber K (1992): Mammalian skeletal muscle C-protein: purification from bovine muscle, binding to titin and the characterization of a full-length human cDNA. J Cell Sci 102, 769-778.

Fyrberg CC, Labeit S, Bullard B, Leonard K, Fyrberg E (1992): Drosophila projectin: relatedness to titin and twitchin and correlation with lethal(4) $102 \mathrm{CDa}$ and bent-dominant mutants. Proc Biol Sci 249, 33-40.

Gallagher PJ, Herring BP, Stull JT (1997): Myosin light chain kinases. J Muscle Res Cell Motil 18, 1-16.

Gao ZH, Zhi G, Herring BP, Moomaw C, Deogny L, Slaughter CA, Stull JT (1995): Photoaffinity labeling of a peptide substrate to myosin light chain kinase. J Biol Chem 270 , 10125-10135.

Gaussin V, Tomlinson JE, Depre C, Engelhardt S, Antos CL, Takagi G, Hein L, Topper JN, Liggett SB, Olson EN et al. (2003): Common genomic response in different mouse models of beta-adrenergic-induced cardiomyopathy. Circulation 108, 2926-2933.

Gautel M, Castiglione Morelli MA, Pfuhl M, Motta A, Pastore A (1995): A calmodulinbinding sequence in the C-terminus of human cardiac titin kinase. Eur J Biochem 230, 752759.

Gerull B, Gramlich M, Atherton J, McNabb M, Trombitás K, Sasse-Klaassen S, Seidman JG, Seidman C, Granzier H, Labeit S et al. (2002): Mutations of TTN, encoding the giant muscle filament titin, cause familial dilated cardiomyopathy. Nat Genet $\underline{30}, 201-204$. 
Gerull B, Atherton J, Geupel A, Sasse-Klaassen S, Heuser A, Frenneaux M, McNabb M, Granzier H, Labeit S, Thierfelder L (2006): Identification of a novel frameshift mutation in the giant muscle filament titin in a large Australian family with dilated cardiomyopathy. J Mol Med (Berl) $\underline{84}$, 478-483.

Gluzman Y (1981): SV40-transformed simian cells support the replication of early SV40 mutants. Cell $\underline{23}, 175-182$.

Goldfarb LG, Park KY, Cervenakova L, Gorokhova S, Lee HS, Vasconcelos O, Nagle JW, Semino-Mora C, Sivakumar K, Dalakas MC (1998): Missense mutations in desmin associated with familial cardiac and skeletal myopathy. Nat Genet $\underline{19}, 402-403$.

Goldstein MA, Entman ML (1979): Microtubules in mammalian heart muscle. J Cell Biol $\underline{80}, 183-195$.

Gotthardt M, Hammer RE, Hübner N, Monti J, Witt CC, McNabb M, Richardson JA, Granzier H, Labeit S, Herz J (2003): Conditional expression of mutant M-line titins results in cardiomyopathy with altered sarcomere structure. J Biol Chem $\underline{278}$, 6059-6065.

Gramlich M, Michely B, Krohne C, Heuser A, Erdmann B, Klaassen S, Hudson B, Magarin M, Kirchner F, Todiras M et al. (2009): Stress-induced dilated cardiomyopathy in a knock-in mouse model mimicking human titin-based disease. J Mol Cell Cardiol 47, 352358.

Granzier H, Labeit S (2007): Structure-function relations of the giant elastic protein titin in striated and smooth muscle cells. Muscle Nerve 36, 740-755.

Gräter F, Shen J, Jiang H, Gautel M, Grubmüller H (2005): Mechanically induced titin kinase activation studied by force-probe molecular dynamics simulations. Biophys $\mathrm{J} \underline{88}, 790$ 804.

Gregorio CC, Trombitás K, Centner T, Kolmerer B, Stier G, Kunke K, Suzuki K, Obermayr F, Herrmann B, Granzier H et al. (1998): The NH2 terminus of titin spans the Z-disc: its interaction with a novel $19-\mathrm{kD}$ ligand (T-cap) is required for sarcomeric integrity. $\mathbf{J}$ Cell Biol 143, 1013-1027.

Gregorio CC, Granzier H, Sorimachi H, Labeit S (1999): Muscle assembly: a titanic achievement? Curr Opin Cell Biol 11, 18-25.

Griendling KK, Lassègue B, Alexander RW (1996): Angiotensin receptors and their therapeutic implications. Annu Rev Pharmacol Toxicol 36, 281-306.

Guo JX, Jacobson SL, Brown DL (1986): Rearrangement of tubulin, actin, and myosin in cultured ventricular cardiomyocytes of the adult rat. Cell Motil Cytoskeleton $\underline{6}, 291-304$.

Hackman P, Vihola A, Haravuori H, Marchand S, Sarparanta J, De Seze J, Labeit S, Witt C, Peltonen L, Richard I et al. (2002): Tibial muscular dystrophy is a titinopathy caused by mutations in TTN, the gene encoding the giant skeletal-muscle protein titin. Am J Hum Genet 71, 492-500.

Hackman P, Marchand S, Sarparanta J, Vihola A, Pénisson-Besnier I, Eymard B, Pardal-Fernández JM, Hammouda el-H, Richard I, Illa I et al. (2008): Truncating mutations in C-terminal titin may cause more severe tibial muscular dystrophy (TMD). Neuromuscul Disord 18, 922-928.

Hakeda S, Endo S, Saigo K (2000): Requirements of Kettin, a giant muscle protein highly conserved in overall structure in evolution, for normal muscle function, viability, and flight activity of Drosophila. J Cell Biol $\underline{148}, 101-114$. 
Hall RA (2004): Studying protein-protein interactions via blot overlay or Far Western blot. Methods Mol Biol 261, 167-74.

Harper JW, Adami GR, Wei N, Keyomarsi K, Elledge SJ (1993): The p21 Cdk-interacting protein Cip1 is a potent inhibitor of G1 cyclin-dependent kinases. Cell $\underline{75}, 805-816$

Hayashi T, Arimura T, Itoh-Satoh M, Ueda K, Hohda S, Inagaki N, Takahashi M, Hori H, Yasunami M, Nishi H et al. (2004): Tcap gene mutations in hypertrophic cardiomyopathy and dilated cardiomyopathy. J Am Coll Cardiol 44, 2192-2201.

Heierhorst J, Probst WC, Kohanski RA, Buku A, Weiss KR (1995): Phosphorylation of myosin regulatory light chains by the molluscan twitchin kinase. Eur J Biochem 233, 426431.

Heineke J, Molkentin JD (2006): Regulation of cardiac hypertrophy by intracellular signalling pathways. Nat Rev Mol Cell Biol 7, 589-600.

Heineke J, Ruetten H, Willenbockel C, Gross SC, Naguib M, Schaefer A, Kempf T, Hilfiker-Kleiner D, Caroni P, Kraft T et al. (2005): Attenuation of cardiac remodeling after myocardial infarction by muscle LIM protein-calcineurin signaling at the sarcomeric Zdisc. Proc Natl Acad Sci USA 102, 1655-1660.

Hu E, Lee D (2003): Rho kinase inhibitors as potential therapeutic agents for cardiovascular diseases. Curr Opin Investig Drugs $\underline{4}, 1065-1075$.

Hu H, Sachs F (1996): Mechanically activated currents in chick heart cells. J Membr Biol $\underline{154}, 205-216$.

Hughes SE, McKenna WJ (2005): New insights into the pathology of inherited

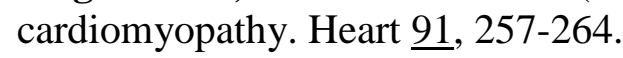

Ikebe M, Hartshorne DJ (1986): Proteolysis and actin-binding properties of 10S and 6S smooth muscle myosin: identification of a site protected from proteolysis in the $10 \mathrm{~S}$ conformation and by the binding of actin. Biochemistry $\underline{25}, 6177-6185$.

Inagaki N, Hayashi T, Arimura T, Koga Y, Takahashi M, Shibata H, Teraoka K, Chikamori T, Yamashina A, Kimura A (2006): Alpha B-crystallin mutation in dilated cardiomyopathy. Biochem Biophys Res Commun 342, 379-386.

Ito H, Hiroe M, Hirata Y, Fujisaki H, Adachi S, Akimoto H, Ohta Y, Marumo F (1994): Endothelin ETA receptor antagonist blocks cardiac hypertrophy provoked by hemodynamic overload. Circulation $\underline{89}$, 2198-2203.

Itoh-Satoh M, Hayashi T, Nishi H, Koga Y, Arimura T, Koyanagi T, Takahashi M, Hohda S, Ueda K, Nouchi T et al. (2002): Titin mutations as the molecular basis for dilated cardiomyopathy. Biochem Biophys Res Commun 291, 385-393.

Jeyaseelan R, Poizat C, Baker RK, Abdishoo S, Isterabadi LB, Lyons GE, Kedes L (1997): A novel cardiac-restricted target for doxorubicin. CARP, a nuclear modulator of gene expression in cardiac progenitor cells and cardiomyocytes. J Biol Chem $\underline{272}$, 22800-22802.

Jia N, Okamoto H, Shimizu T, Chiba S, Matsui Y, Sugawara T, Akino M, Kitabatake A (2003): A newly developed angiotensin II type 1 receptor antagonist, CS866, promotes regression of cardiac hypertrophy by reducing integrin beta1 expression. Hypertens Res $\underline{26}$, 737-742.

Kamisago M, Sharma SD, DePalma SR, Solomon S, Sharma P, McDonough B, Smoot L, Mullen MP, Woolf PK, Wigle ED et al. (2000): Mutations in sarcomere protein genes as a cause of dilated cardiomyopathy. N Engl J Med $\underline{343}, 1688-1696$. 
Kamm KE, Stull JT (2001): Dedicated myosin light chain kinases with diverse cellular functions. J Biol Chem 276, 4527-4530.

Kawamura S, Miyamoto S, Brown JH (2003): Initiation and transduction of stretch-induced RhoA and Rac1 activation through caveolae: cytoskeletal regulation of ERK translocation. J Biol Chem 278, 31111-31117.

Kärkkäinen S, Miettinen R, Tuomainen P, Kärkkäinen P, Heliö T, Reissell E, Kaartinen M, Toivonen L, Nieminen MS, Kuusisto J et al. (2003): A novel mutation, Arg71Thr, in the delta-sarcoglycan gene is associated with dilated cardiomyopathy. J Mol Med. $\underline{81}, 795-800$.

Kärkkäinen S, Heliö T, Jääskeläinen P, Miettinen R, Tuomainen P, Ylitalo K, Kaartinen M, Reissell E, Toivonen L, Nieminen MS et al. (2004): Two novel mutations in the betamyosin heavy chain gene associated with dilated cardiomyopathy. Eur J Heart Fail $\underline{6}, 861$ 868.

Kim D (1992): A mechanosensitive $\mathrm{K}^{+}$channel in heart cells. Activation by arachidonic acid. J Gen Physiol 100, 10221-10240.

Kinbara K, Sorimachi H, Ishiura S, Suzuki K (1997): Muscle-specific calpain, p94, interacts with the extreme C-terminal region of connectin, a unique region flanked by two immunoglobulin C2 motifs. Arch Biochem Biophys 년, 99-107.

Knöll R, Hoshijima M, Hoffman HM, Person V, Lorenzen-Schmidt I, Bang ML, Hayashi T, Shiga N, Yasukawa H, Schaper W et al. (2002): The cardiac mechanical stretch sensor machinery involves a $\mathrm{Z}$ disc complex that is defective in a subset of human dilated cardiomyopathy. Cell $\underline{111}, 943-955$.

Knöll R, Postel R, Wang J, Krätzner R, Hennecke G, Vacaru AM, Vakeel P, Schubert C, Murthy K, Rana BK et al. (2007): Laminin-alpha4 and integrin-linked kinase mutations cause human cardiomyopathy via simultaneous defects in cardiomyocytes and endothelial cells. Circulation 116, 515-525.

Knöll R, Kostin S, Klede S, Savvatis K, Klinge L, Stehle I, Gunkel S, Kötter S, Babicz K, Sohns M et al. (2010): A common MLP (muscle LIM protein) variant is associated with cardiomyopathy. Circ Res 106, 695-704.

Kobayashi T, Solaro RJ (2005): Calcium, thin filaments, and the integrative biology of cardiac contractility. Annu Rev Physiol 67, 39-67.

Kobe B, Heierhorst J, Feil SC, Parker MW, Benian GM, Weiss KR, Kemp BE (1996): Giant protein kinases: domain interactions and structural basis of autoregulation. EMBO J $\underline{15}$, 6810-6821.

Kolmerer B, Olivieri N, Witt CC, Herrmann BG, Labeit S (1996): Genomic organization of $\mathrm{M}$ line titin and its tissue-specific expression in two distinct isoforms. J Mol Biol 256, 556563.

Kolmerer B, Clayton J, Benes V, Allen T, Ferguson C, Leonard K, Weber U, Knekt M, Ansorge W, Labeit S et al. (2000): Sequence and expression of the kettin gene in Drosophila melanogaster and Caenorhabditis elegans. J Mol Biol 296, 435-448.

Kong Y, Flick MJ, Kudla AJ, Konieczny SF (1997): Muscle LIM protein promotes myogenesis by enhancing the activity of MyoD. Mol Cell Biol 17, 4750-4760.

Kong Y, Shelton JM, Rothermel B, Li X, Richardson JA, Bassel-Duby R, Williams RS (2001): Cardiac-specific LIM protein FHL2 modifies the hypertrophic response to betaadrenergic stimulation. Circulation 103, 2731-2738. 
Kontrogianni-Konstantopoulos A, Catino DH, Strong JC, Bloch RJ (2006): De novo myofibrillogenesis in $\mathrm{C} 2 \mathrm{C} 12$ cells: evidence for the independent assembly of $\mathrm{M}$ bands and $\mathrm{Z}$ disks. Am J Physiol Cell Physiol 290, C626-C637.

Koretz JF, Irving TC, Wang K (1993): Filamentous aggregates of native titin and binding of C-protein and AMP-deaminase. Arch Biochem Biophys 304, 305-309.

Kuppuswamy D, Kerr C, Narishige T, Kasi VS, Menick DR, Cooper G 4th (1997): Association of tyrosine-phosphorylated c-Src with the cytoskeleton of hypertrophying myocardium. J Biol Chem 272, 4500-4508.

Kutschera W, Zauner W, Wiche G, Propst F (1998): The mouse and rat MAP1B genes: genomic organization and alternative transcription. Genomics $\underline{49}$, 430-436.

Labeit S, Kolmerer B (1995): Titins: giant proteins in charge of muscle ultrastructure and elasticity. 270, 293-296.

Labeit S, Barlow DP, Gautel M, Gibson T, Holt J, Hsieh CL, Francke U, Leonard K, Wardale J, Whiting A et al. (1990): A regular pattern of two types of 100-residue motif in the sequence of titin. Nature $\underline{345}, 273-276$.

Labeit S, Gautel M, Lakey A, Trinick J (1992): Towards a molecular understanding of titin. EMBO J $\underline{11}, 1711-1716$.

Labeit S, Lahmers S, Burkart CH, Fong C, McNabb M, Witt S, Witt CH, Labeit D, and Granzier H (2006): Expression of Distinct Classes of Titin Isoforms in Striated and Smooth Muscles by Alternative Splicing, and Their Conserved Interaction with Filamins. Journal of Molecular Biology $\underline{362}$, 664-681.

Laemmli UK (1970): Cleavage of structural proteins during the assembly of the head of bacteriophage T4. Nature 227, 680-685.

Lakey A, Labeit S, Gautel M, Ferguson C, Barlow DP, Leonard K, Bullard B (1993): Kettin, a large modular protein in the Z-disc of insect muscles. EMBO J 12, 2863-2671.

Lal H, Verma SK, Smith M, Guleria RS, Lu G, Foster DM, Dostal DE (2007): Stretchinduced MAP kinase activation in cardiac myocytes: differential regulation through beta1integrin and focal adhesion kinase. J Mol Cell Cardiol 43, 137-147.

Lange S, Auerbach D, McLoughlin P, Perriard E, Schäfer BW, Perriard JC, Ehler E (2002): Subcellular targeting of metabolic enzymes to titin in heart muscle may be mediated by DRAL/FHL-2. J Cell Sci 115, 4925-4936.

Lange S, Xiang F, Yakovenko A, Vihola A, Hackman P, Rostkova E (2005): The kinase domain of titin controls muscle gene expression and protein turnover. Science $\underline{308}$, 15991603.

Li D, Tapscott T, Gonzalez O, Burch PE, Quinones M, Zoghbi WA, Hill R, Bashinski LL, Mann DL, Roberts R (1999): A desmin mutation responsible for idiopathic dilated cardiomyopathy. Circulation $\underline{100}, 461-464$.

Li D, Czernuszewicz GZ, Gonzalez O, Tapscott T, Karibe A, Durand JB, Brugada R, Hill R, Gregoritch JM, Anderson JL et al. (2001): Novel cardiac troponin T mutation as a cause of familial dilated cardiomyopathy. Circulation 104, 2188-2193.

Li Z, Colucci-Guyon E, Pinçon-Raymond M, Mericskay M, Pournin S, Paulin D, Babinet C (1996): Cardiovascular lesions and skeletal myopathy in mice lacking desmin. Dev Biol 175, 362-366. 
Linke WA (2008): Sense and stretchability: the role of titin and titin-associated proteins in myocardial stress-sensing and mechanical dysfunction. Cardiovasc Res $\underline{77}$, 637-648.

Loo DT, Kanner SB, Aruffo A (1998): Filamin binds to the cytoplasmic domain of the beta1-integrin. Identification of amino acids responsible for this interaction. J Biol Chem $\underline{273}$, 23304-23312.

Lu H, Fedak PW, Dai X, Du C, Zhou YQ, Henkelman M, Mongroo PS, Lau A, Yamabi H, Hinek A et al. (2006): Integrin-linked kinase expression is elevated in human cardiac hypertrophy and induces hypertrophy in transgenic mice. Circulation 114, 2271-2279.

Lu S, Carroll SL, Herrera AH, Ozanne B, Horowits R (2003): New N-RAP-binding partners alpha-actinin, filamin and Krp1 detected by yeast two-hybrid screening: implications for myofibril assembly. J Cell Sci 116, 2169-2178.

Luk A, Ahn E, Soor GS, Butany J (2009): Dilated cardiomyopathy: a review. J Clin Pathol $\underline{62}, 219-225$.

Machado C, Andrew DJ (2000): D-Titin: a giant protein with dual roles in chromosomes and muscles. J Cell Biol 151, 639-652.

Maestrini E, Patrosso C, Mancini M, Rivella S, Rocchi M, Repetto M, Villa A, Frattini A, Zoppè M, Vezzoni $\mathbf{P}$ et al. (1993): Mapping of two genes encoding isoforms of the actin binding protein ABP-280, a dystrophin like protein, to Xq28 and to chromosome 7 . Hum Mol Genet 2 , 761-766.

Mansfield SG, Diaz-Nido J, Gordon-Weeks PR, Avila J (1991): The distribution and phosphorylation of the microtubule-associated protein MAP 1B in growth cones. J Neurocytol $\underline{20}, 1007-1022$.

Maron BJ, Towbin JA, Thiene G, Antzelevitch C, Corrado D, Arnett D, Moss AJ, Seidman CE, Young JB et al. (2006): Contemporary definitions and classification of the cardiomyopathies: an American Heart Association Scientific Statement from the Council on Clinical Cardiology, Heart Failure and Transplantation Committee; Quality of Care and Outcomes Research and Functional Genomics and Translational Biology Interdisciplinary Working Groups; and Council on Epidemiology and Prevention. Circulation 113, 1807-1816.

Maruyama K, Yoshioka T, Higuchi H, Ohashi K, Kimura S, Natori R (1985): Connectin filaments link thick filaments and $\mathrm{Z}$ lines in frog skeletal muscle as revealed by immunoelectron microscopy. J Cell Biol 101, 2167-2172.

Matsuda N, Hagiwara N, Shoda M, Kasanuki H, Hosoda S (1996): Enhancement of the Ltype $\mathrm{Ca} 2+$ current by mechanical stimulation in single rabbit cardiac myocytes. Circ Res 78 , 650-659.

Matsumoto Y, Hayashi T, Inagaki N, Takahashi M, Hiroi S, Nakamura T, Arimura T, Nakamura K, Ashizawa N, Yasunami $M$ et al. (2005): Functional analysis of titin/connectin N2-B mutations found in cardiomyopathy. J Muscle Res Cell Motil 26, 367374.

Mayans O, van der Ven PF, Wilm M, Mues A, Young P, Fürst DO, Wilmanns M, Gautel M (1998): Structural basis for activation of the titin kinase domain during myofibrillogenesis. Nature 395, 863-869.

McElhinny AS, Kakinuma K, Sorimachi H, Labeit S, Gregorio CC (2002): Musclespecific RING finger-1 interacts with titin to regulate sarcomeric M-line and thick filament structure and may have nuclear functions via its interaction with glucocorticoid modulatory element binding protein-1. J Cell Biol 157, 125-136. 
Miller JH: Experiments in Molecular Genetics. Cold Spring Harbor Laboratory Press, New York 1972.

Miller G, Musa H, Gautel M, Peckham M (2003): A targeted deletion of the C-terminal end of titin, including the titin kinase domain, impairs myofibrillogenesis. J Cell Sci 116, 48114819.

Miller MK, Bang ML, Witt CC, Labeit D, Trombitas C, Watanabe K, Granzier H, McElhinny AS, Gregorio CC, Labeit S (2003): The muscle ankyrin repeat proteins: CARP, ankrd2/Arpp and DARP as a family of titin filament-based stress response molecules. J Mol Biol 333, 951-964.

Mitra SK, Hanson DA, Schlaepfer DD (2005): Focal adhesion kinase: in command and control of cell motility. Nat Rev Mol Cell Biol $\underline{6}, 56-68$.

Mogensen J, Murphy RT, Shaw T, Bahl A, Redwood C, Watkins H, Burke M, Elliott PM, McKenna WJ (2004): Severe disease expression of cardiac troponin C and T mutations in patients with idiopathic dilated cardiomyopathy. J Am Coll Cardiol 44, 2041-2043.

Mohapatra B, Jimenez S, Lin JH, Bowles KR, Coveler KJ, Marx JG, Chrisco MA, Murphy RT, Lurie PR, Schwartz RJ et al. (2003): Mutations in the muscle LIM protein and alpha-actinin-2 genes in dilated cardiomyopathy and endocardial fibroelastosis. Mol Genet Metab $\underline{80}, 207-215$.

Muntoni F, Ferlini A, Sewry C, Mateddu A, Marrosu G, Porcu M, Di Lenarda A, Sinagra G, Mestroni L (1999): Dilated cardiomyopathy and muscular dystrophies: which lesson can be learned? Cardiologia 44, 209-211.

Murphy RT, Mogensen J, Shaw A, Kubo T, Hughes S, McKenna WJ (2004): Novel mutation in cardiac troponin I in recessive idiopathic dilated cardiomyopathy. Lancet $\underline{363}$, 371-372.

Nagueh SF, Shah G, Wu Y, Torre-Amione G, King NM, Lahmers S, Witt CC, Becker K, Labeit S, Granzier HL (2004): Altered titin expression, myocardial stiffness, and left ventricular function in patients with dilated cardiomyopathy. Circulation $\underline{110}, 155-162$.

Nave R, Fürst DO, Weber K (1989): Visualization of the polarity of isolated titin molecules: a single globular head on a long thin rod as the M band anchoring domain? J Cell Biol 109, 2177-2187.

Noiges R, Eichinger R, Kutschera W, Fischer I, Nemeth Z, Wiche G, Propst F (2002): Microtubule-Associated Protein 1A (MAP1A) and MAP1B: Light Chains Determine Distinct Functional Properties. J Neurosci 22, 2106-2114.

Obermann WM, Gautel M, Steiner F, van der Ven PF, Weber K, Fürst DO (1996): The structure of the sarcomeric $\mathrm{M}$ band: localization of defined domains of myomesin, M-protein, and the $250-\mathrm{kD}$ carboxy-terminal region of titin by immunoelectron microscopy. J Cell Biol 134, 1441-1453.

Obermann WM, Gautel M, Weber K, Fürst DO (1997): Molecular structure of the sarcomeric $\mathrm{M}$ band: mapping of titin and myosin binding domains in myomesin and the identification of a potential regulatory phosphorylation site in myomesin. EMBO J $\underline{16}, 211$ 220.

Obermann WM, van der Ven PF, Steiner F, Weber K, Fürst DO (1998): Mapping of a myosin-binding domain and a regulatory phosphorylation site in M-protein, a structural protein of the sarcomeric M band. Mol Biol Cell $\underline{9}, 829-840$ 
Olson TM, Michels VV, Thibodeau SN, Tai YS, Keating MT (1998): Actin mutations in dilated cardiomyopathy, a heritable form of heart failure. Science 280, 750-752.

Olson TM, Illenberger S, Kishimoto NY, Huttelmaier S, Keating MT, Jockusch BM (2002): Metavinculin mutations alter actin interaction in dilated cardiomyopathy. Circulation $\underline{105}, 431-437$.

Olson TM, Michels VV, Ballew JD, Reyna SP, Karst ML, Herron KJ, Horton SC, Rodeheffer RJ, Anderson JL (2005): Sodium channel mutations and susceptibility to heart failure and atrial fibrillation. JAMA 293 , 447-454.

Osterziel KJ, Hassfeld S, Geier C, Perrot A (2005): Familiäre dilatative Kardiomyopathie. Herz $\underline{30}$, 529-534.

Pan J, Singh US, Takahashi T, Oka Y, Palm-Leis A, Herbelin BS, Baker KM (2005): PKC mediates cyclic stretch-induced cardiac hypertrophy through Rho family GTPases and mitogen-activated protein kinases in cardiomyocytes. J Cell Physiol 202, 536-553.

Pankiv S, Clausen TH, Lamark T, Brech A, Bruun JA, Outzen H, Øvervatn A, Bjørkøy G, Johansen T (2007): p62/SQSTM1 binds directly to Atg8/LC3 to facilitate degradation of ubiquitinated protein aggregates by autophagy. J Biol Chem 282, 24131-24145.

Pedrotti B, Ulloa L, Avila J, Islam K (1996): Characterization of microtubule-associated protein MAP1B: phosphorylation state, light chains, and binding to microtubules. Biochemistry $\underline{35}, 3016-3023$.

Peng J, Raddatz K, Molkentin JD, Wu Y, Labeit S, Granzier H, Gotthardt M (2007): Cardiac hypertrophy and reduced contractility in hearts deficient in the titin kinase region. Circulation $\underline{115}$, 743-751.

Person V, Kostin S, Suzuki K, Labeit S, Schaper J (2000): Antisense oligonucleotide experiments elucidate the essential role of titin in sarcomerogenesis in adult rat cardiomyocytes in long-term culture. J Cell Sci 113, 3851-3859.

Pfaff M, Liu S, Erle DJ, Ginsberg MH (1998): Integrin beta cytoplasmic domains differentially bind to cytoskeletal proteins. J Biol Chem $\underline{273}$, 610-619.

Pham CG, Harpf AE, Keller RS, Vu HT, Shai SY, Loftus JC, Ross RS (2000): Striated muscle-specific beta(1D)-integrin and FAK are involved in cardiac myocyte hypertrophic response pathway. Am J Physiol Heart Circ Physiol 279, H2916-H2926.

Pizon V, Iakovenko A, Van Der Ven PF, Kelly R, Fatu C, Fürst DO, Karsenti E, Gautel M (2002): Transient association of titin and myosin with microtubules in nascent myofibrils directed by the MURF2 RING-finger protein. J Cell Sci 115, 4469-4482.

Postel R, Vakeel P, Topczewski J, Knöll R, Bakkers J (2008): Zebrafish integrin-linked kinase is required in skeletal muscles for strengthening the integrin-ECM adhesion complex. Dev Biol 318, 92-101.

Rai TS, Ahmad S, Bahl A, Ahuja M, Ahluwalia TS, Singh B, Talwar KK, Khullar M (2009): Genotype phenotype correlations of cardiac beta-myosin heavy chain mutations in Indian patients with hypertrophic and dilated cardiomyopathy. Mol Cell Biochem $\underline{321}$, 18996.

Rajan S, Ahmed RP, Jagatheesan G, Petrashevskaya N, Boivin GP, Urboniene D, Arteaga GM, Wolska BM, Solaro RJ, Liggett SB et al. (2007): Dilated cardiomyopathy mutant tropomyosin mice develop cardiac dysfunction with significantly decreased fractional shortening and myofilament calcium sensitivity. Circ Res 101, 205-214. 
Rappaport L, Samuel JL, Bertier B, Bugaisky L, Marotte F, Mercadier A, Schwartz K (1984): Isomyosins, microtubules and desmin during the onset of cardiac hypertrophy in the rat. Eur Heart J $\underline{5}, 243-250$.

Rappaport L, Samuel JL, Bertier-Savalle B, Marotte F, Schwartz K (1985): Microtubules and desmin filaments during the onset of heart growth in the rat. Basic Res Cardiol $\underline{\text { 80, }}$ 129132 .

Rayment I (1996): The structural basis of the myosin ATPase activity. J Biol Chem 271, 15850-15853.

Ren J, Fang CX (2005): Small guanine nucleotide-binding protein Rho and myocardial function. Acta Pharmacol Sin 26, 279-258.

Richard I, Broux O, Allamand V, Fougerousse F, Chiannilkulchai N, Bourg N, Brenguier L, Devaud C, Pasturaud P, Roudaut C et al. (1995): Mutations in the proteolytic enzyme calpain 3 cause limb-girdle muscular dystrophy type 2A. Cell $\underline{81}, 27-40$.

Riederer BM (2007): Microtubule-associated protein 1B, a growth-associated and phosphorylated scaffold protein. Brain Res Bull 71, 541-558.

Rothen-Rutishauser BM, Ehler E, Perriard E, Messerli JM, Perriard JC (1998): Different behaviour of the non-sarcomeric cytoskeleton in neonatal and adult rat cardiomyocytes. J Mol Cell Cardiol 30, 19-31.

Rottbauer W, Wessels G, Dahme T, Just S, Trano N, Hassel D, Burns CG, Katus HA, Fishman MC (2006): Cardiac myosin light chain-2: a novel essential component of thickmyofilament assembly and contractility of the heart. Circ Res 99, 323-331.

Ruknudin A, Sachs F, Bustamante JO (1993): Stretch-activated ion channels in tissuecultured chick heart. Am J Physiol 264, H960-H972.

Ryder JW, Lau KS, Kamm KE, Stull JT (2007): Enhanced skeletal muscle contraction with myosin light chain phosphorylation by a calmodulin-sensing kinase. J Biol Chem $\underline{282}$, 20447-20454.

Sachs F, Sokabe M (1990): Stretch-activated ion channels and membrane mechanics. Neurosci Res Suppl 12, 1-4.

Sadoshima J, Xu Y, Slayter HS, Izumo S (1993): Autocrine release of angiotensin II mediates stretch-induced hypertrophy of cardiac myocytes in vitro. Cell $\underline{75}, 977-984$.

Saitoh O, Arai T, Obinata T (1988): Distribution of microtubules and other cytoskeletal filaments during myotube elongation as revealed by fluorescence microscopy. Cell Tissue $\underline{252}, 263-273$.

Sakamoto O, Kitoh T, Ohura T, Ohya N, Iinuma K (2002): Novel missense mutation (R94S) in the TAZ ( G4.5) gene in a Japanese patient with Barth syndrome. J Hum Genet 4 , 229-231.

Salazar NC, Chen J, Rockman HA (2007): Cardiac GPCRs: GPCR signaling in healthy and failing hearts. Biochim Biophys Acta 1768, 1006-1018.

Samarel AM (2005): Costameres, focal adhesions, and cardiomyocyte mechanotransduction. J Physiol Heart Circ Physiol 289, H2291-H2301.

Samuel JL, Bertier B, Bugaisky L, Marotte F, Swynghedauw B, Schwartz K, Rappaport L (1984): Different distributions of microtubules, desmin filaments and isomyosins during the onset of cardiac hypertrophy in the rat. Eur J Cell Biol 34, 300-306. 
Sanbe A, Fewell JG, Gulick J, Osinska H, Lorenz J, Hall DG, Murray LA, Kimball TR, Witt SA, Robbins J (1999): Abnormal Cardiac Structure and Function in Mice Expressing Nonphosphorylatable Cardiac Regulatory Myosin Light Chain 2. J Biol Chem 274, 2108521094.

Sanger F, Nicklen S, Coulson AR (1992): DNA sequencing with chain-terminating inhibitors. 1977. Biotechnology 24, 104-108.

Sanger JW, Sanger JM (2001): Fishing out proteins that bind to titin. J Cell Biol 154, 123136.

Satoh M, Takahashi M, Sakamoto T, Hiroe M, Marumo F, Kimura A (1999): Structural analysis of the titin gene in hypertrophic cardiomyopathy: identification of a novel disease gene. Biochem Biophys Res Commun 262, 411-417.

Sato-Yoshitake R, Shiomura Y, Miyasaka H, Hirokawa N (1989): Microtubule-associated protein 1B: molecular structure, localization, and phosphorylation-dependent expression in developing neurons. Neuron $\underline{3}, 229-238$

Schmitt JP, Kamisago M, Asahi M, Li GH, Ahmad F, Mende U, Kranias EG, MacLennan DH, Seidman JG, Seidman CE (2003): Dilated cardiomyopathy and heart failure caused by a mutation in phospholamban. Science 299, 1410-1403.

Schmitt JP, Debold EP, Ahmad F, Armstrong A, Frederico A, Conner DA, Mende U, Lohse MJ, Warshaw D, Seidman CE et al. (2006): Cardiac myosin missense mutations cause dilated cardiomyopathy in mouse models and depress molecular motor function. Proc Natl Acad Sci USA $\underline{103}$, 14525-14530.

Schneider S, Buchert M, Hovens CM (1996): An in vitro assay of beta-galactosidase from yeast. Biotechniques 20, 960-962.

Seidman JG, Seidman C (2001): The genetic basis for cardiomyopathy: from mutation identification to mechanistic paradigms. Cell 104, 557-567.

Sharma CP, Ezzell RM, Arnaout MA (1995): Direct interaction of filamin (ABP-280) with the beta 2-integrin subunit CD18. J Immunol 154, 3461-3470.

Sheikh F, Raskin A, Chu PH, Lange S, Domenighetti AA, Zheng M, Liang X, Zhang T, Yajima T, Gu Y et al. (2008): An FHL1-containing complex within the cardiomyocyte sarcomere mediates hypertrophic biomechanical stress responses in mice. J Clin Invest $\underline{118}$, 3870-3880.

Shi R, Zhang Y, Yang C, Huang C, Zhou X, Qiang H, Grace AA, Huang CL, Ma A (2008): The cardiac sodium channel mutation delQKP 1507-1509 is associated with the expanding phenotypic spectrum of LQT3, conduction disorder, dilated cardiomyopathy, and high incidence of youth sudden death. Europace 10, 1329-1335.

Sigurdson W, Ruknudin A, Sachs F (1992): Calcium imaging of mechanically induced fluxes in tissue-cultured chick heart: role of stretch-activated ion channels. Am J Physiol 262, H1110-H1115.

Sorota S, Siegal MS, Hoffman BF (1991): The isoproterenol-induced chloride current and cardiac resting potential. J Mol Cell Cardiol 23, 1191-1198.

Spencer JA, Eliazer S, Ilaria RL Jr, Richardson JA, Olson EN (2000): Regulation of microtubule dynamics and myogenic differentiation by MURF, a striated muscle RING-finger protein. J Cell Biol 150, 771-784. 
Stahlhut M, van Deurs B (2000): Identification of filamin as a novel ligand for caveolin-1: evidence for the organization of caveolin-1-associated membrane domains by the actin cytoskeleton. Mol Biol Cell 11, 325-337.

Studier FW, Rosenberg AH, Dunn JJ, Dubendorff JW (1990): Use of T7 RNA polymerase to direct expression of cloned genes. Methods Enzymol 185, 60-89.

Suomalainen A, Paetau A, Leinonen H, Majander A, Peltonen L, Somer H (1992): Inherited idiopathic dilated cardiomyopathy with multiple deletions of mitochondrial DNA. Lancet 340, 1319-1320.

Sweeney HL, Bowman BF, Stull JT (1993): Myosin light chain phosphorylation in vertebrate striated muscle: regulation and function. Am J Physiol 264, C1085-C1095.

Takemura R, Okabe S, Umeyama T, Kanai Y, Cowan NJ, Hirokawa N (1992): Increased microtubule stability and alpha tubulin acetylation in cells transfected with microtubuleassociated proteins MAP1B, MAP2 or tau. J Cell Sci 103, 953-964.

Taylor MR, Slavov D, Ku L, Di Lenarda A, Sinagra G, Carniel E, Haubold K, Boucek MM, Ferguson D, Graw SL et al. (2007): Prevalence of desmin mutations in dilated cardiomyopathy. Circulation $\underline{115}, 1244-1251$.

Terrenoire C, Lauritzen I, Lesage F, Romey G, Lazdunski M (2001): A TREK-1-like potassium channel in atrial cells inhibited by beta-adrenergic stimulation and activated by volatile anesthetics. Circ Res $\underline{89}$, 336-342.

Thompson RD, Wakelin MW, Larbi KY, Dewar A, Asimakopoulos G, Horton MA, Nakada MT, Nourshargh S (2000): Divergent effects of platelet-endothelial cell adhesion molecule-1 and beta 3 integrin blockade on leukocyte transmigration in vivo. J Immunol 165 , 426-434.

Tohtong R, Yamashita H, Graham M, Haeberle J, Simcox A, Maughan D (1995): Impairment of muscle function caused by mutations of phosphorylation sites in myosin regulatory light chain. Nature $\underline{374}, 650-653$.

Toyama Y, Forry-Schaudies S, Hoffman B, Holtzer H (1982): Effects of taxol and Colcemid on myofibrillogenesis. Proc Natl Acad Sci USA $\underline{79}$, 6556-6560.

Tögel M, Wiche G, Propst F (1998): Novel features of the light chain of microtubuleassociated protein MAP1B: microtubule stabilization, self interaction, actin filament binding, and regulation by the heavy chain. J Cell Biol 143, 695-707.

Tskhovrebova L, Trinick J (2003): Titin: properties and family relationships. Nat Rev Mol Cell Biol $\underline{4}, 679-689$.

Tsubata S, Bowles KR, Vatta M, Zintz C, Titus J, Muhonen L, Bowles NE, Towbin JA (2000): Mutations in the human delta-sarcoglycan gene in familial and sporadic dilated cardiomyopathy. J Clin Invest 106, 655-662.

Udd B, Vihola A, Sarparanta J, Richard I, Hackman P (2005): Titinopathies and extension of the M-line mutation phenotype beyond distal myopathy and LGMD2J. Neurology 64, 636-642.

Unger T (2002): The role of the renin-angiotensin system in the development of cardiovascular disease. Am J Cardiol ⒐ 3A-9A.

Valianpour F, Wanders RJ, Overmars H, Vreken P, van Gennip AH, Baas F, Plecko B, Santer R, Becker K, Barth PG (2002): Cardiolipin deficiency in X-linked cardioskeletal 
myopathy and neutropenia (Barth syndrome, MIM 302060): a study in cultured skin fibroblasts. J Pediatr 141, 729-733.

van der Loop FT, van der Ven PF, Fürst DO, Gautel M, van Eys GJ, Ramaekers FC (1996): Integration of titin into the sarcomeres of cultured differentiating human skeletal muscle cells. Eur J Cell Biol $\underline{69}$, 301-307.

van der Ven PF, Bartsch JW, Gautel M, Jockusch H, Fürst DO (2000a): A functional knock-out of titin results in defective myofibril assembly. J Cell Sci 113, 1405-1414.

van der Ven PF, Obermann WM, Lemke B, Gautel M, Weber K, Fürst DO (2000b): Characterization of muscle filamin isoforms suggests a possible role of gamma-filamin/ABPL in sarcomeric Z-disc formation. Cell Motil Cytoskeleton 45, 149-162.

Vasile VC, Will ML, Ommen SR, Edwards WD, Olson TM, Ackerman MJ (2006): Identification of a metavinculin missense mutation, R975W, associated with both hypertrophic and dilated cardiomyopathy. Mol Genet Metab $\underline{87}, 169-174$.

Vatta M, Mohapatra B, Jimenez S, Sanchez X, Faulkner G, Perles Z, Sinagra G, Lin JH, Vu TM, Zhou Q et al. (2003): Mutations in Cypher/ZASP in patients with dilated cardiomyopathy and left ventricular non-compaction. J Am Coll Cardiol 42, 2014-2027.

Vesel S, Stopar-Obreza M, Trebusak-Podkrajsek K, Jazbec J, Podnar T, Battelino T (2003): A novel mutation in the G4.5 (TAZ) gene in a kindred with Barth syndrome. Eur J Hum Genet 11, 97-101.

Villard E, Duboscq-Bidot L, Charron P, Benaiche A, Conraads V, Sylvius N, Komajda M (2005): Mutation screening in dilated cardiomyopathy: prominent role of the beta myosin heavy chain gene. Eur Heart J 26, 794-803.

von Mering C, Krause R, Snel B, Cornell M, Oliver SG, Fields S, Bork P (2002): Comparative assessment of large-scale data sets of protein-protein interactions. Nature $\underline{417}$, 399-403.

Waters S, Marchbank K, Solomon E, Whitehouse C, Gautel M (2009): Interactions with LC3 and polyubiquitin chains link nbr1 to autophagic protein turnover. FEBS Lett $\underline{583}$, 18461852 .

Watkins H, McKenna WJ, Thierfelder L, Suk HJ, Anan R, O'Donoghue A, Spirito P, Matsumori A, Moravec CS, Seidman JG et al. (1995): Mutations in the genes for cardiac troponin $\mathrm{T}$ and alpha-tropomyosin in hypertrophic cardiomyopathy. N Engl J Med $\underline{332}, 1058-$ 1064

Wei L, Wang L, Carson JA, Agan JE, Imanaka-Yoshida K, Schwartz RJ (2001): beta1 integrin and organized actin filaments facilitate cardiomyocyte-specific RhoA-dependent activation of the skeletal alpha-actin promoter. FASEB J $\underline{15}, 785-796$.

Weinert S, Bergmann N, Luo X, Erdmann B, Gotthardt M (2006): M line-deficient titin causes cardiac lethality through impaired maturation of the sarcomere. J Cell Biol 173, 559570.

Wilkins BJ, Dai YS, Bueno OF, Parsons SA, Xu J, Plank DM, Jones F, Kimball TR, Molkentin JD (2004): Calcineurin/NFAT coupling participates in pathological, but not physiological, cardiac hypertrophy. Circ Res 94, 110-118.

Wu X, Zhang T, Bossuyt J, Li X, McKinsey TA, Dedman JR, Olson EN, Chen J, Brown JH, Bers DM (2006): Local InsP3-dependent perinuclear $\mathrm{Ca}^{2+}$ signaling in cardiac myocyte excitation-transcription coupling. J Clin Invest 116, 675-682. 
Xie Z, Xu W, Davie EW, Chung DW (1998): Molecular cloning of human ABPL, an actinbinding protein homologue. Biochem Biophys Res Commun 251, 914-919.

Yamasaki R, Wu Y, McNabb M, Greaser M, Labeit S, Granzier H (2002): Protein kinase A phosphorylates titin's cardiac-specific N2B domain and reduces passive tension in rat cardiac myocytes. Circ Res $\underline{90}, 1181-1188$.

Yamazaki T, Komuro I, Kudoh S, Zou Y, Shiojima I, Hiroi Y, Mizuno T, Maemura K, Kurihara H, Aikawa R et al. (1996): Endothelin-1 is involved in mechanical stress-induced cardiomyocyte hypertrophy. J Biol Chem $\underline{271}$, 3221-3228.

Yaffe D, Saxel O (1977): A myogenic cell line with altered serum requirements for differentiation. Differentiation $\underline{7}, 159-166$.

Zeng T, Bett GC, Sachs F (2000): Stretch-activated whole cell currents in adult rat cardiac myocytes. Am J Physiol Heart Circ Physiol 278, H548-H557.

Zhang Y, Featherstone D, Davis W, Rushton E, Broadie K (2000): Drosophila D-titin is required for myoblast fusion and skeletal muscle striation. J Cell Sci Vol. 113, 3103-3115.

Zhi G, Ryder JW, Huang J, Ding P, Chen Y, Zhao Y, Kamm KE, Stull JT (2005): Myosin light chain kinase and myosin phosphorylation effect frequency-dependent potentiation of skeletal muscle contraction. Proc Natl Acad Sci USA 102, 17519-17524.

Zolk O, Frohme M, Maurer A, Kluxen FW, Hentsch B, Zubakov D, Hoheisel JD, Zucker IH, Pepe S, Eschenhagen T (2002): Cardiac ankyrin repeat protein, a negative regulator of cardiac gene expression, is augmented in human heart failure. Biochem Biophys Res Commun 293, 1377-1382.

Zou Y, Evans S, Chen J, Kuo HC, Harvey RP, Chien KR (1997): CARP, a cardiac ankyrin repeat protein, is downstream in the Nkx2-5 homeobox gene pathway. Development 124 , 793-804.

Zou Y, Akazawa H, Qin Y, Sano M, Takano H, Minamino T, Makita N, Iwanaga K, Zhu W, Kudoh S et al. (2004): Mechanical stress activates angiotensin II type 1 receptor without the involvement of angiotensin II. Nat Cell Biol $\underline{6}, 499-506$. 


\section{Acknowledgements}

First and foremost, I would like to express my gratitude to Prof. Gerd Hasenfuss, director of the Heart Research Center, for giving me a possibility to study and work in his esteemed department. I appreciate his support, kindness, encouragement and helpful suggestions during the final steps of the manuscript-submission.

I would like to extend my gratitude to Prof. Ralph Knöll for accepting me as a doctoral student in his research group of cardiovascular molecular genetics, and for giving me the opportunity to work on the fascinating giant muscle protein titin.

My special thanks go to Pathoo (Dr. Padmanabhan Vakeel) for his valuable guidance during whole course of my work in the department, for teaching me molecular and cell biology methods, and for critical reading and correction of the manuscript. Under his guidance I developed "scientific" way of thinking. I admire very much his broad scientific views and his scientific honesty.

I would like to extend my gratitude to other members of our research group: Dr. Sylvia Gunkel, Katrin, Susanne and Alex for making work in the lab easy and joyful. I would like to thank my college Josee for providing me mouse tissues and especially for her enthusiastic outlook.

I would like to thank members of molecular cardiology research group: Conny (Dr. Cornelia Grebe), Sandra and Jessica for guiding me to work in clean and healthy laboratory environment which we shared. I would also like to thank members of the stem cell research group headed by Dr. Kaomei Guan (Dr. Katrin Strekfuss-Bomeke and Diana Kaiser) for providing secondary antibodies and their advices in regard to immunofluorescent microscopy with great scientific spirit whenever requested.

I would like to thank Dr. Thomas Quentin from the Pediatric Cardiology for providing us with neonatal cardiomyocytes although could not obtain required results for my dissertation. I am very thankful to the Dr. Elke Oetjen from the department of pharmacology for providing radioactive lab facility and for the scientific suggestions in establishing of the radioactive kinase assay. 